\title{
§ 5 Die allgemeine Leistungsklage
}

Der gutachterlichen Prüfung der allgemeinen Leistungsklage liegt die folgende 1 Struktur zugrunde:

A. Zulässigkeit

I. Eröffnung des Verwaltungsrechtswegs (dazu bereits $\S 1$ Rn. 162ff.)

II. Statthafte Klageart (dazu einführend §1 Rn. 222ff. und ausführlich in diesem $\S$ Rn. 2 ff.)

III. Klagebefugnis (dazu Rn. 31f.)

IV. Beteiligte (dazu Rn. $37 \mathrm{ff}$.)

V. Zuständiges Gericht (dazu Rn. $38 \mathrm{ff}$.)

VI. Rechtsschutzbedürfnis (dazu Rn. $46 \mathrm{ff}$.)

B. Begründetheit (zur Struktur der Begründetheitsprüfung einführend Rn. $49 \mathrm{ff}$.)

I. Anspruchsgrundlage (dazu einführend Rn. $55 \mathrm{ff}$.)

II. Voraussetzungen der Anspruchsgrundlage erfüllt?

Die Prüfung der Anspruchsgrundlagen aus öffentlich-rechtlichem Vertrag wird vertieft dargestellt in Rn. 65 ff.; Zum öffentlich-rechtlichen Abwehr- und Unterlassungsanspruch Rn. $134 \mathrm{ff}$.; zu weiteren Ansprüchen aus dem Recht der Öffentlichen Ersatzleistungen Rn. 153ff.; zur Leistungsklage im Polizei- und Ordnungsrecht Rn. $223 \mathrm{ff}$. und im Kommunalrecht Rn. $235 \mathrm{ff}$.

\section{Gliederung}

A. Die Statthaftigkeit der allgemeinen Leistungsklage (Roman Weidinger) -699

I. Klagegegenstände - 699

1. Der Realakt als Gegenstand der allgemeinen Leistungsklage $-\mathbf{7 0 0}$

a) Die Abgrenzung von Verwaltungsakt und Realakt $-\mathbf{7 0 0}$

b) Typische Realakte - $\mathbf{7 0 2}$

c) Dem Realakt vorgelagerte Verwaltungsakte $-\mathbf{7 0 2}$

2. Weitere Klagegegenstände -703

II. Tun, Dulden oder Unterlassen -704

1. Die Vornahmeklage $-\mathbf{7 0 4}$

2. Die Unterlassungsklage -705

III. Besondere Klausurkonstellation: Die Bürgerverurteilungsklage -707

B. Weitere Zulässigkeitsvoraussetzungen -708

I. Klagebefugnis (Hendrik Burbach) -708

II. (Kein) Vorverfahren (Renana Braun) 709

III. (Keine) Klagefrist (Patrick Stockebrandt) -709

IV. Beteiligte (Carola Creemers) — $\mathbf{7 1 0}$

Ә OpenAccess. (C) 2019 Nikolas Eisentraut, publiziert von De Gruyter. (cc) BY-SA Dieses Werk ist lizenziert unter der Creative Commons Attribution-ShareAlike 4.0. International. 
V. Zuständiges Gericht (Katharina Goldberg) - $\mathbf{7 1 0}$

VI. Rechtsschutzbedürfnis (Dana-Sophia Valentiner) 711

\section{Begründetheit $-\mathbf{7 1 2}$}

I. Die Struktur der Begründetheitsprüfung (Roman Weidinger) - 712

1. Passivlegitimation 712

2. Anspruchsgrundlagen -713

a) Ansprüche aus Unions- und Verfassungsrecht -713

b) Ansprüche aus einfachem Recht und Gewohnheitsrecht 714

c) Ansprüche aus Verwaltungsakt $-\mathbf{7 1 4}$

d) Ansprüche aus öffentlich-rechtlichem Vertrag - 715

3. Spruchreife $-\mathbf{7 1 5}$

4. Literaturhinweise - $\mathbf{7 1 5}$

II. Öffentlich-rechtliche Verträge als Anspruchsgrundlage (Wolfgang Abromeit) 716

1. Der Vertrag als Handlungsform der Behörde 717
a) Entwicklung - 717
b) Begriff -718
c) Arten - 719
d) Rechtsgrundlagen $-\mathbf{7 2 0}$
e) Abgrenzung $\mathbf{7 2 1}$

aa) Abgrenzung zum privatrechtlichen Verwaltungsvertrag 722

bb) Abgrenzung zu einseitigen Handlungsformen

\section{3}

cc) Abgrenzung zu unverbindlichen Absprachen - 723

dd) Abgrenzung bei verwaltungsrechtlichen Schuldverhältnissen - 723

f) Rechtsverhältnislehre als lohnende Perspektive auf den Verwaltungsvertrag

2. Der Vertrag als Anspruchsgrundlage -724

a) Einigung -725

b) Schriftformerfordernis -726

3. Keine Vertragsformverbote -726

4. Wirksamkeit 728

a) Nichtigkeit nach § 59 VwVfG 729

b) Der subordinationsrechtliche Vertrag als Voraussetzung des §59 II VwVfG — 729

aa) Offenkundige schwere Inhalts- und Formfehler nach § 59 II Nr. 1 VwVfG 730

bb) Keine Kollusion gem. §59 II Nr. 2 VwVfG — 730

cc) Fehlende Voraussetzungen beim Vergleichsvertrag nach § 59 II Nr. 3

VwVfG 730

dd) Insbesondere unzulässige Gegenleistung beim Austauschvertrag nach § 59 II Nr. 4 VwVfG 730

(1) Vorliegen eines Austauschvertrags nach §56 VwVfG — 731

(2) Sachlicher Zusammenhang zur Leistung — 731

(3) Bestimmung eines konkreten Zwecks — 733

(4) Zur Erfüllung öffentlicher Aufgaben — 733

(5) Angemessenheit — 733

(6) Anspruch des Bürgers auf die Leistung der Behörde gem. § 56 S. 2 VwVfG 734

c) Allgemeine Nichtigkeitsgründe nach §59 I VwVfG 734

aa) In Verbindung mit §59 I VwVfG anwendbare Regelungen des BGB 734

bb) Die Anwendbarkeit von § 134 BGB i. V.m. 59 VwVfG 735 
(1) Anknüpfung an zivilrechtliche Dogmatik — 735

(2) Einzelfallanalyse zur qualifizierten Rechtswidrigkeit — 736

(3) Die Wirkung von § 59 । VwVfG i. V.m. § 134 BGB i.V.m. EU-Recht - 736

d) Folgen der Nichtigkeit 738

aa) Teilnichtigkeit nach § 59 III VwVfG

738

bb) Unterscheidung zwischen nichtigem Verpflichtungs- und Verfügungsvertrag - 738

e) Fehlende Zustimmung nach $\S 58$ VwVfG — 739

f) Das Rechtsregime des wirksamen öffentlich-rechtlichen

Verwaltungsvertrags -740

5. Schadensersatzansprüche -741

6. Anpassungs- und Kündigungsrechte nach $\S 60 \mathrm{VwVfG}$

7. Ansprüche auf Rückabwicklung oder Folgenbeseitigung 743

8. Literaturhinweise - $\mathbf{7 4 4}$

III. Der öffentlich-rechtliche Abwehr- und Unterlassungsanspruch (Jana Himstedt) -744

1. Anspruchsziele -745

a) (Negatorischer) Störungsabwehranspruch -745

b) Vorbeugender Unterlassungsanspruch -745

c) Bedeutung der Unterscheidung — 746

d) Abgrenzung zum Folgenbeseitigungsanspruch -747

2. Dogmatische Herleitung -748

3. Anspruchsvoraussetzungen $-\mathbf{7 4 9}$

a) Eingriff in ein subjektives öffentliches Recht des Klägers - 749

b) Durch öffentlich-rechtliches Handeln - $\mathbf{7 4 9}$

c) Unmittelbar bevorstehend oder andauernd $-\mathbf{7 5 0}$

d) Rechtswidrigkeit $-\mathbf{7 5 0}$

aa) Hoheitlich herbeigeführte Immissionen - $\mathbf{7 5 0}$

bb) Staatliche Informationstätigkeit — $\mathbf{7 5 1}$

4. Abschließender Überblick: Öffentlich-rechtlicher Abwehr- und Unterlassungsanspruch $-\mathbf{7 5 1}$

5. Literaturhinweise - $\mathbf{7 5 2}$

IV. Ansprüche auf öffentliche Ersatzleistungen (Jana Himstedt) - 752

1. Die Struktur des Staatshaftungsrechts: Systematisierungsansätze -753

a) Das materielle Anspruchssystem — 753

aa) Unrechtshaftung vs. Sonderopferentschädigung - 754

bb) Verschuldenshaftung - 754

b) Rechtswegsystematik 755

a) $\S 40$ II 1 VwGO 755

bb) Art. 14 Abs. 3 S. 4 GG 756

cc) Examenswissen: Rechtswegübergreifende Entscheidungskompetenz des $\S 17$ II 1 GVG 756

dd) Schlussfolgerungen für die verwaltungsrechtliche Klausur - 757

ee) Schaubild/Überblick — 758

2. Der Folgenbeseitigungsanspruch $-\mathbf{7 5 8}$

a) Anspruchsziel: Herstellung des „status quo ante in natura“ — 759

b) Anspruchsvoraussetzungen $-\mathbf{7 6 0}$

aa) Keine spezialgesetzliche Regelung — 760 
bb) Hoheitlicher Eingriff in ein subjektives Recht -761

cc) Andauernder rechtswidriger Zustand - 761

dd) Unmittelbarkeit der Eingriffsfolgen (Zurechnungszusammenhang) - 762

ee) Kein Ausschluss/Umwandlung in den „Folgenentschädigungsanspruch“

c) Exkurs: Die Folgenbeseitigungslast -763

d) Abschließender Überblick: Der Folgenbeseitigungsanspruch -764

e) Literaturhinweise -764

3. Der allgemeine öffentlich-rechtliche Erstattungsanspruch - $\mathbf{7 6 5}$

a) Die Rückabwicklung rechtswidriger Vermögenslagen im öffentlichen Recht -765

b) Exkurs: § 49a I VwVfG — 766

aa) Anspruchsvoraussetzungen - 766

bb) Anspruchsumfang und Ausschlussgründe -767

cc) Rechtsfolge: Zwingende Festsetzung durch schriftlichen Verwaltungsakt (§ 49a I S. 2 VwVfG) -768

c) Der allgemeine öffentlich-rechtliche Erstattungsanspruch — 768

aa) Mögliche Anspruchsteller — 768

bb) Anspruchsvoraussetzungen -769

(1) Vermögensverschiebung 769

(2) In einer öffentlich-rechtlichen Rechtsbeziehung - 769

(3) Ohne Rechtsgrund - $\mathbf{7 7 0}$

cc) Anspruchsumfang und Ausschlussgründe - $\mathbf{7 7 0}$

dd) Durchsetzung mittels Verwaltungsakts (Verwaltungsaktbefugnis) - 771

d) Abschließender Überblick: Der allgemeine öffentlich-rechtliche

Erstattungsanspruch $-\mathbf{7 7 1}$

e) Literaturhinweise $-\mathbf{7 7 2}$

4. Ausgleich für Inhalts- und Schrankenbestimmungen (Art. 14 I S. 2 GG) -772

a) Anspruchsvoraussetzungen -773

aa) Gesetzliche Ausgleichsregelung - 773

bb) Verfassungsmäßigkeit der Regelung — 773

cc) Tatbestand der Ausgleichsregelung - 774

b) Anspruchsumfang $-\mathbf{7 7 5}$

c) Literaturhinweise $\mathbf{7 7 5}$

V. Die allgemeine Leistungsklage im Polizei- und Ordnungsrecht (Nikolas Eisentraut)

1. Anspruch auf polizeiliches Realhandeln $-\mathbf{7 7 6}$

2. Anspruch auf Unterlassung polizeilichen Realhandelns — 777

VI. Die allgemeine Leistungsklage im Kommunalrecht (Sebastian Piecha) - 778

1. Kommunalverfassungsstreit in Leistungssituationen - 778

a) Zulässigkeit $\longrightarrow \mathbf{7 7 9}$

b) Begründetheit $\longrightarrow \mathbf{7 8 0}$

2. Zulassung zu kommunalen Einrichtungen in privater Trägerschaft $-\mathbf{7 8 1}$

3. Wirtschaftliche Betätigung von Kommunen — $\mathbf{7 8 1}$

4. Beratung und Entscheidung eines Einwohnerantrages — 785

5. Fachaufsichtsmaßnahmen $\mathbf{7 8 6}$ 


\section{A. Die Statthaftigkeit der allgemeinen Leistungsklage (Roman Weidinger)}

Wurde der Verwaltungsrechtsweg als eröffnet erkannt (s. ausführlich zur Prüfung 2 $\S 1$ Rn. 162ff.), ist im Rahmen der Zulässigkeit als nächstes die statthafte Klagebzw. Antragsart zu untersuchen. Die korrekte Ermittlung der statthaften Klage-/ Antragsart ist das zentrale Scharnier für die gesamte restliche Klausur. Nach ihr richten sich sowohl die weiteren Zulässigkeitsvoraussetzungen als auch die Struktur der Begründetheitsprüfung. Entsprechend wichtig ist die saubere Prüfung, welche Klage- bzw. Antragsart einschlägig ist (eine erste Übersicht über die Klage- und Antragsarten der VwGO findet sich in $\S 1$ Rn. $222 \mathrm{ff}$.).

Die allgemeine Leistungsklage ist, anders als die Anfechtungs-, Verpflich- 3 tungs- und (allgemeine) Feststellungsklage, nicht ausdrücklich gesetzlich geregelt. Sie wird aber in den $\S \S 43$ II, 111 und 113 IV VwGO vorausgesetzt, ${ }^{1}$ ergibt sich also aus der Gesamtschau dieser Normen. In der Klausur ist dies in der Prüfung der Statthaftigkeit kurz darzustellen.

\section{Klagegegenstände}

Die allgemeine Leistungsklage ist statthaft, wenn das klägerische Begehren dar- 4 auf gerichtet ist, die beklagte Partei zu jeglichem Tun, Dulden oder Unterlassen $\mathrm{zu}$ verpflichten, das kein Verwaltungsakt ist. ${ }^{2}$

Daher ist die allgemeine Leistungsklage insbesondere von den Klagearten mit Verwaltungsaktbezug abzugrenzen - vor allem von der Verpflichtungsklage, da es sich in entsprechenden Klausuren meist um Anspruchsbegehren handelt (zum Verwaltungsaktbegriff s. § 2 Rn. $38 \mathrm{ff}$.).

Die in Betracht kommenden Klagegegenstände sind breit gefasst: Neben $\mathbf{5}$ Realakten - als in der Klausur am häufigsten vorkommendem Klagegegenstand (zu Realakten sogleich Rn. 6 ff.) - können auch andere Verwaltungsmaßnahmen, die keine Verwaltungsakte sind, Gegenstand der allgemeinen Leistungsklage sein. Hiervon sind insbesondere öffentlich-rechtliche Willenserklärungen oder innerdienstliche Rechtsakte (beispielsweise Weisungen) (klausur-)relevant. ${ }^{3}$

1 Vgl. BVerwG, Urt. v. 25.2.1969, Az.: I C 65.67 = BVerwGE 31, 301.

2 BVerwG, Urt. v. 25.2.1969, Az.: I C 65.67 = BVerwGE 31, 301 (303); Schenke, Verwaltungsprozessrecht, 16. Aufl. 2019, Rn. 344.

3 Vgl. Schenke, Verwaltungsprozessrecht, 16. Aufl. 2019, Rn. 346. 


\section{Der Realakt als Gegenstand der allgemeinen Leistungsklage}

6 Als „Realakt“ bzw. „Verwaltungsrealakt“ bezeichnet man tatsächliches Verwaltungshandeln. ${ }^{4}$

7 Darunter sind Maßnahmen zu verstehen, die nicht auf einen rechtlichen Erfolg (beispielsweise Verwaltungsakte, Satzungen, Rechtsverordnungen oder öffentlich-rechtliche Verträge), sondern auf einen tatsächlichen Erfolg gerichtet sind. ${ }^{5}$ Insbesondere finden sich Realakte dort, wo mangels Regelungswirkung ein Verwaltungshandeln keinen Verwaltungsakt darstellt (§ 351 VwVfG).

Beispiel: Die Behörde (B) teilt dem Gastronom G in einem Rundschreiben mit, dass von nun an neue Hygieneregelungen gelten (= Realakt).

Wenn die Behörde dem $G$ aber nach einer Überprüfung mitteilt, dass er in seinem Betrieb gegen die neuen Hygienevorschriften verstößt, liegt mit dieser Einzelfeststellung des Verstoßes ein rechtlicher Erfolg vor - also ein Verwaltungsakt.

8 Die Abgrenzung zum privatrechtlichen Realakt (beispielsweise der Kaufpreiszahlung zwischen Privaten) erfolgt dabei nach den zur Unterscheidung zwischen öffentlichem und privatem Recht entwickelten Kriterien. ${ }^{6}$

\section{a) Die Abgrenzung von Verwaltungsakt und Realakt}

9 Die Abgrenzung von Realakten und Verwaltungsakten nach der Regelungseigenschaft der Maßnahme kann im Einzelfall schwierig sein. Maßgeblich ist dabei, ob sich der entsprechenden Verwaltungshandlung ein Regelungs- bzw. Rechtsbindungswille entnehmen lässt. ${ }^{7}$ Dies ist durch Auslegung zu ermitteln; die Auslegungsregel des $\S 133$ BGB findet insoweit entsprechend Anwendung. ${ }^{8}$ Entscheidend ist also, ob nach dem objektiven Erklärungsgehalt einer Maßnahme diese als Verwaltungsakt verstanden werden kann. ${ }^{9}$ Dabei können die von der Verwaltung gewählte Rechtsform des Handelns, eine der Maßnahme beigefügte Rechtsbehelfsbelehrung ( 37 VI VwVfG) oder weitere im Zusammenhang mit der

4 In der Literatur auch: „schlichtes Verwaltungshandeln“, „schlicht-hoheitliches Verwaltungshandeln“, „tatsächliches hoheitliches Verwaltungshandeln“ und „nicht-förmliches Verwaltungshandeln“: Ipsen, Verwaltungsrecht, 11. Aufl. 2019, Rn. 820 ff.; Hufen, Verwaltungsprozessrecht, 11. Aufl. 2019, § 17 Rn. 1.

5 Zu der Unterscheidung zwischen „Rechtserfolg“ und „tatsächlichem Erfolg“: Maurer/Waldhoff, Allgemeines Verwaltungsrecht, 19. Aufl. 2017, § 15 Rn. 1.

6 Vgl. Erbguth/Guckelberger, Allgemeines Verwaltungsrecht, 9. Aufl. 2018, § 23 Rn. 3.

7 BVerwG, Urt. v. 21.6.2017, Az.: 6 C 3.16 m.w. N.

8 BVerwG, Urt. v. 21.6.2017, Az.: 6 C 3.16 m.w.N.

9 BVerwG, Urt. v. 25.5.1984, Az.: 8 C 100.83; BVerwG, Urt. v. 21.6.2006, Az.: 6 C 19.06. 


\section{Verwaltungshandlung getroffene Äußerungen Anhaltspunkte für diese Beurtei- lung bieten.}

Examenswissen: Besonders schwierig ist die Abgrenzung von Hinweisen auf die bestehende 10 Rechtslage, die mangels Regelungswirkung keine Verwaltungsakte darstellen, gegenüber feststellenden oder gesetzeskonkretisierenden Verwaltungsakten. Auch hier gelten im Grunde die obigen Ausführungen zur Abgrenzung. Da aber vielfach bei (bloßen) Hinweisen auf die Rechtslage der objektive Erklärungsgehalt keine klare Zuordnung als Verwaltungsakt oder als schlichtes Verwaltungshandeln zulässt, bietet sich eher der Grad der Konkretisierung der gesetzlichen Regelung auf den Einzelfall als Anhaltspunkt an. Regelmäßig sind danach solche Maßnahmen Verwaltungsakte, deren „Regelungswirkung [...] darin liegt, dass rechtserhebliche Eigenschaften in Bezug auf einen Einzelfall verbindlich und in einer der Rechtsbeständigkeit fähigen Weise festgestellt oder abgelehnt werden“. ${ }^{10}$ Nichtsdestotrotz ist dieses Kriterium allein nicht (immer) treffsicher, sodass die Zuordnung der Maßnahme letztlich von den Umständen des Einzelfalls abhängt. ${ }^{11}$

So ist etwa die „Mitteilung“ des Dienstherm an eine/n ihm unterstellte/n Beamten/Beamtin, dass sein Beamtenverhältnis nach §31 I, II BBG zu einem bestimmten zukünftigen Zeitpunkt enden und er mithin keine Dienstbezüge mehr erhalten wird, da er wegen vorsätzlich begangener Straftaten vorbestraft wurde, ein feststellender Verwaltungsakt. Denn damit wird nicht bloß der Gesetzeswortlaut wiederholt, sondern in Anwendung der Vorschrift gegenüber dem Beamten/der Beamtin konkretisiert, wie genau die Rechtsfolge der Beendigung des Beamtenverhältnisses ihm gegenüber ausgestaltet wird, insbesondere durch die Festsetzung des genauen Beendigungszeitpunktes. ${ }^{12}$

Im Rahmen des Verwaltungsvollstreckungsrechts ist umstritten, ob schlicht-hoheitliche Vollstreckungshandlungen - beispielsweise das Aufbrechen einer Tür, um die Durchsuchung einer Wohnung ausführen zu können, oder die Abgabe eines Schusses gegen einen Störer ausschließlich als Realakte einzustufen sind, oder ob nicht zugleich jeweils eine Verfügung ergeht, das staatliche Vollstreckungshandeln zu dulden (sog. Duldungsverfügung). Während früher für die Einordnung als Verwaltungsakt sprach, dass ansonsten ein gerichtlicher Rechtsschutz gegen das jeweilige hoheitliche Handeln nicht möglich war, sind diese Bedenken mittlerweile durch Rechtsschutzmöglichkeiten auch gegen Realakte - die allgemeine Leistungsklage und die Feststellungsklage - ausgeräumt, sodass die h.M. tatsächliches Vollstreckungshandeln ausschließlich als Realakt einordnet (dazu auch § 2 Rn. 71). ${ }^{13}$

In der Examensklausur ist dieser „Streit“ v. a. in der Feststellung der statthaften Klageart (bei Verwaltungsakten: Fortsetzungsfeststellungsklage bei bereits eingetretener Erledigung gem. $\S 43$ II VwVfG, was regelmäßig der Fall ist; bei Realakt: allgemeine Feststellungsklage/Unterlassungsklage) relevant, dessen Darstellung aber angesichts der starken h.M. wohl nicht zwingend.

10 BVerwG, Urt. v. 16.01.2007, Az.: 6 C 15.06 = NJW 2007, $1478 \mathrm{ff}$.

11 So spricht etwa für die Einordnung der Verwaltungsmaßnahme als Verwaltungsakt, wenn sie als Titel zugleich Verwaltungsvollstreckungsmaßnahmen als Grundlage dienen kann (§ 6 I VwVG, bzw. die jeweilige Landesnorm).

12 BVerwG, Urt. v. 29.12.1969, Az.: VI C 4.65 = BVerwGE 34, $353 \mathrm{ff}$.

13 Barczak, JuS 2018, 238 m.w.N. 


\section{b) Typische Realakte}

12 Typische Realakte sind:

- tatsächliche Verrichtungen (etwa die Dienstfahrt eines Beamten),

- Leistungen des Staates an Bürger/Bürgerinnen (beispielsweise im Rahmen der Daseinsvorsorge) oder

- Wissenserklärungen (z.B. Auskünfte/Mitteilungen, Warnungen oder Ansprachen $\left.^{14}\right)$.

\section{c) Dem Realakt vorgelagerte Verwaltungsakte}

13 Examenswissen: Manchen Realakten sind Regelungen in Form von Verwaltungsakten zu der Entscheidung über das „ob“ der Vornahme/des Unterlassens des Realakts vorgelagert (s. hierzu auch $\S 2$ Rn. 65 ff.). So werden etwa an sich als Realakt zu qualifizierende Zahlungen regelmäßig auf erster Stufe durch als Verwaltungsakt zu qualifizierende Bewilligungsbescheide festgesetzt. Auf zweiter Stufe folgt dann die Vornahme der Zahlung als schlichtes Verwaltungshandeln. Dass einem Realakt ein solcher Verwaltungsakt vorauszugehen hat, kann sich etwa aus einer gesetzlichen Anordnung (z. B. Festsetzung der Versorgungsbezüge bei Beamten, § 49 BeamtVG) oder auch daraus ergeben, dass vor der Vornahme des Realakts eine Ermessensentscheidung (damit also mit Verwaltungsakt-Regelungscharakter ${ }^{15}$ ) zu treffen ist. ${ }^{16}$ So muss etwa einer Auskunftserteilung als Realakt dann ein Verwaltungsakt vorangehen, wenn im Rahmen einer Ermessensentscheidung verschiedene Belange gegeneinander abgewogen werden müssen, z. B. Informationsgegen Geheimhaltungsinteresse bei einem Auskunftsersuchen gegenüber einem Geheimdienst. ${ }^{17}$

14 Da der vorgelagerte Verwaltungsakt die Grundlage für den späteren Realakt bietet, muss zunächst ein - erfolgreicher - Antrag auf den Erlass dieses Verwaltungsakts gestellt ${ }^{18} \mathrm{bzw}$. bei dessen Ablehnung die Verpflichtungsklage erfolgreich angestrengt worden sein, bevor eine allgemeine Leistungsklage auf Vornahme des Realakts erhoben werden kann (gestuftes Verfahren). ${ }^{19}$

Examenswissen: Weil das eine (Erlass des Verwaltungsakts) dem anderen (begehrtes schlichtes Verwaltungshandeln) notwendigerweise vorausgehen muss, ist die Verbindung beider im Rah-

14 Dazu ist insbesondere die sog. Gefährderansprache immer wieder ein gern gewähltes Klausurthema. Näher zu diesem Thema: Hebeler, NVwZ 2011, 1364; eine Falllösung findet sich bei Hebeler/Spitzlei, JA 2019, 282.

15 Eine Ausnahme dazu besteht insbesondere bei beamtenrechtlichen Maßnahmen, also bspw. wenn ein Beamter eine innerdienstliche Maßnahme begehrt (z. B. eine Umsetzung), deren Gewährung eine Ermessensentscheidung voraussetzt. Denn diese Entscheidung ist mangels $\mathrm{Au}-$ ßenwirkung kein Verwaltungsakt (§ $35 \mathrm{~S} .1 \mathrm{VwVfG}$ ).

16 Erbguth/Guckelberger, Allgemeines Verwaltungsrecht, 9. Aufl. 2018, § 12 Rn. 12; vgl. BVerwG, Urt. v. 25.02.1969, Az.: I C 65.67 = BVerwGE 31, 301 (307); vgl. Steiner, JuS 1984, 853 (857).

17 Vgl. BVerwG, Urt. v. 25.02.1969, Az.: I C 65.67 = BVerwGE 31, 301.

18 Denn sonst entfällt regelmäßig das Rechtsschutzbedürfnis im Rahmen der Verpflichtungsklage: Hufen, Verwaltungsprozessrecht, 11. Aufl. 2019, § 17 Rn. 11.

19 Steiner, JuS 1984, 853 (855).

Roman Weidinger 
men der objektiven Klagehäufung (§ $44 \mathrm{VwGO}$, s. allgemein hierzu §1 Rn. 251) mangels gleichzeitiger Entscheidungsreife als ungeschriebene Voraussetzung des § 44 VwGO nicht möglich.

Gesetzlich geregelte Ausnahmen hiervon gibt es allerdings im Rahmen der Anfechtungsklage. ${ }^{20}$ Hier kann parallel zum Begehren der Aufhebung eines Verwaltungsakts eine Leistung (nach § 113 I 2 VwGO als Vollzugsfolgenbeseitigungsanspruch oder gem. §113 IV VwGO) gerichtlich geltend gemacht werden (näher zum Vollzugsfolgenbeseitigungsanspruch § 2 Rn. 1387). Zudem findet auf den Fall, dass mit einer Anfechtungsklage ein Folgeverwaltungsakt aufgehoben werden soll, wobei dessen Aufhebung von der vorherigen Aufhebung des „Ausgangsverwaltungsakts“ abhängt, § 113 IV VwGO analog Anwendung - sofern nicht spezieller § 113 I 2 VwGO einschlägig ist. ${ }^{21} \mathrm{Ob}$ die $\S \S 113$ I 2, 113 IV VwGO auf die Verpflichtungsklage analoge Anwendung finden, ist umstritten. ${ }^{22}$

\section{Weitere Klagegegenstände}

Examenswissen: Auch andere Maßnahmen ohne Verwaltungsakt-Charakter sind als Klagegegenstände denkbar - so etwa neben innerdienstlichen Rechtsakten und öffentlich-rechtlichen Willenserklärungen auch Flächennutzungspläne, die mangels Außenwirkung keine Verwaltungsakte sind $(\S 351 \mathrm{VwVfG}){ }^{23}$

Hausarbeitswissen: Ebenso wird von der h.M. die Statthaftigkeit der allgemeinen Leistungsklage auch dann angenommen, wenn Streitgegenstand eine Regelung eines Organs bzw. Organteils gegenüber einem anderen Organ(-teil) der gleichen juristischen Person des öffentlichen Rechts ist, denn sei dies, auch wenn die Regelung gezielt in ein Organrecht eingreift, kein Verwaltungsakt. ${ }^{24}$

Examenswissen: Ob bzw. in welchem Umfang untergesetzliche Rechtsvorschriften (insbe- 17 sondere Rechtsverordnungen, Satzungen) Gegenstand der allgemeinen Leistungsklage sein können, ist umstritten. ${ }^{25}$ Nach überwiegender Lehrmeinung ${ }^{26}$ kann sie auch dann statthaft sein, wenn der Erlass (echte Normerlassklage) oder die Änderung/Ergänzung (unechte Normerlassklage) einer untergesetzlichen Rechtsnorm begehrt wird (zur Möglichkeit der Klage auf Normunterlassung s. Rn. 25). Denn die VwGO schließe dies nicht aus und die - von der Gegenauffassung als statthaft befundene - allgemeine Feststellungsklage sei nach § 43 II 1 VwGO subsidiär zur allgemeinen Leistungsklage (zum Streitstand näher § 6 Rn. 71). Der Anwendungsbereich der allgemeinen Leistungsklage wäre in diesen Fällen durch den Gewaltenteilungsgrundsatz als Teil

20 Riese, in: Schoch/Schneider/Bier, VwGO, 36. EL Februar 2019, § 113 Rn 190 m.w. N.

21 W.-R. Schenke/R.-P. Schenke, in: Kopp/Schenke, VwGO, 25. Aufl. 2019, § 113 Rn. 176; a. A. Pauly/Pudelka, DVBl. 1999, 1613.

22 Für eine analoge Anwendung: Gärditz, VwGO, 2. Aufl. 2018, § 113 Rn. 33, 88 m.w. N.; a.A. Riese, in Schoch/Schneider/Bier, VwGO, 36. EL Februar 2019, § 113 Rn. 83, 191 m.w. N.

23 Schenke, NVwZ 2007, 134 (137 ff.).

24 Lange, in: Festschrift für Schenke, 2011, S. 959; Vgl. Pietzcker, in: Schoch/Schneider/Bier, VwGO, 36. EL Februar 2019, Vor § 42 I, Rn 18.

25 Dass der Verwaltungsrechtsweg wegen des Vorliegens einer verfassungsrechtlichen Streitigkeit verschlossen bliebe, §40 I 1 VwGO, wird hingegen überwiegend verneint: Pietzcker, in: Schoch/Schneider/Bier, VwGO, 36. EL Februar 2019, § 42 I Rn. 160.

26 Übersicht über die Problematik in Hufen, Verwaltungsprozessrecht, 11. Aufl. 2019, § 20 Rn. 8; Duken, NVwZ 1993, 546 (548). 
des Rechtsstaatsprinzips, Art. 20 III GG, allerdings insoweit beschränkt, als dass Gerichte außer in besonderen Ausnahmefällen, in denen das Gebot effektiven Rechtsschutzes aus Art. 19 IV 1 GG dies erfordere, kaum die (vollstreckbare) Verpflichtung aussprechen dürften, eine konkrete untergesetzliche Norm zu erlassen - denn der Erlass untergesetzlicher Normen sei Sache des jeweiligen demokratisch legitimierten Legislativorgans. ${ }^{27}$ Daher dürfte sich der Urteilstenor regelmäßig auch nur auf den Normerlass oder die Normergänzung als solche beziehen, nicht etwa auf einen konkreten Norminhalt. Er ähnelt damit der Tenorierung eines Bescheidungsurteils (§ $113 \mathrm{~V} 2$ VwGO analog)..$^{28}$

18 Die Rechtsprechung favorisiert hingegen die allgemeine Feststellungsklage mit Blick auf das Gewaltenteilungsprinzip, denn nach diesem obliege es nicht der Judikative, Normen - bzw. vollstreckbare Verpflichtungen zum Normerlass/zur Normergänzung - festzusetzen, sondern der Legislative. ${ }^{29}$ Die Gerichte seien insoweit auf die Feststellung der Rechtswidrigkeit des Unterlassens eines Normerlassens zu beschränken. Die Subsidiarität der allgemeinen Feststellungsklage gegenüber der allgemeinen Leistungsklage (§ 43 II 1 VwGO) stünde dem bei Klagen gegen den Hoheitsträger nicht entgegen (s. dazu § 6 Rn. 71).

19 Soweit der Erlass oder die Unterlassung eines formellen Gesetzes begehrt wird, ist die allgemeine Leistungsklage nicht einschlägig. Denn neben erheblichen legitimatorischen und rechtsstaatlichen Bedenken handelt es sich dabei um eine verfassungsrechtliche Streitigkeit, sodass der Verwaltungsrechtsweg gem. § 40 I 1 VwGO schon nicht eröffnet ist. ${ }^{30}$

\section{Tun, Dulden oder Unterlassen}

20 Mit der allgemeinen Leistungsklage kann ein Tun, Dulden oder Unterlassen begehrt werden, das kein Verwaltungsakt ist (s. Rn. 24).

\section{Die Vornahmeklage}

21 Dies umfasst die allgemeine Leistungsklage als sog. Vornahmeklage („Tun“, z. B. Widerruf einer ehrverletzenden Aussage durch einen Beamten/eine Beamtin gegenüber einem Bürger/einer Bürgerin), als Unterlassungsklage („Unterlassen“, beispielsweise die getätigte Aussage auch weiterhin zu unterlassen) oder die Kombination aus beidem.

27 Vgl. Pietzcker, in: Schoch/Schneider/Bier, VwGO, 36. EL Februar 2019, § 42 I Rn. 160.

28 Vgl. Detterbeck, Allgemeines Verwaltungsrecht, 17. Aufl. 2019, Rn. 1441.

29 BVerwG, Urt. v. 4.7.2002, Az.: 2 C 13/01; BVerwG, Urt.v. 3.11.1988, Az.: 7 C 115/86 = BVerwGE 80, 355 (361); BVerwG, Urt. v. 7.9.1989, Az.: 7 C 4.89 = NVwZ 1990, 162 mit der letztlich allerdings offenen Formulierung, dass ,auf die Entscheidungsfreiheit der rechtsetzenden Organe gerichtlich nur in dem für den Rechtsschutz des Bürgers unumgänglichen Umfang einzuwirken ist“.

30 Schenke, Verwaltungsprozessrecht, 16. Aufl. 2019, Rn. 347; Einzelne natürliche oder juristische Personen müssten eine Verfassungsbeschwerde erheben: BVerfG, Beschluss v. 14.5.1985, Az.: 2 BvR 397/82 = BVerfGE 70, 35 (55).

\section{Roman Weidinger}




\section{Die Unterlassungsklage}

Die (allgemeine) Unterlassungsklage zielt dabei auf die Beendigung eines bereits 22 eingetretenen bzw. sich wiederholenden Verwaltungshandelns, das kein Verwaltungsakt ist (z.B. andauernde Lärmemissionen). Daneben kann ein solches Verwaltungshandeln aber auch (bloß) mit „mehr oder minder großer Gewissheit“"31 drohen, ohne bereits eingetreten zu sein (z.B. eine in Aussicht gestellte Veröffentlichung behördlich zuvor festgestellter Hygienemängel in einem Gastronomiebetrieb ${ }^{32}$ ). Grundsätzlich wird verwaltungsgerichtlicher Rechtsschutz allerdings nur dann gewährt, wenn die (mögliche) subjektive Rechtsverletzung bereits eingetreten ist (,repressiver Rechtsschutz“). ${ }^{33}$ Soweit aber ein Abwarten des Klägers/der Klägerin bis zum Eintritt der Verletzung ihm/ihr nicht zumutbar ist bzw. „der Verweis auf nachgängigen Rechtsschutz - einschließlich des einstweiligen Rechtsschutzes - mit für den Kläger unzumutbaren Nachteilen verbunden wäre“34 - das ist im Rechtsschutzbedürfnis als sog. qualifiziertes Rechtsschutzbedürfnis ${ }^{35} \mathrm{zu}$ prüfen -, besteht im Sinne des Gebots effektiven Rechtsschutzes (Art. 19 IV 1 GG) die Möglichkeit einer vorbeugenden Unterlassungsklage. ${ }^{36}$

Examenswissen: Die Statthaftigkeit dieser Klage wird im Einzelnen verschiedentlich beurteilt, je nachdem, ob das drohende Verwaltungshandeln Verwaltungsaktqualität hat oder nicht. Denn bei drohenden Verwaltungsakten kann, anders als bei drohendem Nicht-Verwaltungshandeln ohne Verwaltungsaktqualität, regelmäßig schon durch die Einlegung eines Widerspruchs mit Suspensiveffekt (§ 80 I VwGO) Rechtsschutz unmittelbar nach dem Verwaltungsakt-Erlass erlangt werden, ohne dass sich überhaupt gerichtlich damit befasst werden muss. Im Falle der sofortigen Vollziehung (§ 80 II VwGO) besteht zudem mit der Möglichkeit des Eilantrags nach $\S \S 80 \mathrm{~V}, 80 \mathrm{a}$ VwGO grundsätzlich eine ausreichende Rechtsschutzmöglichkeit. Eine gerichtliche Entscheidung im Rahmen der allgemeinen Leistungsklage trotz dieser Regelung in $\S 80 \mathrm{I}, \mathrm{V}$ VwGO ist daher mit Blick auf die Eigenverantwortlichkeit der Verwaltung regelmäßig nicht mit dem Grundsatz der Gewaltenteilung (Art. 20 II S. 2 GG) vereinbar. ${ }^{37}$ Schließlich wird nachträglich Rechtsschutz auch dadurch gewährleistet, dass im Gestaltungsurteil der erfolgreichen Anfechtungsklage der angegriffene Verwaltungsakt rückwirkend aufgehoben wird (§ 113 I 1 VwGO). Bei Gewährung präventiven Rechtschutzes vor Verwaltungsakten im Rahmen der allgemeinen Leistungsklage würden zudem die besonderen Sachentscheidungsvoraussetzungen des „repressiven“ Rechts-

31 Erbguth/Guckelberger, Allgemeines Verwaltungsrecht, 9. Aufl. 2018, § 23 Rn. 9.

32 Solche Veröffentlichungen sind schon mehrfach Gegenstand gerichtlicher Verfahren gewesen, etwa: VG Regensburg, Beschluss v. 21.12.2012, Az.: RN 5 E 12.1895; VG München, Beschluss v. 3.12.2012, Az.: M 18 E 12.5736; VG Berlin, Urt. v. 28.11.2012, Az.: 14 K 79/12.

33 Vgl. dazu Erbguth/Guckelberger, Allgemeines Verwaltungsrecht, 9. Aufl. 2018, § 23 Rn. 13.

34 BVerwG, Urt. v. 22.10.2014, Az.: 6 C 7/13 = NVwZ 2015, 906 m.w. N.

35 Erbguth/Guckelberger, Allgemeines Verwaltungsrecht, 9. Aufl. 2018, § 23 Rn. 13.

36 Schenke, Verwaltungsprozessrecht, 16. Aufl. 2019, Rn. 354.

37 Schmidt, Verwaltungsprozessrecht, 19. Aufl. 2019, Rn. 387 m.w. N.

Roman Weidinger 
schutzes der Anfechtungsklage (vgl. §§ $68 \mathrm{ff}$. VwGO) ausgehöhlt. Damit ist die allgemeine Leistungsklage auf (vorbeugende) Unterlassung des Erlasses eines Verwaltungsakts grundsätzlich unstatthaft, da der klagenden Partei insoweit das (qualifizierte) Rechtsschutzbedürfnis abzusprechen ist. ${ }^{38}$

24 Ausnahmen dazu können sich aus dem Gebot effektiven Rechtsschutzes aus Art. 19 IV 1 GG ergeben. So ist die allgemeine Leistungsklage als (vorbeugende) Unterlassungsklage gegen den Erlass eines Verwaltungsakts statthaft, wenn unmittelbar die Gefahr besteht, dass es durch den Verwaltungsakt bzw. dessen Vollziehung zu Beeinträchtigungen für den Kläger/die Klägerin kommt, die durch die Einlegung eines Widerspruchs, eines Eilantrags und die spätere Entscheidung in der Hauptsache nicht mehr beseitigt werden können..$^{39}$ Dies ist etwa der Fall, wenn der Verwaltungsakt straf- bzw. bußgeldbewehrt ist ${ }^{40}$, bei einer absehbaren Zahl sich kurzfristig erledigender oder gleichartiger Verwaltungsakte ${ }^{41}$ oder bei Verwaltungsakten, deren Erlass zu nur schwer rückgängig zu machenden oder bereits vollendeten Tatsachen zu Lasten des Klägers/der Klägerin führt. ${ }^{42}$

25 Schließlich kann das drohende Verwaltungshandeln auch in dem Erlass einer untergesetzlichen Rechtsnorm (beispielsweise Rechtsverordnung oder Satzung) liegen. Die vorbeugende Unterlassungsklage ist hierbei grundsätzlich nicht statthaft. Dies ergibt sich einerseits aus der daraus folgenden Systemwidrigkeit gegenüber der prinzipalen Normkontrolle (§ 47 VwGO), die gem. § 47 I Nr. 1 VwGO nur gegen bestimmte Rechtsvorschriften - und darüber hinaus nur nach jeweiligem Landesrecht, § 47 I Nr. 2 VwGO - lediglich die nachträgliche Möglichkeit gerichtlichen Rechtsschutzes eröffnet. Außerdem steht dem der Gewaltenteilungsgrundsatz und dabei vor allem der Grundsatz gestalterischer Freiheit der Verwaltung entgegen, denn es kann einem Gericht nicht gestattet sein, schon vorbeugend die Unvereinbarkeit einer untergesetzlichen Norm mit höherrangigem Recht festzustellen, bevor die zuständigen Rechtssetzungsgremien ihre Beratungen abgeschlossen haben und die Norm mit Geltungsanspruch nach außen verkündet wurde. Nur in besonderen Ausnahmefällen, in denen das Gebot effektiven Rechtsschutzes es erfordert, kann die allgemeine Leistungsklage auf Unterlassen eines drohenden Erlasses einer untergesetzlichen Rechtsnorm als statthafte Klageart in Betracht kommen. ${ }^{43}$

26 Hausarbeitswissen: Auch bei Annahme der Statthaftigkeit der allgemeinen Leistungsklage für Normerlassklagen stünde ohnehin regelmäßig die fehlende Klagebefugnis einem Klageerfolg ent-

38 Vgl. Happ, in: Eyermann, VwGO, 15. Aufl. 2019, § 42 Rn. 67. Anders meint Schenke, Verwaltungsprozessrecht, 16. Aufl. 2019, § 8 Rn. 355, dass die allgemeine Leistungsklage wegen der Verfahrenskonkurrenz zu $\S \S 42,68 \mathrm{ff}$. VwGO grundsätzlich nicht statthaft sei.

39 Vgl. Schenke, JZ 1996, 1103 (1112); Erbguth/Guckelberger, Allgemeines Verwaltungsrecht, 9. Aufl. 2018, § 23 Rn. 13; übersichtlich zu verschiedenen Fallkonstellationen: vgl. Dreier, JA 1987, 415 (421f.).

40 Vgl. BVerwG, Urt. v. 23.6.2016, Az.: 2 C 18/15 = NVwZ-RR 2016, 907, 908.

41 BVerwG, Urt. v. 7.5.1996, Az.: 1 C 10/95 = NVwZ 1997, 276; VGH München, Beschl. v. 12. 8. 2016, Az.: 10 ZB 16/731, Rn. 8f. juris; BayVGH, Urt. v. 9.12.1992, Az.: 11 B 91.2196 = NVwZ-RR 1993, 384. 42 BVerwG, Urt. v. 29.6.1977, Az.: IV C 51/75 = BVerwGE 54, 211 (215f.).

43 Pietzcker, in: Schoch/Schneider/Bier, VwGO, 36. EL Februar 2019, § 42 I Rn. 169; Schenke, Verwaltungsprozessrecht, 16. Aufl. 2019, Rn 1092.

Roman Weidinger 
gegen, da auf den Nichterlass von Normen gerichtete Unterlassungsansprüche als subjektive Rechte grundsätzlich nicht bestehen. ${ }^{44}$

Die vorbeugende Unterlassungsklage in Bezug auf formelle Gesetze scheitert indes schon an der Eröffnung des Verwaltungsrechtsweges nach § 40 I 1 VwGO, denn liegt dabei immer eine verfassungsrechtliche Streitigkeit vor (s. Rn. 19).

\section{Besondere Klausurkonstellation: Die Bürgerverurteilungsklage}

Examenswissen: Die allgemeine Leistungsklage umfasst nicht nur Fälle, in denen der Bürger/die Bürgerin den Staat verklagt (etwa auf die Gewährung einer schlichten Leistung), sondern kann auch umgekehrt die statthafte Klageart sein, wenn Hoheitsträger den/die Bürger/in auf Erfüllung einer öffentlich-rechtlichen Pflicht verklagen, beispielsweise auf Vornahme einer öffentlichrechtlichen Gebührenzahlung (sog. Bürgerverurteilungsklage). ${ }^{45}$ Allerdings ist dem Staat als Kläger regelmäßig das allgemeine Rechtsschutzbedürfnis abzusprechen, denn er bedarf grundsätzlich zur Durchsetzung eines öffentlich-rechtlichen Anspruchs keines gerichtlichen Titels, sondern kann durch den Erlass eines Verwaltungsakts selbst einen Vollstreckungstitel schaffen (Selbsttitulierungsrecht der Verwaltung). ${ }^{46}$ Eine Ausnahme dazu besteht aber, wenn ohnehin mit einer Klage des/der beteiligten Bürgers/Bürgerin und damit mit einer gerichtlichen Auseinandersetzung zu rechnen ist. ${ }^{47}$

Daneben ist die allgemeine Leistungsklage des Staates gegen Bürger/innen auch dann nicht ausgeschlossen, wenn Ansprüche streitig sind, bei denen der Verwaltung kein Selbsttitulierungsrecht zusteht. Das sind etwa solche aus öffentlich-rechtlichen Verträgen, in denen der Staat sich zur gegenseitigen Erfüllung verpflichtet, ohne einseitig Regelungen zu treffen (sog. Ebene der Gleichordnung und Waffengleichheit ${ }^{48}$ ) - außer der/die betroffene Bürger/in hat sich der sofortigen Vollstreckung unterworfen (§ $61 \mathrm{VwVfG}){ }^{49}$ Auch Ansprüche aus dem öffentlich-rechtlichen Erstattungsanspruch (dazu näher $\S 5$ Rn. 189 ff.) oder vereinzelt aus der Geschäftsführung ohne Auftrag im öffentlichen Recht (dazu näher § 11 Rn. 50 ff.) sind mangels Selbsttitulierungsrecht im Rahmen der allgemeinen Leistungsklage gegen den/die Bürger/in einklagbar. ${ }^{50}$

44 Happ, in: Eyermann, VwGO, 15. Aufl. 2019, § 42 Rn. 65; Schenke, Verwaltungsprozessrecht, 16. Aufl. 2019, Rn. 1092 - beide auch zu den Ausnahmen, in denen subjektive Rechte auf Unterlassung bestehen können.

45 Schenke, Verwaltungsprozessrecht, 16. Aufl. 2019, Rn. 351 ff.; näher zu den Leistungsklagen der öffentlichen Hand Hartwig/Himstedt/Eisentraut, DÖV 2018, 901.

46 Würtenberger/Heckmann, Verwaltungsprozessrecht, 4. Aufl. 2018, Rn. 453.

47 BVerwG, Urteil vom 6.09.1988, Az.:1 C 15/86 = BVerwGE 80, 164 (165f.); Schenke, JZ 1996, 1103

(1112). § 42 II VwGO analog ist in dieser Konstellation nicht zu prüfen, denn dient diese Vorschrift dem Ausschluss von Popularklagen: R. P. Schenke, in: Kopp/Schenke, VwGO, 25. Aufl. 2019, Vorb $\S 40$ Rn. 50; vgl. Hufen, Verwaltungsprozessrecht, 11. Aufl. 2019, § 14 Rn. 53.

48 Mann/Wahrendorf, Verwaltungsprozessrecht, 4. Aufl. 2015, Rn. 282.

49 Zum öffentlich-rechtlichen Vertrag übersichtlich Voßkuhle/Kaiser, JuS 2013, $687 \mathrm{ff}$. und Rn. $65 \mathrm{ff}$.

50 Hufen, Verwaltungsprozessrecht, 11. Aufl. 2019, § 28 Rn. 16. 
Hingewiesen sei auf die weiterführenden Literaturhinweise auch zur Statthaftigkeit der Leistungsklage Rn. 64.

\section{B. Weitere Zulässigkeitsvoraussetzungen}

30 Nach der Prüfung der Eröffnung des Verwaltungsrechtswegs und der Prüfung der statthaften Klageart sind im Falle der allgemeinen Leistungsklage regelmäßig die folgenden weiteren Zulässigkeitsvoraussetzungen anzusprechen, wobei es auch hierbei auf problembewusstes Arbeiten ankommt (dazu § 1 Rn. 52, 123ff.).

\section{Klagebefugnis (Hendrik Burbach)}

$31 \S 42$ II VwGO umfasst seinem Wortlaut nach lediglich die Anfechtungs- und Verpflichtungsklage.

32 Nach teilweise vertretener Auffassung muss der Kläger deshalb bei der allgemeinen Leistungsklage nicht nach § 42 II VwGO klagebefugt sein. Dies wird damit begründet, dass die Statthaftigkeit der Leistungsklage bereits aus den zugrunde liegenden subjektiv-öffentlichen Rechten konstruiert werde. ${ }^{51}$ Die erforderlichen Erwägungen zur Klagebefugnis seien in der Prozessführungsbefugnis bzw. im allgemeinen Rechtsschutzbedürfnis sowie in der Begründetheit auszuführen. ${ }^{52}$ Somit könne die Verletzung eines Rechtes bereits zwangsläufig geltend gemacht werden, ohne dass es einer unter dem Gesichtspunkt des Vorbehaltes des Gesetzes für den Kläger nicht unproblematischen Analogie zu § 42 II VwGO zu dessen Nachteil bedürfe. ${ }^{53}$

Nach überzeugender (und auch herrschender) Ansicht muss der Kläger auch bei der allgemeinen Leistungsklage analog § 42 II VwGO klagebefugt sein. Die in der VwGO ungeregelte Leistungsklage ist zwar nicht von dem Wortlaut des $§ 42$ II VwGO erfasst. Die Notwendigkeit der Klagebefugnis folgt aber aus der strukturellen Ähnlichkeit von Verpflichtungs- und Leistungsklage sowie dem die VwGO prägenden Grundsatz der Abwehr von Popular- und Interessensklagen. ${ }^{54}$

51 Württemberger/Heckmann, Verwaltungsprozessrecht, 4. Aufl. 2018, § 24 Rn. 454.

52 Württemberger/Heckmann, Verwaltungsprozessrecht, 4. Aufl. 2018, § 24 Rn. 454.

53 Gärditz, in: Gärditz, VwGO, 2. Aufl. 2018, § 42 Rn. 51.

54 Detterbeck, Allgemeines Verwaltungsrecht, 17. Aufl. 2019, § 7 Rn. 1392; Balbach/Morfeld, NVwZ 2014, 1499 (1500); Meickmann, JuS 2017, 663 (666); BVerwG, Urt. v. 5.9. 2013, Az.: 7 C 21/12 Rn. 18 = NVwZ 2014, 64 . 
Wie im Rahmen der Verpflichtungsklage (s. $§ 3$ Rn. 28f.) ist auch bei der Leistungsklage zu untersuchen, ob es möglich erscheint, dass dem Kläger ein subjektiven Recht auf die begehrte Leistung zusteht (s. zu den typischerweise relevanten subjektiven Rechten im Rahmen der Leistungsklage näher Rn. $55 \mathrm{ff}$.).

\section{II. (Kein) Vorverfahren (Renana Braun)}

Grundsätzlich ist die Durchführung eines Vorverfahrens im Rahmen der Leis- 33 tungsklage nicht erforderlich, für einige Ausnahmefälle ist es allerdings ausdrücklich angeordnet (Bsp.: § 54 II 1 BeamtStG, § 126 II 1 BBG). In der gutachterlichen Prüfung ist dieser Prüfungspunkt also nicht anzusprechen, soweit ein Vorverfahren nicht ausnahmsweise erforderlich ist.

Literaturhinweis: Hufen, Verwaltungsprozessrecht, 11. Aufl. 2019, Teil 2 § 6 Rn. 16. 34

\section{III. (Keine) Klagefrist (Patrick Stockebrandt)}

Für die allgemeine Leistungsklage gilt grundsätzlich keine Klagefrist. ${ }^{55}$ In der 35 gutachterlichen Prüfung ist dieser Prüfungspunkt also nicht anzusprechen, soweit nicht ausnahmsweise eine Klagefrist erforderlich ist. Dies ist dann der Fall, wenn eine Frist spezialgesetzlich angeordnet wird. ${ }^{56}$ Eine unredliche, gegen Treu und Glauben verstoßende Verzögerung der Klageerhebung führt zur Verwirkung des Klagerechts (s. § 2 Rn. 399ff.). ${ }^{57}$

Im Hinblick auf die Fristberechnung und die Rechtsbehelfsbelehrung 36 (s. $\S 2$ Rn. $361 \mathrm{ff}$.) und die Wiedereinsetzung in den vorigen Stand (s. $\S 2$ Rn. 394 ff.) wird auf die entsprechenden Ausführungen im Rahmen der Anfechtungsklage verwiesen.

Weiterführende Literaturhinweise finden sich in $\S 2$ Rn. 402.

55 Schenke, Verwaltungsprozessrecht, 16. Aufl. 2019, Rn. 363 und Rn. 704.

56 Z. B. § 54 II 1 BeamtStG und § 126 II 1 BBG, s. hierzu Schenke, Verwaltungsprozessrecht, 16. Aufl. 2019, Rn. 363 und Rn. 704.

57 Schenke, Verwaltungsprozessrecht, 16. Aufl. 2019, Rn. 363 und Rn. 704. 


\section{Beteiligte (Carola Creemers)}

37 Die Ausführungen zu den Beteiligten im Rahmen der Anfechtungsklage gelten weitestgehend entsprechend für die allgemeine Leistungsklage (s. ausführlich $\S 2$ Rn. 403 ff.).

38 Eine Besonderheit ergibt sich jedoch mit Blick auf $\S 78$ VwGO. Dieser steht systematisch im 8. Abschnitt der VwGO, sodass $§ 78$ VwGO unmittelbar nur für Anfechtungs- und Verpflichtungsklagen gilt. $§ 78$ VwGO ist auf die allgemeine Leistungsklage auch nicht entsprechend anwendbar. ${ }^{58}$

39 Der richtige Beklagte bestimmt sich daher für die allgemeine Leistungsklage nach dem allgemeinen Rechtsträgerprinzip, d.h. richtiger Beklagter ist der Rechtsträger der verpflichteten Behörde. Demnach sind allgemeine Leistungsklagen grundsätzlich gegen die Körperschaft zu richten, die nach dem materiellen Recht verpflichtet ist, den geltend gemachten Leistungsanspruch zu erfüllen, bzw. zum Unterlassen verpflichtet ist. ${ }^{59}$

\section{Zuständiges Gericht (Katharina Goldberg)}

40 Die allgemeine Leistungsklage ist nur zulässig, wenn das zuständige Gericht angerufen wurde (zur Verweisung bei fehlerhafter Zuständigkeit s. näher § 1 Rn. 49, 163; § 2 Rn. 468).

41 Bei der Frage des zuständigen Gerichts liegt häufig kein Schwerpunkt der Klausurlösung. Dennoch müssen die sachliche und örtliche Zuständigkeit in jeder Klausur zumindest angesprochen und die relevanten Normen benannt werden.

42 Formulierungsvorschlag: „Das angerufene Gericht müsste sachlich gem. $\S 45$ VwGO und örtlich gem. $§ 52$ VwGO zuständig sein.“

43 Das Verwaltungsgericht ist sachlich in der ersten Instanz für alle Streitigkeiten zuständig, für die der Verwaltungsrechtsweg gem. § 40 VwGO eröffnet ist, $\S 45 \mathrm{VwGO}^{60}$ (zur ausnahmsweise abweichenden Zuständigkeit von OVG und BVerwG s. $§ 2$ Rn. 466f.).

58 h.M., vgl. u.a. Schenke, in: Kopp/Schenke, VwGO, 25. Aufl. 2019, § 78 Rn. 2; Kintz, in: Posser/ Wolff, VwGO, 50. Ed., Stand: 1.7.2019, § 78 Rn. 6; Rozek, JuS 2007, 601 (603).

59 BVerwG, Urt. v. 28.8.2003, Az.: 4 C 9/02 = NVwZ-RR 2004, 84; Meissner/Schenk, in: Schoch/ Schneider/Bier, VwGO, 36. EL Februar 2019, § 78 Rn. 52; Brenner, in: Sodan/Ziekow, VwGO, 5. Aufl. 2018, § 78 Rn. 11.

60 Berstermann, in: Posser/Wolf, VwGO, 50. Ed., Stand 01.10.2018, § 45 Rn. 2. 
Die örtliche Zuständigkeit richtet sich bei allen Klagearten nach §52 VwGO. 44 Sie muss bestimmt werden, wenn verschiedene Gerichte sachlich zuständig sind. In den meisten Klausuren wird die örtliche Zuständigkeit durch den Klausursteller vorgegeben.

Wenn dies nicht gegeben ist müssen die einzelnen Nummern des $§ 52$ VwGO gründlich gelesen werden. Sie geben eine Reihenfolge vor, nach der die örtliche Zuständigkeit bestimmt werden muss. Bei der allgemeinen Leistungsklage sind folgende Nummern des $\S 52$ VwGO in folgender Reihenfolge relevant: Nr. 1, Nr. 4, Nr. 5 (ein Überblick über die Nummern des $\S 52$ VwGO findet sich in $\S 2$ Rn. 473).

\section{Rechtsschutzbedürfnis (Dana-Sophia Valentiner)}

Bei der allgemeinen Leistungsklage ergibt sich das allgemeine Rechtsschutz- 46 bedürfnis in aller Regel bereits aus dem Umstand, dass die klagende Person einen auf Leistung an sich selbst gerichteten, bislang nicht erfüllten Anspruch geltend macht. ${ }^{61}$ Das Bundesverwaltungsgericht hat am Beispiel der allgemeinen Leistungsklage subjektive und objektive Elemente des Rechtsschutzbedürfnisses herausgearbeitet. ${ }^{62}$ Das subjektive Interesse ergebe sich bereits daraus, dass die klagende Person sich wegen einer ausstehenden Leistung an das Gericht wende. Das objektive Interesse an der Inanspruchnahme des Gerichts liege immer dann vor, wenn die Rechtsordnung ein materielles Recht gewährt, dessen sich die klagende Person als Anspruchsinhaberin sieht.

Bei der vorbeugenden Unterlassungsklage (s. hierzu Rn. 22ff.) ist das 47 Rechtsschutzbedürfnis hingegen besonders festzustellen. ${ }^{63}$ Ihre Legitimation finden die vorbeugenden Rechtsschutzverfahren in der Rechtsschutzgarantie, Art. 19 IV GG. Durch Verfahren des vorbeugenden Rechtsschutzes greifen Gerichte jedoch teils in noch offene Entscheidungsprozesse anderer Gewalten, z. B. der Exekutive ein. Die potentielle Betroffenheit der Gewaltenteilung erfordert daher ein qualifiziertes Rechtsschutzbedürfnis, an dem es fehlt, wenn der klagenden Person der nachgelagerte, in der Systematik der Verwaltungsgerichtsordnung angelegte Rechtsschutz zumutbar ist. ${ }^{64}$

61 BVerwG, Urt. v. 17.1.1989, Az.: 9 C 44/87 = BVerwGE 81, 164 (165f.).

62 BVerwG, Urt. v. 17.1.1989, Az.: 9 C 44/87 = BVerwGE 81, 164 (165f.).

63 Schmidt-Aßmann, in: Maunz/Dürig, GG, 85. EL 2018, Art. 19 Abs. 4 Rn. 279.

64 Vgl. BVerwG, Urt. v. 12.01.1967, Az.: III C 58.65 = BVerwGE 26, 23 (24f.); BVerwG, Urt. v. 29.07. 1977, Az.: IV C 51.75 = BVerwGE 54, 211 (215f.). 


\section{Begründetheit}

48 Ist die allgemeine Leistungsklage zulässig, ist in einem zweiten Schritt zu prüfen, ob sie auch begründet ist.

\section{Die Struktur der Begründetheitsprüfung (Roman Weidinger)}

49 Die Begründetheitsprüfung von Leistungsklagen ist wie bei allen anderen Klagearten auch durch einen Obersatz einzuleiten, der zugleich die Prüfungsstruktur vorgibt.

Unterschieden werden kann zwischen dem Obersatz für die Vornahmeklage und dem für die Unterlassungsklage:

50 Formulierungsvorschlag Obersatz für die Vornahmeklage: „Die Klage ist begründet, wenn der Kläger/die Klägerin einen Anspruch auf die begehrte Vornahme eines hoheitlichen Handelns hat, das kein Verwaltungsakt ist.“

Formulierungsvorschlag Obersatz für die Unterlassungsklage: „Die Klage ist begründet, wenn der Kläger/die Klägerin einen Anspruch auf Unterlassung eines hoheitlichen Handelns hat, das kein Verwaltungsakt ist.“ 65

\section{Passivlegitimation}

52 Während bereits innerhalb der Zulässigkeit unter dem Punkt „Antragsgegner“ die „passive Prozessführungsbefugnis“ geprüft wurde (vgl. § 2 Rn. 409 ff., s. in diesem $\S$ Rn. 38f.), könnte dies - alternativ oder wiederholt - innerhalb der Begründetheit als „Passivlegitimation“ geprüft werden. Da in der Anspruchsprüfung jedoch stets mitgeprüft werden muss, gegen wen sich der Anspruch richtet, ist die gesonderte Prüfung der Passivlegitimation grundsätzlich entbehrlich (s. zu dieser Problematik auch $\S 2$ Rn. 510).

53 Examenswissen: Das gilt jedoch nicht, sofern sie sich in der Klausur oder Hausarbeit aufdrängt. So etwa, wenn unklar ist, wem das klageweise angegriffene Verwaltungshandeln zuzuordnen ist. Beispielsweise bei Klagen auf Widerruf und/oder Unterlassung von Informationen oder Warnungen ist im Rahmen der Passivlegitimation regelmäßig zu prüfen, ob sich die Klage gegen den Akteur/die Akteurin richtet, von dem/der die Äußerung ausging. Und auch bei allgemeinen Leistungsklagen zwischen Organen muss geprüft werden, ob sich die Klage gegen das jeweils

65 Dazu zählt ausnahmsweise auch die Unterlassung eines Verwaltungsakt-Erlasses, s. dazu in diesem § Rn 24. 
richtig beklagte Organteil (beispielsweise Bürgermeister/in, Gemeinderat, etc.) richtet, dieses also passivlegitimiert ist. ${ }^{66}$

Die Bestimmung des/der richtigen Beklagten richtet sich dabei nach dem (allgemeinen) $\mathbf{5 4}$ Rechtsträgerprinzip, also danach, welche Körperschaft nach materiellem Recht verpflichtet ist, den geltend gemachten Leistungsanspruch zu erfüllen. ${ }^{67}$ Denn § 78 I VwGO findet keine analoge Anwendung, ${ }^{68}$ außer der Kläger verknüpft eine Anfechtungsklage mit Leistungsansprüchen nach $\S 113$ IV VwGO (s. zum richtigen Beklagten der allgemeinen Leistungsklage auch Rn. 38f.). ${ }^{69}$

\section{Anspruchsgrundlagen}

Ansprüche im Rahmen der allgemeinen Leistungsklage können sich aus ver- 55 schiedenen Rechtsbereichen ergeben.

\section{a) Ansprüche aus Unions- und Verfassungsrecht}

Anspruchsgrundlagen können sich zunächst unmittelbar aus dem Unionsrecht 56 oder aus der Verfassung ergeben.

Beispiele: Anspruch auf die Aufstellung von Aktionsplänen zum Gesundheitsschutz; ${ }^{70}$ Informationsanspruch aus Art. 5 I 1 GG, derivativer Teilhabeanspruch aus Art. 3 I GG i.V.m. dem jeweilig betroffenen Freiheitsgrundrecht ${ }^{71}$ oder als Unterlassungsanspruch aus dem allgemeinen Persönlichkeitsrecht, Art. 2 I GG i.V.m. Art. 1 I GG. ${ }^{72}$

66 Vgl. Hufen, Verwaltungsprozessrecht, 11. Aufl. 2019, § 27 Rn. 2, § 28 Rn. 2.

67 BVerwG, Urt. v. 28.8.2003, Az.: 4 C 9.02.

68 Kintz, in: Posser/Wolff, VwGO, 49. Ed., Stand: 1.4.2019, § 78 Rn. 6; gegen die analoge Anwendbarkeit von $\S 78$ I Nr. 2: vgl. Meissner/Schenk, in: Schoch/Schneider/Bier, VwGO, 36. EL Februar 2019, § 78 Rn. 52; für die analoge Anwendung des § 78 I Nr. 1 2. HS.: Schenke, Verwaltungsprozessrecht, 16. Aufl. 2019, Rn. $554 \mathrm{f}$.

69 OVG Lüneburg, Urt. v. 2.11.1999, Az.: 7 L 3645/97 = NdsVBl 2000, 215; § 78 I VwGO findet auch in der Begründetheit eines Vollzugsfolgenbeseitigungsanspruchs (Verknüpfung von Anfechtungsklage und Leistungsbegehren, § 113 I 2 VwGO, s. näher dazu § 2 Rn. 1387) analoge Anwendung: BVerwG, Urt. v. 4.12.2001, Az.: 4 C 2.00 = NVwZ 2002, 718; OVG Lüneburg, Urt. v. 2.11.1999, Az.: 7 L 3645/97 = NdsVBl 2000, 215.

70 EuGH, Urt. v. 25.7.2008, Az.: C-237/07 = NVwZ 2008, 984; Couzinet, DVBl. 2008, 754.

71 Vgl. BVerfG, Urteil v. 19.12.2017, Az.: 1 BvL 3/14 = BVerfGE 147, 253ff.; Hufen, Verwaltungsprozessrecht, 11. Aufl. 2019, § 28 Rn. 4 dazu: ,„[...] hier verfolgt das BVerfG allerdings erkennbar die Tendenz, die Entscheidung über unmittelbare Leistungsansprüche dem Gesetz[g]eber vorzubehalten (vgl. BVerfG, Urteil v. 24.1.2001, Az.: 1 BvR 2623/95 = BVerfGE 103, 44 (59).“

72 Hufen, Verwaltungsprozessrecht, 11. Aufl. 2019, § 27 Rn. 4. 


\section{b) Ansprüche aus einfachem Recht und Gewohnheitsrecht}

57 Vielfach ergeben sich Ansprüche, die im Rahmen der allgemeinen Leistungsklage geltend gemacht werden können, aus dem einfachen Recht, teilweise i.V.m. dem Gewohnheitsrecht.

Neben Ansprüchen aus öffentlich-rechtlichen Normen, wie etwa dem Anspruch auf Löschung in $\S 35$ II BPolG, werden solche auch aus der teils analogen Anwendung zivilrechtlicher Normen (gewohnheitsrechtlich) abgeleitet, ${ }^{73}$ namentlich §§ 1004, 812 I BGB, jeweils analog, ${ }^{74} \S 823$ I BGB, §§ 823 II oder 826 BGB i.V.m. dem allgemeinen Persönlichkeitsrecht (Art. 2 I GG i.V.m. Art. 1 I GG) oder Art. 14 I GG und auch den $\S \S 677$ ff. BGB analog.

59 Besonders klausurrelevant sind der allgemeine Folgenbeseitigungsanspruch und der Vollzugsfolgenbeseitigungsanspruch (näher zu beiden Rn. 169 ff., zum Vollzugsfolgenbeseitigungsanspruch auch § 2 Rn. 1387).

60 Beide Ansprüche unterscheiden sich insbesondere dadurch voneinander, dass der Vollzugsfolgenbeseitigungsanspruch (§ 113 I 2 VwGO) einen Anspruch auf die Rückgängigmachung/Beseitigung der Folgen eines rechtswidrigen und bereits vollzogenen Verwaltungsakts regelt, während der allgemeine Folgenbeseitigungsanspruch sich auf Folgen von Verwaltungshandeln bezieht, das kein Verwaltungsakt ist.

\section{c) Ansprüche aus Verwaltungsakt}

61 Daneben sind auch Ansprüche unmittelbar aus - wirksamen, §§ $43 \mathrm{ff}$. VwVfG (s. zur Wirksamkeit näher $§ 2$ Rn. 98 ff.) - Verwaltungsakten denkbar, insbesondere dann, wenn eine Behörde durch Verwaltungsakt die Gewährung einer Leistung regelt (z. B. in einem Subventionsbescheid), dieser Pflicht aber nicht nachkommt. Sofern der Verwaltungsakt nicht vollstreckbar ist, bleibt dem Bürger/der Bürgerin nur der Weg über die allgemeine Leistungsklage auf Gewährung der Leistung.

62 Examenswissen: Einen weiteren erwähnenswerten Fall hierzu bilden Ansprüche aus allgemeinen, mit Bindungswillen getroffenen ${ }^{75}$ Zusagen $^{76}$. Diese beziehen sich nicht, wie Zusicherungen

73 Zur einer Übersicht über solche Ansprüche samt Beispielen: Hufen, Verwaltungsprozessrecht, 11. Aufl. 2019, § 28 Rn. 5.

$74 \S 1004$ BGB analog als sog. quasi-negatorischer Abwehranspruch, (Beseitigungs- und Unterlassungsanspruch) und § 812 I BGB analog als öffentlich-rechtlicher Erstattungsanspruch. S. dazu: Hufen, Verwaltungsprozessrecht, 11. Aufl. 2019, § 27 Rn. 6 ff., § 28 Rn. 5.

75 In Abgrenzung zu einer unverbindlichen Zusage: Maurer/Waldhoff, Allgemeines Verwaltungsrecht, 19. Aufl. 2017, § 9, Rn. 60. 
nach § 38 I 1 VwVfG, auf den Erlass eines Verwaltungsakts, sondern auf ein schlichtes hoheitliches Handeln oder Unterlassen. ${ }^{77}$ Damit ist anders als für Zusicherungen (dazu die Verpflichtungsklage) die allgemeine Leistungsklage die statthafte Klageart.

\section{d) Ansprüche aus öffentlich-rechtlichem Vertrag}

Schließlich können auch Ansprüche aus öffentlich-rechtlichen Verträgen im Wege 63 der allgemeinen Leistungsklage geltend gemacht werden. Dabei kann es sich um Ansprüche des Bürgers/der Bürgerin gegen den Staat, aber auch umgekehrt des Staates gegen den Bürger/die Bürgerin handeln (näher Rn. $65 \mathrm{ff}$.).

\section{Spruchreife}

Ist der geltend gemachte Anspruch nicht spruchreif, kann in Anwendung des 64 $\S 113$ V 2 VwGO analog ein „Bescheidungsurteil“ ergehen (es geht nicht um eine Bescheidung, sondern um die Vornahme/das Unterlassen hoheitlichen Handelns, das kein Verwaltungsakt ist). ${ }^{78}$ Bei Ermessens-/Beurteilungsspielraum ist $\S 114$ VwGO analog anzuwenden. ${ }^{79}$

Beispiel: Auf die Neubewertung einer Klausur (zur Verwaltungsaktqualität von Noten s. $§ 2$ Rn. 153) besteht regelmäßig kein spruchreifer Anspruch, das Gericht kann (nur) deren Neubewertung durch die zuständige Stelle anordnen.

\section{Literaturhinweise}

Zwar älter, aber viele Aspekte übersichtlich abgehandelt: Steiner, Die allgemeine Leistungsklage im Verwaltungsprozess, Jus 1984, 853; Aufbereitung der zentralen Punkte zur Statthaftigkeit der allgemeinen Leistungsklage in klausurtypischem Aufbau: Geis/Meier, Grundfälle zur allgemeinen Leistungsklage, JuS 2013, 28; Abhandlung auch zu eher nebensächlichen Themen der allgemeinen Leistungsklage (insoweit gute Ergänzung vor allem zu dem oben genannten JuS-Aufsatz von Geis/Meier): Frenz, Die allgemeine Leistungs(vornahme)klage, JA 2010, 328; Übersichtliche Gesamtdarstellung: Pietzcker, in: Schoch/Schneider/Bier, VwGO, 36. EL Februar 2019, § 42 I Rn. 150 ff.

76 Deren Dogmatik ist weiterhin umstritten, dazu: Maurer/Waldhoff, Allgemeines Verwaltungsrecht, 19. Aufl. 2017, § 9 Rn. $59 \mathrm{ff}$ m.w.N.

77 Dennoch sind die Regelungen zu $§ 38$ VwVfG (Schriftform, zuständige Behörde, keine Nichtigkeit § 38 II i.V.m. § 44 VwVfG) analog anzuwenden.

78 Schenke, Verwaltungsprozessrecht, 16. Aufl. 2019, § 23 Rn. 867.

79 W.-R. Schenke/Ruthig, in: Kopp/Schenke, VwGO, 25. Aufl. 2019, § 114 Rn. 2.

Roman Weidinger 


\section{II. Öffentlich-rechtliche Verträge als Anspruchsgrundlage (Wolfgang Abromeit)}

65 Der Vertrag ist neben dem Verwaltungsakt die einzige Handlungsform (dazu $\S 1 \mathrm{Rn}$. 235ff.) im VwVfG, die eigens geregelt ist (wenn man von den besonderen Verfahrensarten absieht). Dadurch wurde ihm vom Gesetzgeber eine besondere Bedeutung verliehen, die ihm allerdings in der Ausbildung häufig noch verwehrt bleibt. Aufgrund der wachsenden Bedeutung in der Praxis ist jedoch zu erwarten, dass er auch in zukünftigen Examensaufgaben eine größere Rolle spielen wird. Aus der Studierendenperspektive spielt der Vertrag gleichwohl im Vergleich zum Verwaltungsakt noch eine deutlich untergeordnete Rolle. Diese Rollenverteilung hat ihren Ursprung sicherlich auch in der VwGO: Während die in der Klausurpraxis bedeutsamsten verwaltungsgerichtlichen Verfahrenstypen um die unterschiedlichen Spielarten und Stadien des Verwaltungsakts designt wurden (s. bereits $\S 1$ Rn. 245ff.), müssen sich Streitigkeiten, die aus vertraglichen Rechtsverhältnissen entstehen, in die „übrigen“ Klagearten einfügen.

In Prüfungsarbeiten, in denen es um Verträge geht, unterscheidet sich meist auch das Rechtschutzbegehren deutlich von Verwaltungsakt-Klausuren, bei denen es regelmäßig um die Aufhebung oder den Erlass eines Verwaltungsakts oder den darauf bezogenen einstweiligen Rechtsschutz geht. Hingegen ist die prüfungsbestimmende Frage bei Klausuren, in denen der Vertrag im Zentrum der Bearbeitung steht, regelmäßig, ob er wirksam ist.

67 Entscheidend für die Antragsart ist - wie sonst auch - das Ziel des Antragstellers (s. näher $§ 1$ Rn. 223ff.). Das bedeutet im Rahmen dieses Lehrbuchs, dass an dieser Stelle jedenfalls die klageweise Erfüllung der Hauptleistungspflichten des Vertrags zu behandeln sind, soweit sich diese auf „sonstiges Verwaltungshandeln“ und Geldleistungen beziehen, weil dann die allgemeine Leistungsklage einschlägig ist. ${ }^{80}$ Verpflichtet sich die Behörde vertraglich zum Erlass eines Verwaltungsakts, wäre die Verpflichtungsklage einschlägig (s. näher $§ 3$ Rn. 71).

Die Prüfung des Vertrags ist in Klausuren - vermutlich auch praktisch - meist in Konstellationen des öffentlich-rechtlichen Erstattungsanspruchs eingekleidet, bei denen die Wirksamkeit des Vertrags unter dem Prüfungspunkt „fehlender Rechtsgrund“ zu thematisieren ist (s. näher Rn. 206). Dies hat seine Ursache häufig darin, dass die Parteien zunächst den Vertrag abwickeln und die Leistungen austauschen, um sich die jeweilige Gegenleistung zu sichern. Erst im Anschluss wird der eine Vertragspartner die Wirksamkeit des Vertrags im Rechtsweg anfechten, um die eigene Leistung zurück zu erhalten.

80 Gurlit, in: Ehlers/Pünder, Allgemeines Verwaltungsrecht, 15. Aufl. 2016, § 34 Rn. 2. 


\section{Der Vertrag als Handlungsform der Behörde}

In der Praxis ist der Vertrag mittlerweile in der Massenverwaltung angekom- 69 men, somit in der Praxis etabliert, wissenschaftlich als gleichwertige Handlungsform anerkannt und auch bereits weitgehend systematisiert und aufgearbeitet. Die grundsätzliche Zulässigkeit des Vertrags als Handlungsform ist folglich geklärt. In konzeptioneller Hinsicht bietet es sich an, auch einige der Grundlagen vertraglichen Handelns an dieser Stelle zu erläutern.

\section{a) Entwicklung}

Die deutliche - wenn auch tendenziell schwindende - Unterrepräsentation des 70 vertraglichen Handelns in der juristischen Ausbildung kann teilweise auf eine verwaltungsrechtliche Lehre zurückgeführt werden, der ein überholtes Staatsbild zu Grunde lag: das Subjectionsverhältnis. In dieser Vorstellung herrschte eine strikte, auch ideelle Über- Unterordnung zwischen Staat und Bürger. Die strukturelle Gleichberechtigung der Vertragspartner schien den Vertretern dieser Lehre in einem unauflöslichen Widerspruch zu ihrer Auffassung zu stehen. ${ }^{81}$ Idealtypisch repräsentiert wird diese Lehre von Otto Mayer, der u.a. mit dem Satz „(d)arum sind wahre Verträge des Staates auf dem Gebiete des öffentlichen Rechtes überhaupt nicht denkbar“, federführend die Ablehnung vertraglichen Handelns formulierte. In der Folge wurde dies kurz zusammengefasst: „Der Staat paktiert nicht!“ 82 Auch wenn diese Auffassung nie unumstritten war, prägte sie bis in die Mitte des 20. Jahrhunderts die Diskussion um das vertragliche Handeln von Behörden. Mittlerweile kann sie als überwunden gelten. Allerspätestens durch die ausdrückliche gesetzliche Regelung in $\S 541$ VwVfG ist sie Geschichte. ${ }^{83}$ Danach gilt: „Ein Rechtsverhältnis auf dem Gebiet des öffentlichen Rechts kann durch Vertrag begründet, geändert oder aufgehoben werden“. Das dadurch besiegelte Ende der Diskussion um die Möglichkeit vertraglichen Verwaltungshandelns war überfällig, zumal die vertragliche Regelung von Vertragsrechtsverhältnissen kein besonders modernes Phänomen ist. ${ }^{84}$ Über die Anwendung als Alternative zum Verwaltungsakt geht der Verwaltungsvertrag jedenfalls auch hinaus, bringt eigene Stärken ins Spiel und steht mit der durch ihn symbolisch-rechtsförmlichen Kristallisation des Kooperationsprinzips auch für das heute gewandelte Verständnis

81 Höfling/Krings, JuS 2001, 625 (625); Maurer/Waldhoff, Allgemeines Verwaltungsrecht, 19. Aufl. 2017, § 14 Rn. 27; Bauer, in: Schmidt-Aßmann/Hoffmann-Riem, 2. Aufl. 2012, § 36 Rn. 1.

82 Bauer, in: Schmidt-Aßmann/Hoffmann-Riem, 2. Aufl. 2012, § 36 Rn. 1.

83 Vgl. BVerwG, Urt. v. 4.2.1966, Az.: IV C 64/65 = BVerwGE 23, 213 = NJW 1966, 1936.

84 Maurer/Waldhoff, Allgemeines Verwaltungsrecht, 19. Aufl. 2017, §14 Rn. 27f.; Bauer, in: Schmidt-Aßmann/Hoffmann-Riem, 2. Aufl. 2012, § 36 Rn. 1 f. 
der Stellung des Bürgers im und zum Staat. ${ }^{85}$ Er ermöglicht flexible und atypischen Fällen gerecht werdende Lösungen, fördert Rechtsfrieden, Rechtssicherheit sowie Akzeptanz und ist somit ein „notwendiges und legitimes Regelungsinstrument der Verwaltung“. ${ }^{86}$ Im Fokus der Wissenschaft stehen die einzelnen rechtlichen Voraussetzungen, die Fehlerfolgen und zunehmend die rechtliche Ausgestaltung - also die Vertragsgestaltung. ${ }^{87}$

\section{b) Begriff}

71 Nach der allgemeinen Rechtslehre ist der Vertrag materiell von drei Voraussetzungen abhängig:

Es muss 1. eine Einigung von 2. mindestens zwei Rechtssubjekten 3. über die Herbeiführung bestimmter Rechtsfolgen vorliegen. Damit ein Vertragsschluss festgestellt wird, müssen also mindestens zwei Parteien diesen Rechtsbindungswillen mittels übereinstimmender Willenserklärungen ${ }^{88}$ (Angebot und Annahme) zum Ausdruck bringen. ${ }^{89}$

72 Es stellt sich allerdings darüberhinausgehend die Frage, was den Vertrag nach $\S \S 54 \mathrm{ff}$. VwVfG ausmacht. Wenig aufschlussreich ist die amtliche Überschrift „Der öffentlich-rechtliche Vertrag“, da natürlich nicht alle öffentlich-rechtlichen Verträge gemeint sind. Der Anwendungsbereich der Verwaltungsverfahrensgesetze bezieht sich nach $\S 1$ II VwVfG nur auf die Verwaltungstätigkeit von Bund, bzw. Ländern und Gemeinden. Nicht gemeint sein können daher völkerrechtliche Verträge, sonstige Staatsverträge, Verwaltungsabkommen, kirchenrechtliche Verträge insbesondere Staatskirchenverträge, etc. Allerdings deckt sich die Formel „,auf dem Gebiet des öffentlichen Rechts“ mit dem entsprechenden Begriffsmerkmal in $\S 35$ VwVfG. Sie ist also „hier wie dort“ eingeschränkt auf das Verwaltungsrecht $\mathrm{zu}$ verstehen.

73 Für die Verträge nach $\S \S 54 \mathrm{ff}$. VwVfG selbst ist es aber sinnvoll, ein eingeschränktes und passenderes Begriffsverständnis $\mathrm{zu}$ entwickeln. Teilweise wird

85 Bauer, in: Schmidt-Aßmann/Hoffmann-Riem, 2. Aufl. 2012, § 36 Rn. 9 f.

86 Maurer/Waldhoff, Allgemeines Verwaltungsrecht, 19. Aufl. 2017, § 14 Rn. 29; Peine/Siegel, Allgemeines Verwaltungsrecht, 12. Aufl. 2018, § 17 Rn. 716.

87 Maurer/Waldhoff, Allgemeines Verwaltungsrecht, 19. Aufl. 2017, § 14 Rn. 29.

88 Gurlit, in: Ehlers/Pünder, Allgemeines Verwaltungsrecht, 15. Aufl. 2016, § 28; Kluth, in: Wolff/ Bachof/Stober/Kluth, Verwaltungsrecht I, § 36.

89 Detterbeck, Allgemeines Verwaltungsrecht, 17. Aufl. 2019, Rn. 784; Maurer/Waldhoff, Allgemeines Verwaltungsrecht, 19. Aufl. 2017, § 14 Rn. 9; Peine/Siegel, Allgemeines Verwaltungsrecht, 12. Aufl. 2018, § 17 Rn. 720. 
der Begriff „Verwaltungsvertrag“ vorgeschlagen. ${ }^{90}$ Allerdings empfiehlt sich dieser Begriff jedenfalls in der wissenschaftlichen Beschäftigung vom reinen Wortsinn für ein umfassenderes Verständnis, dass alle und vor allem auch privatrechtliche Verträge umfasst, an denen die Verwaltung als Vertragspartner beteiligt ist. Bezeichnete man nur die im Rechtsweg den Verwaltungsgerichten zugewiesenen Verträge als Verwaltungsverträge, fehlte nämlich für diese allgemeinere Auffassung und für die damit verbundene Strukturierung des wissenschaftlichen Diskurses eine vergleichbar intuitive Alternative. Die Verträge nach $\S \S 54 \mathrm{ff}$. VwVfG, die sich auf die Begründung, Änderung oder Aufhebung eines verwaltungsrechtlichen Rechtsverständnisses beziehen, können hingegen passend und sinnvoll als öffentlich-rechtliche Verwaltungsverträge bezeichnet werden.

\section{c) Arten}

Auch wenn dem VwVfG kein abschließender Katalog an Verträgen zu entnehmen 74 ist, lassen sich die Verträge nach den $\S \S 54 \mathrm{ff}$. VwVfG nach Anhaltspunkten einer gesetzlichen Typisierung unterscheiden und ordnen. ${ }^{91}$ Der in $\S 54 \mathrm{~S}$. 2 VwVfG hervorgehobene Typus des Vertrags, mit dem die Behörde, anstatt einen Verwaltungsakt $\mathrm{zu}$ erlassen, einen öffentlich-rechtlichen Vertrag mit demjenigen schließt, an den sie sonst den Verwaltungsakt richten würde, wird allgemein als subordinationsrechtlicher Vertrag bezeichnet. ${ }^{92}$ Allerdings darf das Verständnis nicht in einem engen Verständnis dem Wortsinn nach auf verwaltungsrechtliche Verträge begrenzt werden, die einen Verwaltungsakt ersetzen bzw. enthalten (sog. verwaltungsaktersetzende Verträge). Nicht nur, dass auch Verträge gemeint sind, die die Behörde zum Erlass eines Verwaltungsakts verpflichten (sog. verwaltungsaktvorbereitende Verträge). ${ }^{93}$ Darüber hinaus sind auch alle Verträge subordinationsrechtlich einzuordnen, die nicht streng verwaltungsaktbezogen sind, in denen aber bei Betrachtung der konkreten Rechtsbeziehung ein ÜberUnterordnungsverhältnis zwischen den Vertragspartnern besteht.

Für all diese Verträge gilt das Rechtsregime der $\S \S 55,56,59$ II, 61 VwVfG, 75 deren Verständnis viele examensrelevante Probleme erschließt. Eine besondere Ausprägung des subordinationsrechtlichen Vertrags ist wiederum der Aus-

90 Maurer/Waldhoff, Allgemeines Verwaltungsrecht, 19. Aufl. 2017, § 14 Rn. $11 \mathrm{ff}$.

91 Vgl. Detterbeck, Allgemeines Verwaltungsrecht, 17. Aufl. 2019, Rn. 788.

92 Maurer/Waldhoff, Allgemeines Verwaltungsrecht, 19. Aufl. 2017, § 14 Rn. 17; Peine/Siegel, Allgemeines Verwaltungsrecht, 12. Aufl. 2018, § 17 Rn. 740.

93 Gurlit, in: Ehlers/Pünder, Allgemeines Verwaltungsrecht, 15. Aufl. 2016, § 29 Rn. 7; Detterbeck, Allgemeines Verwaltungsrecht, 17. Aufl. 2019, Rn. 790; Vgl. Peine/Siegel, Allgemeines Verwaltungsrecht, 12. Aufl. 2018, § 17 Rn. 743. 
tauschvertrag nach $\S 56 \mathrm{VwVfG},{ }^{94}$ für den besondere Rechtmäßigkeitsvoraussetzungen verankert wurden (s. Rn. $103 \mathrm{ff}$.). Eine weitere Ausprägung der subordinationsrechtlichen Verträge ist der Vergleichsvertrag nach $\S 55 \mathrm{VwVfG}$, in dem besondere Voraussetzungen für Verträge geregelt werden, mit denen Rechtsstreitigkeiten beigelegt werden. ${ }^{95} \S 55$ VwVfG bezieht sich nur auf subordinationsrechtliche Verträge. Die Vorschrift $\S 55$ VwVfG regelt nur materielle Voraussetzungen des Vergleichsvertrages, für Prozessvergleiche enthält wiederum § 106 VwGO eine Sonderregelung.

76 Daneben firmiert unter der Bezeichnung als koordinationsrechtlicher Vertrag ein Typus verwaltungsrechtlicher Verträge als Gegenentwurf zum subordinationsrechtlichen Vertrag, bei denen die Vertragspartner eher einander gleichgeordnet gegenüberstehen. ${ }^{96}$ Solche Verträge, die insbesondere zwischen Behörden geschlossen werden, betreffen Rechtsverhältnisse, die nicht durch Verwaltungsakt geregelt werden können. Für die gleichgeordnete Zusammenarbeit zwischen Behörde und Bürger, beispielsweise bei der Erfüllung öffentlicher Aufgaben, bietet sich der Begriff des Kooperationsvertrags an. ${ }^{97}$

77 Wie im Zivilrecht kann auch im Verwaltungsvertragsrecht zwischen Verpflichtungsverträgen, die den Rechtsgrund für zu erbringende Leistungen bilden, und Verfügungsverträgen unterschieden werden, die unmittelbar eine Rechtsänderung herbeiführen..$^{98}$ Da die Verträge in einem Dokument zusammenfallen oder auch teilweise nicht logisch voneinander getrennt werden können, ist in der Fallbearbeitung jeweils auf eine genaue Ermittlung des Vertragsinhalts zu achten.

\section{d) Rechtsgrundlagen}

78 Das Rechtsregime der verwaltungsrechtlichen Verträge (ohne Berücksichtigung des Fachrechts) ist dreistufig strukturiert: Die speziell für den Vertrag geltenden Regeln finden sich in den $\S \S 54-61$ VwVfG. Nach § 62 S. 1 VwVfG gelten darüber hinaus die übrigen Vorschriften des VwVfG und nach § $62 \mathrm{~S} .2$ VwVfG

94 Maurer/Waldhoff, Allgemeines Verwaltungsrecht, 19. Aufl. 2017, § 14 Rn. 21; Detterbeck, Allgemeines Verwaltungsrecht, 17. Aufl. 2019, Rn. 795.

95 Maurer/Waldhoff, Allgemeines Verwaltungsrecht, 19. Aufl. 2017, § 14 Rn. 22; Detterbeck, Allgemeines Verwaltungsrecht, 17. Aufl. 2019, Rn. 799.

96 Gurlit, in: Ehlers/Pünder, Allgemeines Verwaltungsrecht, 15. Aufl. 2016, § 29 Rn. 9.

97 Maurer/Waldhoff, Allgemeines Verwaltungsrecht, 19. Aufl. 2017, § 14 Rn. 23.

98 Peine/Siegel, Allgemeines Verwaltungsrecht, 12. Aufl. 2018, § 17 Rn. 743.

Wolfgang Abromeit 
auch die Vorschriften des Bürgerlichen Gesetzbuchs ergänzend und entsprechend. ${ }^{99}$

Im Rahmen des Prüfungsstoffs sind im besonderen Teil des öffentlich- 79 rechtlichen Kanons insbesondere die baurechtlichen Sonderregelungen für den Vertrag relevant. ${ }^{100}$ Für die Entwicklung des Verwaltungsvertragsrechts und auch in der Klausur hat das Städtebaurecht eine besondere Bedeutung, da der dort geforderte Interessenausgleich über die bereits durch die Institution des Vertrags symbolisierte Kooperation in besonderem Maß relevant wird. ${ }^{101}$ Mit dem Erschließungsvertrag ist in $\S 11$ BauGB auch ein besonderes und examensrelevantes Rechtsregime zu finden. ${ }^{102}$ Referenzgebiete des Vertragsrechts finden sich außerdem im Umweltrecht, im Bodenschutzrecht, im Beamtenrecht, im Subventionsrecht, allgemein im öffentlichen Wirtschaftsrecht ${ }^{103}$ und (weniger examensrelevant aber praktisch besonders bedeutsam) im Sozialrecht. ${ }^{104}$

Für alle verwaltungsrechtlichen Verträge gelten außerdem gem. § 62 VwVfG die übrigen Vorschriften des VwVfG, wenn sich nicht, wie bei den Regeln über den Verwaltungsakt, etwas anderes ergibt. Darüber hinaus gelten die Vorschriften des BGB entsprechend. Diese Regelung reagiert auf das lückenhafte Regime der \$§ 54 ff. VwVfG und eröffnet für wirksame Verträge die Anwendbarkeit des BGB. Klausuren, die das Rechtsregime des Verwaltungsvertragsschuldrechts betreffen, sind zwar noch relativ selten, allerdings gehört die Kenntnis aufgrund der normativen Verankerung im VwVfG zweifellos zum Pflichtstoff der meisten, wenn nicht aller Prüfungsordnungen.

\section{e) Abgrenzung}

Die Bestimmung der jeweiligen Handlungsform der Behörde kann in der Klausur 81 wie im realen Leben teilweise sehr einfach, in manchen (Lebens-)Sachverhalten aber auch hoch problematisch sein. Wenn die Zuordnung nicht eindeutig ist, kann dieses Thema auch einen der Schwerpunkte der Klausurbearbeitung darstellen. Die Problematik ist entweder in der Eröffnung des Verwaltungsrechtsweges

99 Peine/Siegel, Allgemeines Verwaltungsrecht, 12. Aufl. 2018, § 17 Rn. 719.

100 Drechsler, Jura 2017, 413; Decker, JA 2012, 286.

101 Vgl. z. B. BVerwG, Urt. v. 25.11.2005, Az.: 4 C 15.04 = BVerwGE 124, 385 = NVwZ 2006, 336 ff.; BVerwG, Urt. v. 16.5.2000, Az.: 4 C 4/99 = BVerwGE 111, 162 = NVwZ 2000, 1285.

102 Peine/Siegel, Allgemeines Verwaltungsrecht, 12. Aufl. 2018, § 17 Rn. 719.

103 Siegel/Eisentraut, VerwArch 2018, 454.

104 Maurer/Waldhoff, Allgemeines Verwaltungsrecht, 19. Aufl. 2017, §14 Rn. 3ff.; Gurlit, in: Ehlers/Pünder, Allgemeines Verwaltungsrecht, 15. Aufl. 2016, § 29 Rn. 3; Kretschmer, Das Recht der Eingliederungsvereinbarung des SGB II, 2012.

Wolfgang Abromeit 
(s. § 1 Rn. 185 ff.) oder unter dem Prüfungspunkt „Antrags-/Klageart“ anzusprechen. Der öffentlich-rechtliche Verwaltungsvertrag muss dann anhand seiner charakteristischen Merkmale von anderen Handlungsformen abgegrenzt werden.

\section{aa) Abgrenzung zum privatrechtlichen Verwaltungsvertrag}

Die Unterscheidung des öffentlich-rechtlichen vom privatrechtlichen Verwaltungsvertrag ist dabei vermutlich die klausurrelevanteste Konstellation, zumal sie regelmäßig auch über den Rechtsweg entscheidet. Die Schwierigkeit der Unterscheidung hat ihre Ursache auch in der Annäherung des öffentlich-rechtlichen Verwaltungsvertrags zum privatrechtlichen in der Praxis und spiegelt sich in einer uneinheitlichen Rechtsprechung wieder. ${ }^{105}$ In manchen problematischen Fällen blieb die Frage bis zur höchstrichterlichen Entscheidung ungeklärt. ${ }^{106}$ Vorherrschend ist wohl die Abgrenzung nach dem „Gesamtcharakter“ des Vertragsgegenstands. ${ }^{107}$ Für die Abgrenzung von öffentlich-rechtlichem und zivilrechtlichem Vertrag kommt es nach dem gemeinsamen Senat der obersten Gerichtshöfe des Bundes auf dessen Gegenstand und Zweck an; die Rechtsnatur des Vertrages bestimmt sich danach, ob der Vertragsgegenstand dem öffentlichen oder dem bürgerlichen Recht zuzuordnen ist. ${ }^{108}$ Problematisch wird es, wenn der Vertrag privatrechtliche und öffentlich-rechtlich einzuordnende Elemente umfasst. Es ist nicht unzulässig öffentlich-rechtliche und privatrechtliche Elemente in einem „gemischten Vertrag“ zu verbinden. ${ }^{109}$ In dem Fall komme es auf den „Schwerpunkt der vertraglichen Regelung an“, also die Regelungen, die dem Vertrag sein Gepräge verleihen (sog. Schwerpunkts- oder Geprägetheorie). ${ }^{110}$ Kommt man in der Prüfungssituation in solchen Fällen nicht zu einem eindeutigen Ergebnis, ist es vermutlich klausurtaktisch am geschicktesten in einer verwaltungsrechtlichen Klausur, die Streitigkeit als öffentlich-rechtliche einzuordnen und dementsprechend in einer zivilrechtlichen als privatrechtliche.

105 Übersichten bei: Detterbeck, Allgemeines Verwaltungsrecht, 17. Aufl. 2019, Rn. 786; Peine/ Siegel, Allgemeines Verwaltungsrecht, 12. Aufl. 2018, § 17 Rn. $734 \mathrm{f}$.

106 Maurer/Waldhoff, Allgemeines Verwaltungsrecht, 19. Aufl. 2017, § 14 Rn. $11 \mathrm{f}$.

107 Maurer/Waldhoff, Allgemeines Verwaltungsrecht, 19. Aufl. 2017, § 14 Rn. 15; Peine/Siegel, Allgemeines Verwaltungsrecht, 12. Aufl. 2018, § 17 Rn. 734.

108 GmS-OGB, Beschl. v. 10.4.1986, Az.: GmS-OGB 1/85 = BVerwGE 74, 368 = NJW 1986, 2359. 109 BVerwG, Urt. v. 11.2.1993, Az.: 4 C 18/91 = BVerwGE 92, 56 (59) = NJW 1993, 2695.

110 Peine/Siegel, Allgemeines Verwaltungsrecht, 12. Aufl. 2018, § 17 Rn. 735; BVerwG, Urt. v. 18.7. 2012, Az.: 8 C 4/11 Rn. 45 = BVerwGE 143, $335 \mathrm{ff}=$ NVwZ 2013, 209. 


\section{bb) Abgrenzung zu einseitigen Handlungsformen}

Als zweiseitige, auf Einigung angewiesene Regelung, ist die Abgrenzung vom 83 einseitig-hoheitlich erlassenen Verwaltungsakt in den meisten Fällen unproblematisch. Schwieriger wird es bei den Sonderkonstellationen (s. auch $\S 2$ Rn. 49 ff.) wie beispielsweise bei mitwirkungsbedürftigen Verwaltungsakten, also meistens wenn der Adressat einen Antrag stellt oder zustimmen muss. ${ }^{111}$ Beispiele hierfür sind die Beamtenernennung nach $\S 12 \mathrm{BStG}$, die Einbürgerung von Ausländern gem. AuslG oder Baugenehmigungen. Der Bürger kann in diesen Fällen allerdings nicht den Regelungsinhalt mitgestalten. Das Mitwirkungserfordernis verhindert vor allem, den Verwaltungsakt aufgedrängt zu bekommen. ${ }^{112}$ Zweifel können auch auftreten, wenn der Adressat aufgrund von Nebenbestimmungen zu einer Art Gegenleistung verpflichtet wird. ${ }^{113}$

\section{cc) Abgrenzung zu unverbindlichen Absprachen}

Andere Grenzfälle betreffen die Unterscheidung von unverbindlichen und/oder 84 informierenden Absprachen, bei denen es am Rechtsbindungswillen fehlt. ${ }^{114}$ Weniger klausurrelevant sind vermutlich aktuelle praktische Probleme, die sich beispielsweise bei einer hybriden Rechtsgestaltung oder einem Instrumentenmix ergeben. ${ }^{115}$

\section{dd) Abgrenzung bei verwaltungsrechtlichen Schuldverhältnissen}

Auch bei verwaltungsrechtlichen Schuldverhältnissen, seien sie im Abwasser- 85 recht oder bei der Benutzung einer Schwimmhalle angesiedelt, kann es sein, dass in der Fallbearbeitung eine Abgrenzung zum vertraglichen Handeln vorgenommen werden muss. In diesen Fällen hat die Gemeinde häufig ein gewisses Wahlrecht, ob sie das Benutzungsverhältnis öffentlich-rechtlich oder privatrechtlich ausgestalten will, sie muss dann allerdings in der Ausgestaltung konsequent sein. In solchen Fällen kommt es darauf an, inwiefern die Behörde ihren Willen zur Rechtsform geäußert hat. ${ }^{116}$

111 Maurer/Waldhoff, Allgemeines Verwaltungsrecht, 19. Aufl. 2017, § 14 Rn. 24; Peine/Siegel, Allgemeines Verwaltungsrecht, 12. Aufl. 2018, § 17 Rn. 724 f.

112 Höfling/Krings, JuS 2001, 625 (626).

113 Maurer/Waldhoff, Allgemeines Verwaltungsrecht, 19. Aufl. 2017, § 14 Rn. 26.

114 Peine/Siegel, Allgemeines Verwaltungsrecht, 12. Aufl. 2018, § 17 Rn. 725.

115 Bauer, in: Schmidt-Aßmann/Hoffmann-Riem, 2. Aufl. 2012, § 36 Rn. 81.

116 Maurer/Waldhoff, Allgemeines Verwaltungsrecht, 19. Aufl. 2017, § 14 Rn. 14; Peine/Siegel, Allgemeines Verwaltungsrecht, 12. Aufl. 2018, § 17 Rn. 726. 


\section{f) Rechtsverhältnislehre als lohnende Perspektive auf den Verwaltungsvertrag}

86 Hausarbeitswissen: Es lohnt sich bei dem Verwaltungsvertrag eine dogmatische Perspektivenerweiterung mit Hilfe der Rechtsverhältnislehre vorzunehmen. Sie betrachtet die sich zwischen den Beteiligten entwickelnden Beziehungen zeitlich dynamisch unter Berücksichtigung der Veränderung der Situation. ${ }^{117}$ Die eher prozedural ausgerichtete Programmatik eröffnet den strukturierten Blick auf die unterschiedlichen Phasen der vom Vertrag betroffenen Sachverhalte. Zeitlich voranschreitend lässt sich der Lebenszyklus der vertraglich geordneten Lebenssachverhalte von der vorvertraglichen Vertragsverhandlung und Vertragsanbahnung über den Vertragsschluss, die Vertragsdurchführung mit einem daran anschließenden Vertragscontrolling bis zur „Beendigung“ von Verwaltungsverträgen und der Betrachtung nachvertraglicher Pflichten verstehen. ${ }^{118}$ Während der gegenwärtige Fokus in der Ausbildung noch entsprechend der Regelungsschwerpunkte der \$§ $54 f f$. $V w V f G$ deutlich auf die zulässigen Inhalte und damit verbunden auf die Wirksamkeit des Vertrags nach Vertragsschluss, bzw. die Rückabwicklung gerichtet ist, hilft das prozedurale Verständnis der Rechtsverhältnislehre, die danach noch offen gebliebenen Bereiche sichtbar zu machen. So werden in der Ausbildung beispielsweise die Bereiche

- für die Regelung der Rechtsverhältnisse bis zum Abschluss des Vertrages (wesentlich geprägt durch das Vergaberecht)

- der vorvertraglichen Rechtsverhältnisse (hier ist seit der Schuldrechtsmodernisierung \& 311 II BGB analog i.V.m. \& 62 S. 2 VwVfG einschlägig)

- für die Durchführung des vertraglich vereinbarten Leistungsprogramms (auch hier ist vor allem das Verwaltungsvertragsschuldrecht relevant, das sich aus der entsprechenden Anwendung der Vorschriften des BGB i.V.m. \& 62 S. 2 VwVfG ergibt)

- und der einvernehmlichen vertraglichen Anpassung deutlich weniger oder auch gar nicht behandelt.

- Ein besonderes Desiderat in der Forschung stellt außerdem die Vertragsgestaltungslehre dar, die sich auf die konkrete Rechtsgestaltung der Inhalte verwaltungsvertraglichen Inhalts konzentriert, praktisch damit besonders hohe Relevanz aufweist, aber noch kaum aufgearbeitet ist. ${ }^{119}$

\section{Der Vertrag als Anspruchsgrundlage}

87 Wenn sich eine der Parteien nicht an die vertragliche Vereinbarung nach $\S 54$ VwVfG hält oder vor Leistungsaustausch Streitigkeiten über die Gültigkeit des Vertrags entstehen, müssen die Parteien ihre Ansprüche im Wege der Leistungsklage durchsetzen. ${ }^{120}$ Hier kann sich auch die leicht ungewohnte Konstel-

117 Maurer/Waldhoff, Allgemeines Verwaltungsrecht, 19. Aufl. 2017, § 8; Remmert, in: Ehlers/ Pünder, Allgemeines Verwaltungsrecht, § 18; Bauer, Die Verwaltung 1992, 301 (insbesondere ab S. 319).

118 Bauer, in: Schmidt-Aßmann/Hoffmann-Riem, 2. Aufl. 2012, § 36 Rn. $103 \mathrm{ff}$.

119 Bauer, in: Schmidt-Aßmann/Hoffmann-Riem, 2. Aufl. 2012, § 36 Rn. $121 \mathrm{ff}$.

120 Maurer/Waldhoff, Allgemeines Verwaltungsrecht, 19. Aufl. 2017, § 14 Rn. 65; Peine/Siegel, Allgemeines Verwaltungsrecht, 12. Aufl. 2018, § 17 Rn. 800; Frenz, Öffentliches Recht, 7. Aufl. 2017, $\S 19$ Rn. 1324.

Wolfgang Abromeit 
lation ergeben, dass die Behörde als Kläger im verwaltungsgerichtlichen Klageverfahren auftritt, um eine Geldzahlung oder eine sonstige vertretbare Handlung durchzusetzen. Dadurch, dass sich die Behörde durch die Wahl der vertraglichen Regelung auf Augenhöhe mit dem Bürger begeben hat, ist es ihr nicht mehr möglich, zur Durchsetzung ihres Anspruchs einen Verwaltungsakt zu erlassen es fehlt insoweit an der Verwaltungsakt-Befugnis. ${ }^{121}$ Dies gilt natürlich nicht, wenn sich die Parteien vertraglich der sofortigen Vollstreckung unterwerfen, wobei für die Behörde dafür die Sondervoraussetzungen des §61 I S. 2 VwVfG gelten. ${ }^{122}$ Unabhängig davon, welche Partei den Anspruch durchsetzen möchte: In der Fallbearbeitung empfiehlt sich in solchen Konstellationen eine Orientierung an dem zivilrechtlichen Aufbau. Zunächst erfolgt danach die Prüfung des Vertrags als Anspruchsgrundlage. Daran kann die weitere gutachterliche Prüfung, ob der Anspruch untergegangen oder nicht (mehr) durchsetzbar sein könnte, angeschlossen werden. ${ }^{123}$ Damit ein Anspruch aus einem Vertrag in Frage kommt, müssten sich die Parteien zunächst dementsprechend geeinigt haben, es müsste also ein Vertrag zustande gekommen sein.

\section{a) Einigung}

Im ersten Prüfungsschritt ist also gutachterlich danach zu fragen, ob überhaupt 88 durch einen Vertragsschluss ein Anspruch entstanden ist. Wie bereits angesprochen, müssen dafür zwei Parteien einen dahingehenden Rechtsbindungswillen mittels übereinstimmender Willenserklärungen zum Ausdruck gebracht haben. ${ }^{124}$

Die zu diesem Zweck von der Verwaltung getätigte öffentlich-rechtliche Wil- 89 lenserklärung ist in Abgrenzung zu einem Verwaltungsakt, schlichthoheitliches Handeln, auf das gem. § 62 VwVfG die bürgerlich-rechtlichen Vorschriften, wie die $\S \S 104 \mathrm{ff}$., $116 \mathrm{ff}$., $164 \mathrm{ff}$. und $177 \mathrm{ff}$. BGB entsprechend anzuwenden sind. ${ }^{125}$ Das bedeutet auch, dass der konkrete Vertragsinhalt entsprechend §§ 137, 157 BGB auszulegen ist. Die übrigen Regelungen des VwVfG zum Verfahren gelten nach $\S 621$ VwVfG subsidiär. ${ }^{126}$

121 Maurer/Waldhoff, Allgemeines Verwaltungsrecht, 19. Aufl. 2017, §14 Rn. 65; Peine/Siegel, Allgemeines Verwaltungsrecht, 12. Aufl. 2018, §17 Rn. 800.

122 Maurer/Waldhoff, Allgemeines Verwaltungsrecht, 19. Aufl. 2017, § 14 Rn. 66.

123 Vgl. Frenz, Öffentliches Recht, 7. Aufl. 2017, § 19.

124 Maurer/Waldhoff, Allgemeines Verwaltungsrecht, 19. Aufl. 2017, § 14 Rn. 35.

125 Peine/Siegel, Allgemeines Verwaltungsrecht, 12. Aufl. 2018, § 17 Rn. 722; zur verwaltungsrechtlichen Willenserklärung, Gurlit, in: Ehlers/Pünder, Allgemeines Verwaltungsrecht, 15. Aufl. 2016, § 28, §29 Rn. 2.

126 Gurlit, in: Ehlers/Pünder, Allgemeines Verwaltungsrecht, 15. Aufl. 2016, §29 Rn. 3. 


\section{b) Schriftformerfordernis}

$90 \S 57$ VwVfG ordnet für öffentlich-rechtliche Verwaltungsverträge die Schriftform an (dazu und zur elektronischen Übermittlung § 2 Rn. 685 ff.), die Voraussetzungen sind hier also strenger als beim Verwaltungsakt, der auch formlos ergehen kann. ${ }^{127}$ Es ist umstritten, ob die Einhaltung der Schriftform nach $\S 57$ VwVfG gem. $\S 62$ S. 2 VwVfG, § 126 II 1 BGB immer Urkundeneinheit verlangt. ${ }^{128}$ Allerdings sind Formvorschriften kein Selbstzweck und deshalb unter Berücksichtigung ihres Sinngehalts auszulegen und anzuwenden. ${ }^{129}$ Daher können schriftliche Vertragserklärungen auf unterschiedlichen Dokumenten nach Schriftwechsel einen formgültigen öffentlich-rechtlichen Vertrag zustande bringen, wenn sie von einem entsprechenden Erklärungsbewusstsein getragen sind und mit Bindungswillen abgegeben wurden. ${ }^{130}$ Dieses Ergebnis gilt nach der Rechtsprechung des Bundesverwaltungsgerichts für koordinationsrechtliche ${ }^{131}$ wie für subordinationsrechtliche Verträge. ${ }^{132}$

91 Die Schriftform ist je nach Inhalt des Vertrags die Mindestform. Ordnet eine andere Norm strengere Formvorschriften an, so gelten die erhöhten Anforderungen. Hier ist insbesondere an § 311 b I BGB zu denken, der im Zusammenhang mit städtebaulichen Verträgen, die eine Eigentumsübertragung von Grundstücken enthalten, eine notarielle Beurkundung erforderlich macht. ${ }^{133}$

\section{Keine Vertragsformverbote}

92 Dass der Vertrag grundsätzlich eine zulässige Handlungsform ist, stellt §54 1 VwVfG klar, allerdings nur, soweit Rechtsvorschriften nicht entgegenstehen (§ 541

127 Maurer/Waldhoff, Allgemeines Verwaltungsrecht, 19. Aufl. 2017, § 14 Rn. 36; Peine/Siegel, Allgemeines Verwaltungsrecht, 12. Aufl. 2018, § 17 Rn. 755; Gurlit, in: Ehlers/Pünder, Allgemeines Verwaltungsrecht, 15. Aufl. 2016, §29 Rn. 14.

128 Z. B.: OVG Lüneburg, Urt. v. 13.08.1991, Az.: 9 L 362/89 = NJW 1992, 1404 (1405); Detterbeck, Allgemeines Verwaltungsrecht, 17. Aufl. 2019, Rn. 807.

129 BVerwG, Urt. v. 24.8.1994, Az.: 11 C 14/93 = BVerwGE 96, 326 [333] = NJW 1995, $1104=$ NVwZ 1995, 691.

130 Gurlit, in: Ehlers/Pünder, Allgemeines Verwaltungsrecht, 15. Aufl. 2016, § 32 Rn. 14; Peine/ Siegel, Allgemeines Verwaltungsrecht, 12. Aufl. 2018, § 17 Rn. 757.

131 BVerwG, Urt. v. 19. 5.2005, Az.: 3 A 3/04 = NVwZ 2005, 1083.

132 BVerwG, Urt. v. 24. 8.1994, Az.: 11 C 14/93 = BVerwGE 96, 326 [333] = NJW 1995, 1104 = NVwZ 1995, 691.

133 Peine/Siegel, Allgemeines Verwaltungsrecht, 12. Aufl. 2018, § 17 Rn. 758 ff; Detterbeck, Allgemeines Verwaltungsrecht, 17. Aufl. 2019, Rn. 807; Gurlit, in: Ehlers/Pünder, Allgemeines Verwaltungsrecht, 15. Aufl. 2016, § 32 Rn. 14. 
2. HS). Aufgrund dieser herausgehobenen gesetzlichen Verankerung von Vertragsformverboten, ist es sinnvoll, diese bereits an dieser Stelle zu prüfen.

Aufbauhinweis: Teilweise wird der Verstoß gegen ein Vertragsformverbot 93 auch erst als Nichtigkeitsgrund im Rahmen des § 59 I VwVfG geprüft. ${ }^{134}$ Ob die Prüfung der Rechtsfolgen des Verstoßes gegen ein Vertragsformverbot an dieser Stelle oder bei den anderen Nichtigkeitsgründen erfolgen sollte, wird diskutiert, weil $\S 5412$. HS VwVfG selbst keine Rechtsfolge regelt, sondern die Nichtigkeit sich erst aus § 59 I VwVfG i.V.m. § 541 VwVfG, § 134 BGB ergibt. ${ }^{135}$ Nichtsdestotrotz kann zwischen der inhaltlichen Unzulässigkeit nach § 541 VwVfG und Nichtigkeit nach $\S 59$ VwVfG unterschieden werden. ${ }^{136}$ Wie bei Strukturierungsfragen allgemein, ist hier eine in der Klausur nicht $\mathrm{zu}$ thematisierende, jedoch in sich schlüssige Lösung zu finden, die alle relevanten Punkte möglichst aufeinander aufbauend und mit möglichst wenigen Redundanzen aufgreift. Der hier vorgeschlagene Aufbau orientiert sich vorrangig an der gesetzlichen Regelung der $\S \S 54 \mathrm{ff}$. VwVfG. Für Studierende ist es in dem Zusammenhang mit Fragen nach einem sinnvollen Aufbau der Prüfung vor allem wichtig, nachvollziehend zu verstehen, weshalb welche Aspekte an einer bestimmten Stelle geprüft werden können und nicht als exklusiv richtig verstandene Prüfungsschemata auswendig zu lernen.

Beispiele für Vertragsformverbote sind: die Ernennung zum Beamten (hier folgt das Vertragsformverbot aus $\S 8$ II BeamtStG und für die Entlassung aus $\S 32$ BeamtStG), die höhere Beamtenbesoldung (\$ 2 II BBesG), die Festlegung von Prüfungsleistungen (\$ 2 III Nr. 2 VwVfG), die Einbürgerung (\$\$16, 35 StAG), die vertraglich begründete Verpflichtung über die Aufstellung, Aufhebung oder Änderung von Bebauungsleitplänen (\$ 1 III 2, VIII BauGB), aber auch bei justizähnlichen Kollegialorganen, wie den Entscheidungen der Beschlusskammern der Bundesnetzagentur in telekommunikationsrechtlichen Verfahren (\$132 I 2 TKG) oder Entscheidungen der Vergabekammern (\$ 114 III 1 GWB). Das Verwaltungsrecht kennt nicht nur ausdrückliche, sondern auch stillschweigende Vertragsformverbote. Die Verbote sind jedoch auf den Kernbereich der jeweiligen Rechtsgebiete, also insbesondere das Abgaben-, Beamten- und Prüfungsrecht, beschränkt. ${ }^{137}$ Im Bereich des Baurechts muss beispielsweise gewährleistet werden, dass die verwaltungsaktbezogenen Regeln, die unter bestimmten Umständen eine Aufhebbarkeit gewährleisten sollen, auch bei vertraglichem Handeln durchgesetzt werden

134 Peine/Siegel, Allgemeines Verwaltungsrecht, 12. Aufl. 2018, § 17 Rn. 750.

135 Peine/Siegel, Allgemeines Verwaltungsrecht, 12. Aufl. 2018, § 17 Rn. 750.

136 Gurlit, in: Ehlers/Pünder, Allgemeines Verwaltungsrecht, 15. Aufl. 2016, § 32 Rn. 2.

137 Peine/Siegel, Allgemeines Verwaltungsrecht, 12. Aufl. 2018, § 17 Rn. 751 ff.; Maurer/Waldhoff, Allgemeines Verwaltungsrecht, 19. Aufl. 2017, § 14 Rn. 32f.

Wolfgang Abromeit 
können. ${ }^{138}$ Nicht verboten ist dagegen beispielsweise die Begründung einer vertraglichen Rechtspflicht, einen Vertragspartner zum Beamten zu ernennen. ${ }^{139}$

\section{Wirksamkeit}

95 Anders als beim Verwaltungsakt findet der Schwerpunkt der Prüfung regelmäßig nicht unter der Überschrift Rechtmäßigkeit des Verwaltungsvertrags statt. ${ }^{140}$ Aufgrund der Konzeption der $\S \S 58,59,60$ VwVfG kommt es vielmehr darauf an, ob der Verwaltungsvertrag wirksam, also nicht nichtig oder schwebend unwirksam, ist.

96 Die Rechtsetzungsbefugnis der Verwaltung besteht aufgrund des Rechtsstaatsprinzips grundsätzlich nur im Rahmen des gesetzlich Erlaubten. Sie hat also keine allgemeine Befugnis, die eigenen Rechtsangelegenheiten nach eigenem Belieben im eigenen Interesse zu ordnen, wie es für Privatpersonen aus der Privatautonomie nach Art. 2 I GG abgeleitet wird. Dies belässt der Verwaltung allerdings die Wahl der Rechtsform, die aus der hoheitlichen Rechtssetzungsbefugnis in Kombination mit Ermessensspielräumen folgt. Sie darf jedoch nicht ihren Handlungsspielraum im Vergleich zum Verwaltungsakt erweitern, indem sie als Handlungsform den Vertrag wählt und bleibt insbesondere auch an die Vorgaben zur Ermessensausübung gebunden. ${ }^{141}$ Die konkreten Rechtssetzungsspielräume lassen sich im Einzelfall nicht ohne Rückgriff auf die Fachgesetze feststellen. ${ }^{142}$ Daraus folgt allerdings nicht, dass in der Klausurbearbeitung eine umfassende Rechtmäßigkeitsprüfung der Verträge vorzunehmen ist. ${ }^{143}$

138 Maurer/Waldhoff, Allgemeines Verwaltungsrecht, 19. Aufl. 2017, § 14 Rn. 33; Peine/Siegel, Allgemeines Verwaltungsrecht, 12. Aufl. 2018, § 17 Rn. 750.

139 Vgl. Detterbeck, Allgemeines Verwaltungsrecht, 17. Aufl. 2019, Rn. 804.

140 Alternativer Vorschlag: Peine/Siegel, Allgemeines Verwaltungsrecht, 12. Aufl. 2018, Rn. 812, 782.

141 Gurlit, in: Ehlers/Pünder, Allgemeines Verwaltungsrecht, 15. Aufl. 2016, § 32 Rn. 3; Maurer/ Waldhoff, Allgemeines Verwaltungsrecht, 19. Aufl. 2017, § 14 Rn. 38; Bauer, in: Schmidt-Aßmann/ Hoffmann-Riem, 2. Aufl. 2012, §36 Rn. 12.

142 Gurlit, in: Ehlers/Pünder, Allgemeines Verwaltungsrecht, 15. Aufl. 2016, § 32 Rn. 7.

143 Auch wenn dieses Vorgehen teilweise vorgeschlagen wird; Peine/Siegel, Allgemeines Verwaltungsrecht, 12. Aufl. 2018, Rn. 812, die allerdings im Obersatz auch herausheben, auf die Wirksamkeit abzustellen. Vgl. auch Frenz, Öffentliches Recht, 7. Aufl. 2017, § 19, Rn. 1244. 


\section{a) Nichtigkeit nach $\S 59 \mathrm{VwVfG}$}

$\S 59$ VwVfG regelt die besonderen Voraussetzungen der Nichtigkeit verwaltungs- 97 rechtlicher Verträge. §60 VwVfG regelt Kündigungsrechte und spezielle Anpassungsansprüche. Nach ganz allgemeiner Auffassung bedeutet dies im Umkehrschluss, dass nicht nichtige und dennoch rechtswidrige Verträge wirksam sind. ${ }^{144}$ Die Rechtswidrigkeit bleibt also grundsätzlich folgenlos, wenn nichts anderes geregelt ist, sind die Verträge schlicht rechtswidrig. ${ }^{145}$ Ein Ergebnis, dass bis zur Verankerung des $\S 59$ im VwVfG in der Rechtsprechung anders beurteilt wurde. Die Regelung in $\S 59$ VwVfG stellt einen abschließenden Versuch dar, einen Ausgleich zwischen dem Grundsatz der strikten Vertragsbindung (pacta sunt servanda) auf der einen Seite und dem Gesetzmäßigkeitsprinzip (Art. 20 III GG) auf der anderen Seite zu finden. Dieser wird in der momentan bestehenden Rechtslage (de lege lata) allerdings kritisiert und de lege ferenda wird eine Novellierung des Verwaltungsvertragsrechts gefordert, die gestufte Anpassungsmöglichkeiten umfasst und den aus dem Rechtsstaatsprinzip folgenden normativen Anforderungen eher entspricht. ${ }^{146}$

\section{b) Der subordinationsrechtliche Vertrag als Voraussetzung des §59 II VwVfG}

In der Systematik des $\S 59$ VwVfG ist in Absatz 1 eine Generalklausel für alle 98 verwaltungsrechtlichen Verträge zu sehen und in Absatz 2 die Verankerung spezieller Nichtigkeitsgründe für den subordinationsrechtlichen Vertrag. Als lex specialis ist diese Vorschrift daher vorrangig zu prüfen. ${ }^{147}$ Das Vorliegen eines subordinationsrechtlichen Vertrages ist aufgrund der entscheidenden Bedeutung für die weitere Prüfung an dieser Stelle gutachterlich zu thematisieren. Wie oben bereits erläutert, kommt es darauf an, ob das konkrete Rechtsverhältnis in einer verallgemeinernden Betrachtung subordinationsrechtlich geprägt ist (s. Rn. 74). Bei koordinationsrechtlichen oder Kooperationsverträgen kommt hingegen nur eine Nichtigkeit nach § 59 I VwVfG in Betracht.

144 Maurer/Waldhoff, Allgemeines Verwaltungsrecht, 19. Aufl. 2017, § 14 Rn. 44; Peine/Siegel, Allgemeines Verwaltungsrecht, 12. Aufl. 2018, §17 Rn. 782; Detterbeck, Allgemeines Verwaltungsrecht, 17. Aufl. 2019, Rn. 812.

145 Vgl. z. B. BVerwG, Urt. v. 23.8.1991, Az.: 8 C 61/90 = BVerwGE 89, 7 (10).

146 Maurer/Waldhoff, Allgemeines Verwaltungsrecht, 19. Aufl. 2017, § 14 Rn. 57 ff.; z. B. Stelkens, NWVBl 2006, $1 \mathrm{ff}$.

147 Peine/Siegel, Allgemeines Verwaltungsrecht, 12. Aufl. 2018, Rn. 785; Detterbeck, Allgemeines Verwaltungsrecht, 17. Aufl. 2019, Rn. 813; vgl. Maurer/Waldhoff, Allgemeines Verwaltungsrecht, 19. Aufl. 2017, § 14 Rn. 44.

Wolfgang Abromeit 
aa) Offenkundige schwere Inhalts- und Formfehler nach § 59 II Nr. 1 VwVfG

99 Ein Vertrag ist nichtig, wenn ein entsprechender Verwaltungsakt nach § $44 \mathrm{VwVfG}$ nichtig wäre. ${ }^{148}$ Hier kann im Allgemeinen auf die Ausführungen zu § 44 VwVfG verwiesen werden (s. § 6 Rn. $144 \mathrm{ff}$.).

\section{bb) Keine Kollusion gem. § 59 II Nr. 2 VwVfG}

100 Ein öffentlich-rechtlicher Verwaltungsvertrag ist nach $\S 59$ II Nr. 2 VwVfG auch dann nichtig, wenn den Parteien trotz Kenntnis der Rechtswidrigkeit einen rechtswidrigen Erfolg herbeiführen wollen („Kollusion“). Der ausschlaggebende Zeitpunkt für die Kenntnis ist der Vertragsschluss. Der Maßstab, der an den Zeitpunkt der Kenntnisnahme anzulegen ist, unterscheidet sich je nach Vertragspartner. Während bei dem privaten Partner im Regelfall eine Parallelwertung in der Laiensphäre vorzunehmen ist, muss bei der Behörde eine evidente Ignoranz der Rechtslage vorliegen. ${ }^{149}$

\section{cc) Fehlende Voraussetzungen beim Vergleichsvertrag nach § 59 II Nr. 3 VwVfG}

101 Die Nichtigkeitsgründe des Vergleichsvertrages sind relativ weit gefasst. Ein subordinationsrechtlicher Vergleichsvertrag ist nach $\S 59$ II Nr. 3 VwVfG i.V.m. $\S 55$ VwVfG bereits nichtig, wenn die Überprüfung ergibt, dass der Vergleichsabschluss durch die Behörde nach pflichtgemäßem Ermessen nicht mehr als zweckmäßig erachtet werden kann und ein Verwaltungsakt entsprechenden Inhaltes rechtswidrig wäre. ${ }^{150}$

\section{dd) Insbesondere unzulässige Gegenleistung beim Austauschvertrag nach § 59 II Nr. 4 VwVfG}

102 Besonders klausurrelevant ist die Regelung des $\S 59$ II Nr. 3 VwVfG, eine Schutzvorschrift zugunsten des Bürgers, nach der der Vertrag nichtig ist, sofern es sich um einen Austauschvertrag nach $\S 56$ VwVfG handelt (1) und sich der Staat eine unzulässige Gegenleistung versprechen lässt. ${ }^{151}$ Steht die von der Behörde versprochene Leistung in ihrem Ermessen (§ 56 I VwVfG) darf sie nur von einer Ge-

148 Peine/Siegel, Allgemeines Verwaltungsrecht, 12. Aufl. 2018, Rn. 787; Detterbeck, Allgemeines Verwaltungsrecht, 17. Aufl. 2019, Rn. 812.

149 Peine/Siegel, Allgemeines Verwaltungsrecht, 12. Aufl. 2018, Rn. 787.

150 Peine/Siegel, Allgemeines Verwaltungsrecht, 12. Aufl. 2018, Rn. 790.

151 Peine/Siegel, Allgemeines Verwaltungsrecht, 12. Aufl. 2018, Rn. 791.

Wolfgang Abromeit 
genleistung abhängig gemacht werden, die vier Voraussetzungen erfüllen muss: Sie muss in einem sachlichen Zusammenhang zur Leistung stehen (2) für einem bestimmten Zweck vereinbart worden sein (3), der Erfüllung öffentlicher Aufgaben dienen (4) sowie insgesamt angemessen sein (5). ${ }^{152}$

\section{(1) Vorliegen eines Austauschvertrags nach § 56 VwVfG}

$\S 56$ VwVfG verfolgt nach der Gesetzesbegründung zwei Schutzzwecke: Einer- 103 seits soll der Ausverkauf von Hoheitsrechten verhindert werden, andererseits der Bürger vor überhöhten Forderungen der Behörde geschützt werden. ${ }^{153}$ Damit der Anwendungsbereich eröffnet ist, müsste ein subordinationsrechtlicher Austauschvertrag vorliegen. ${ }^{154}$ Austauchverträge in diesem Sinne sind nicht nur Verträge mit streng synallagmatischen Austauschverhältnis, bei denen die eine Leistung als konkrete Gegenleistung die andere bedingt, sondern auch als „hinkenden Austauschverträge“ bezeichnete Verträge, bei denen die Leistung der Behörde gewissermaßen Bedingung oder Zweck für die Leistung des Bürgers darstellt und in engem, untrennbarem Zusammenhang mit ihr steht. ${ }^{155} \mathrm{Nicht}$ ausreichend ist allerdings, dass die behördliche Leistung bloß die Geschäftsgrundlage für den Vertrag darstellt. Paradebeispiel eines hinkenden Austauschvertrages ist es, eine Zahlungspflicht des Bürgers an das Einleiten von Bauplanungen unabhängig von deren Ergebnis zu koppeln. Mit dieser, nach der Rechtsprechung zulässigen ${ }^{156}$ Konstruktion, wird verhindert, dass der Vertrag gegen $\S 1$ III Nr. 6 BauGB verstößt. Die Vertragspflichten stehen dennoch in einem gewissen Gegenseitigkeitsverhältnis.

\section{(2) Sachlicher Zusammenhang zur Leistung}

Der sachliche Zusammenhang zwischen den Leistungen ist nicht bereits dann 104 gewahrt, wenn die Gegenleistung der behördlichen Aufgabenerfüllung insgesamt

152 Peine/Siegel, Allgemeines Verwaltungsrecht, 12. Aufl. 2018, Rn. 778f.

153 Peine/Siegel, Allgemeines Verwaltungsrecht, 12. Aufl. 2018, Rn. 774; Maurer/Waldhoff, Allgemeines Verwaltungsrecht, 19. Aufl. 2017, § 14 Rn. 22.

154 Peine/Siegel, Allgemeines Verwaltungsrecht, 12. Aufl. 2018, Rn. 776.

155 Peine/Siegel, Allgemeines Verwaltungsrecht, 12. Aufl. 2018, Rn. 777; Gurlit, in: Ehlers/Pünder, Allgemeines Verwaltungsrecht, 15. Aufl. 2016, § 30 Rn. 4; Höfling/Krings, JuS 2001, 625 (627); Detterbeck, Allgemeines Verwaltungsrecht, 17. Aufl. 2019, Rn. 799; Stelkens, DÖV 2009, S. 850 ff. 156 BVerwG, Urt. v. 16.5.2000, Az.: 4 C 4/99 = BVerwGE 111, 162 (167f.)= NVwZ 2000, 1285; BVerwG, Urt. v. 24.8.1994, Az.: 11 C 14/93 = BVerwGE 96, 326 (330); näher Stelkens, DÖV 2009, 850 ff.; BVerwGE 42, $331 \mathrm{ff}$. 
dient. Vielmehr muss sie demselben Interesse der Norm dienen, die die behördliche Leistung gestattet. Entscheidend sind dabei sowohl Inhalt als auch Begleitumstände des Vertrags. ${ }^{157}$ Diese Anforderung ist eine Ausprägung des Koppelungsverbots, das nicht nur für verwaltungsrechtliche Verträge gilt, sondern einen allgemeingültigen Ausfluss des Rechtsstaatsprinzips aus Art. 20 III GG und des Gleichheitssatzes aus Art. 3 GG darstellt. ${ }^{158}$ Ausgeschlossen sind folglich Gegenleistungen, die kein zulässiges Ermessenskriterium nach § 40 VwVfG darstellen können. Positiv formuliert, ist ein Sachzusammenhang zwischen Leistung und Gegenleistung erforderlich. ${ }^{159}$

Beispiele der Rechtsprechung für nichtige Verträge, welche die Anforderungen an diesen $\mathrm{Zu}$ sammenhang nicht aufweisen, ${ }^{160}$ sind:

- Verträge, die einen Baudispens mit einer Verpflichtung zur Entrichtung der Einkommensteuer ${ }^{161}$ oder einer sonstigen gegenstandsfremden Geld- oder Sachleistung verknüpfen, ${ }^{162}$

- Verträge, die das für die Baugenehmigung erforderliche gemeindliche Einvernehmen (nach $\S 36$ BauGB) vertraglich mit der Gegenleistung einer zusätzlichen „Kaufpreiszahlung“ durch den Rechtsnachfolger des Käufers verknüpfen, ${ }^{163}$

- Verträge, die die Ausnahme von der Stellplatzverpflichtung mit einer Verpflichtung des Eigentümers zur Vermietung einer neu entstehenden Wohnung nach den Grundsätzen des sozialen Wohnungsbaus koppeln, ${ }^{164}$

- ein städtebaulicher Vertrag, der eine Baugebietsausweisung mit einer planerisch damit nicht zusammenhängenden Leistung, wie der Sanierung und der Teilübereignung eines Schlosses, an die Gemeinde verknüpft, ${ }^{165}$

- Verträge, die eine Änderung eines Bebauungsplans (z.B. die Ausweisung eines Außenbereichsgrundstücks als Wohngebiet) in einem öffentlich-rechtlichen Vertrag davon abhängig macht, dass der bauwillige Eigentümer anstelle eines nicht mehr festsetzbaren Erschließungsbeitrags einen Geldbetrag an die Gemeinde für einen anderweitigen Zweck (z.B. für die Unterhaltung gemeindlicher Kinderspielplätze) leistet (s.u.). ${ }^{166}$

157 Detterbeck, Allgemeines Verwaltungsrecht, 17. Aufl. 2019, Rn. 801.

158 BVerwG, Urt. v. 16.5.2000, Az.: 4 C 4/99 = BVerwGE 111, 162 (167f.)= NVwZ 2000, 1285; BVerwG, Urt. v. 24. 8.1994, Az.: 11 C 14/93 = BVerwGE 326 (330).

159 Peine/Siegel, Allgemeines Verwaltungsrecht, 12. Aufl. 2018, Rn. 779.

160 Breuer, NVwZ 2017, 112ff. (115), dem Aufsatz sind auch diese Beispiele entnommen; vgl. Stelkens, DÖV 2009, 850 ff.; Drechsler, Jura 2017, S.413ff.; Decker, JA 2012, S. 286 ff.

161 BGH, Urt. v. 14.4.1976, Az.: VIII ZR 253/74 = NJW 1976, 1500.

162 Tegethoff, in: Kopp/Ramsauer, VwVfG, 19. Aufl. 2018, § 56 Rn. 19a.

163 VG München, Urt.v. 18.1.1997, Az.: M 1 K 96.5697 = NJW 1998, 2070; VG Darmstadt, Urt. v. 3.1. 1997, Az.: 5 E 2118-94 = NJW 1998, $2073 \mathrm{f}$.

164 OVG Schleswig, Urt. v. 15.9.1992, Az.: 1 L 303/91.

165 VGH München, Urt. v. 12.5.2004, Az.: 20 N 04.329 und 20 NE 04.336 = NVwZ-RR 2005, 781. 166 BVerwG, Urt. v. 16.5.2000, Az.: 4 C 4/99 = BVerwGE 111, 162. 
Der Sachzusammenhang besteht hingegen beispielsweise bei einer Koppelung 106 einer zustimmenden Stellungnahme zu einem Baugesuch mit Abtretung von Straßenflächen, die für die Erschließung des betroffenen Grundstücks benötigt werden und bei Stellplatzablösungsverträgen, die mit der Zahlung eines Ablösungsbetrags für Parkraumbeschaffung verknüpft werden, selbst wenn der neugeschaffene Parkraum nicht in direkter Umgebung des Baugrundstücks entsteht. $^{167}$

\section{(3) Bestimmung eines konkreten Zwecks}

Im Vertrag muss die Gegenleistung des Bürgers ausdrücklich für einen konkret 107 bestimmten Zweck vereinbart worden sein. Diese Regelung hat den Zweck, die oben dargestellten Anforderungen gerichtlich überprüfbar und die entsprechende Verwendung der erworbenen Leistung nachvollziehbar zu machen. ${ }^{168}$

\section{(4) Zur Erfüllung öffentlicher Aufgaben}

Die Gegenleistung muss außerdem der Behörde zur Erfüllung ihrer öffentlichen 108 Aufgaben dienen. D.h., dass es sich nicht nur um ein legitimes Ermessenskriterium der ermächtigenden Norm handeln muss, die kontrahierende Behörde muss außerdem sachlich und örtlich zuständig sein. ${ }^{169}$

\section{(5) Angemessenheit}

Das Verhältnis zwischen Leistung und Gegenleistung muss ausgewogen sein. Die 109 gesetzlich verankerte Ausprägung des Verhältnismäßigkeitsprinzips, die auch dem allgemeinen Gleichheitssatz Rechnung trägt, umfasst nicht nur ein Übersondern auch ein Untermaßverbot. ${ }^{170}$ Weder darf die Behörde ihre Machtposition ausnutzen, noch darf sie öffentliche Güter verschenken. Die Leistungen sollen, wenn dieser maßgeblich ist, einen vergleichbaren wirtschaftlichen Wert aufweisen und somit keine unzumutbare Belastung für den Vertragspartner darstellen. Der Behörde verbleibt hier ein Einschätzungsspielraum. Nähere Vorgaben für die

167 Bonk/Neumann/Siegel, in: Stelkens/Bonk/Sachs, VwVfG 9. Aufl. 2018, § 56 Rn. 34.

168 Peine/Siegel, Allgemeines Verwaltungsrecht, 12. Aufl. 2018, Rn. 778; Detterbeck, Allgemeines Verwaltungsrecht, 17. Aufl. 2019, Rn. 801.

169 Peine/Siegel, Allgemeines Verwaltungsrecht, 12. Aufl. 2018, Rn. 778.

170 Peine/Siegel, Allgemeines Verwaltungsrecht, 12. Aufl. 2018, Rn. 779.

Wolfgang Abromeit 
Berechnung der angemessenen Gegenleistung sind teilweise dem Fachrecht zu entnehmen, wie beispielsweise bei städtebaulichen Verträgen $§ 11$ II BauGB. ${ }^{171}$

(6) Anspruch des Bürgers auf die Leistung der Behörde gem. §56 S. 2 VwVfG

$110 \S 56$ S. 2 VwVfG stellt an die Gegenleistung des Bürgers noch höhere Anforderungen, wenn er einen Anspruch auf die Leistung der Behörde hat. Dann müsste eine entsprechende Nebenbestimmung durch Rechtsvorschrift zugelassen sein oder sicherstellen, dass die gesetzlichen Voraussetzungen des hypothetischen Verwaltungsakts erfüllt werden. ${ }^{172}$

\section{c) Allgemeine Nichtigkeitsgründe nach § 59 I VwVfG}

111 Nach $\S 59$ I VwVfG ist ein verwaltungsrechtlicher Vertrag auch dann nichtig, wenn sich die Nichtigkeit aus der entsprechenden Anwendung der Vorschriften des Bürgerlichen Gesetzbuchs ergibt. Die Regelung des Absatz 1 gelten für alle verwaltungsrechtlichen Verträge, also auch für koordinationsrechtliche und Kooperationsverträge. Für subordinationsrechtliche Verträge hat sie einen Auffangcharakter.

\section{aa) In Verbindung mit §59 I VwVfG anwendbare Regelungen des BGB}

112 Hier ist an eine Vielzahl bürgerlich rechtlicher Vorschriften zu denken, die die Nichtigkeit zur Folge haben: §§ 105, 116 S. 2, 117, 138, 125 BGB i.V.m. § 57 VwVfG (s. Rn. 92ff.) sowie $§ 779$ BGB für Vergleichsverträge. ${ }^{173}$ Zwar sind beispielsweise sittenwidrige, verwaltungsrechtliche Verträge praktisch nicht besonders häufig, allerdings sind Konstellationen, in denen eine Partei die andere unter Missbrauch einer Machtposition, bzw. einer Notsituation ausnutzt, nach § 59 I VwVfG i.V.m. $\S 138$ BGB nichtig. ${ }^{174}$

171 Drechsler, Jura 2017, S. 413ff.; Decker, JA 2012, S. $286 \mathrm{ff}$.

172 Peine/Siegel, Allgemeines Verwaltungsrecht, 12. Aufl. 2018, Rn. 780 f.; Detterbeck, Allgemeines Verwaltungsrecht, 17. Aufl. 2019, Rn. 802.

173 Maurer/Waldhoff, Allgemeines Verwaltungsrecht, 19. Aufl. 2017, § 14 Rn. 46; Peine/Siegel, Allgemeines Verwaltungsrecht, 12. Aufl. 2018, Rn. 792ff.; Detterbeck, Allgemeines Verwaltungsrecht, 17. Aufl. 2019, Rn. $815 \mathrm{ff}$.

174 Maurer/Waldhoff, Allgemeines Verwaltungsrecht, 19. Aufl. 2017, § 14 Rn. 46; Peine/Siegel, Allgemeines Verwaltungsrecht, 12. Aufl. 2018, Rn. 796.

Wolfgang Abromeit 


\section{bb) Die Anwendbarkeit von § 134 BGB i.V.m. 59 VwVfG}

Besondere Bedeutung hat $\S 134$ BGB, der allgemein festlegt, dass Rechtsge- 113 schäfte, die gegen ein gesetzliches Verbot verstoßen, nichtig sind, soweit sich aus dem Gesetz nichts anderes ergibt. Die Anwendung von § 134 BGB i.V.m. § 59 I VwVfG war lange umstritten, weil sich aus den Gesetzgebungsmaterialen ergibt, dass der historische Gesetzgeber die Verweisung des §59 I VwVfG jedenfalls für subordinationsrechtliche Verträge ursprünglich nicht auf §134 BGB erstrecken wollte. Der Grund dafür war die Befürchtung, die in $\S 59$ II VwVfG getroffenen Wertungen könnten ausgehebelt werden. Allerdings haben die in der Gesetzesbegründung getroffenen Erwägungen des historischen Gesetzgebers keinen Eingang in den Gesetzestext gefunden und sind dementsprechend nur eines unter mehreren Auslegungskriterien. Die lückenhafte Regelung des § 59 II VwVfG führte bei einem Ausschluss der Anwendung von § 134 BGB i.V.m. $§ 59$ I VwVfG bei vielen Konstellationen, in denen gesetzlich klar eine Nichtigkeit durch gesetzliche Wertungen intendiert ist, zur Handlungsunfähigkeit gegenüber bestandskräftigen Verträgen. Dieses, aus rechtsstaatlicher Sicht nur schwer tragbare, Ergebnis kann allerdings unter Heranziehung systematischer Auslegungsmethoden der Norm und durch eine Anwendung von §134 BGB verhindert werden, die diese Befürchtung berücksichtigt. Dementsprechend ist die grundsätzliche Einbeziehung des § 134 BGB in den Anwendungsbereich von § 59 I VwVfG mittlerweile in der Literatur auch ganz überwiegende Ansicht. ${ }^{175}$ Der Aspekt der angemessenen Anwendung des $\S 134$ BGB verlagert die Problematik allerdings in die Auslegung der Gesetze, die als „gesetzliches Verbot“ in Frage kommen. Vor dem Hintergrund von $\S 59$ II VwVfG ist es jedenfalls klar, dass nicht jede Form der Rechtswidrigkeit zur Nichtigkeit führen soll. Als Verbotsgesetze kommen Normen des Unionsrechts, des Verfassungsrechts, der Parlamentsgesetze, der Rechtsverordnungen sowie Satzungen in Frage, nicht jedoch innerbehördlich geltende, untergesetzliche Rechtsnormen wie Verwaltungsvorschriften.

\section{(1) Anknüpfung an zivilrechtliche Dogmatik}

Allerdings muss sich das gesetzliche Verbot dann gerade gegen den Inhalt des Vertrages richten, was beispielsweise bei bloßen Ordnungsvorschriften nicht der Fall ist. Einen ersten Zugriff sollte - auch in der Fallbearbeitung - parallel zur zivilrechtlichen Auslegung von $§ 134$ BGB die Beantwortung der Frage liefern,

175 Maurer/Waldhoff, Allgemeines Verwaltungsrecht, 19. Aufl. 2017, § 14 Rn. 48; Peine/Siegel, Allgemeines Verwaltungsrecht, 12. Aufl. 2018, Rn. 794; Gurlit, in: Ehlers/Pünder, Allgemeines Verwaltungsrecht, 15. Aufl. 2016, § 32 Rn. 22; Detterbeck, Allgemeines Verwaltungsrecht, 17. Aufl. 2019, Rn. 816. 
inwieweit das Verbotsgesetz an beide Parteien gerichtet ist. Außerdem sollte die Norm in ihrer Zielrichtung erkennbar den Erfolg des Vertrages unterbinden.

\section{(2) Einzelfallanalyse zur qualifizierten Rechtswidrigkeit}

115 Die Auslegung von $§ 134$ BGB i.V.m. § 59 I VwVfG erschöpft sich allerdings nicht in der Rezeption der zivilrechtlichen Dogmatik. Die erforderliche verwaltungsrechtliche „qualifizierte Rechtswidrigkeit“"176 nimmt auch öffentlich-rechtliche Wertungen auf. Ansätze, handhabbare Kriterien für diese Qualifikation zu finden, haben jedoch noch keine allgemein anerkannten, klar und einfach zu praktizierenden Ergebnisse nach sich gezogen. Einerseits ist auf die klassischen Auslegungsmethoden, wie Wortlaut und Sinn und Zweck der Norm, gegen die verstoßen wird, zurückzugreifen, andererseits aber auch auf eine Einzelfallanalyse der Erheblichkeit des Rechtsverstoßes abzustellen und eine Abwägung des öffentlichen und privaten Interesses an einer Beseitigung der Rechtswidrigkeit mit dem Interesse an dem Bestand des Vertrags durchzuführen. ${ }^{177}$ Klar ist jedenfalls, dass Vertragsformverbote i.V.m. § 134 BGB die Nichtigkeit herbeiführen (s.o.). ${ }^{178}$ Problematisch sind jedoch Verstöße gegen Verbote, die sich auf den Inhalt beziehen und auch Verstöße gegen Verfahrensrecht.

\section{(3) Die Wirkung von § 59 I VwVfG i. V.m. § 134 BGB i.V.m. EU-Recht}

116 Als Verbotsgesetz i.S.d. § 134 BGB i.V.m. § 59 I VwVfG kommen Normen des EURechts, insbesondere des Beihilfenrechts und des Vergaberechts in Frage. ${ }^{179}$

117 Examenswissen: Im Beihilfenrecht sind beispielsweise Verfahrensverstöße zu thematisieren, wenn Subventionen, die als Beihilfe zu klassifizieren sind, nicht gem. der Art. 107, 108 AEUV der Kommission angezeigt und genehmigt werden. Aus europarechtlicher Perspektive handelt es sich bei einer nicht notifizierten Beihilfe um eine „rechtswidrige Maßnahme“, der EuGH überlässt es aber den nationalen Gerichten, ,entsprechend ihrem nationalen Recht“ sämtliche Konsequenzen aus der Rechtswidrigkeit zu ziehen. ${ }^{180}$ Der BGH hat in diesem Kontext entschieden, dass ein der Beihilfe zugrunde liegender Vertrag nach Art. 108 III AEUV i.V.m. § 134 BGB jedenfalls nichtig ist, wenn die Kommission die Genehmigung verweigert. ${ }^{181}$ Im Ergebnis ist dem Gericht zuzustimmen,

176 BVerwG, Urt. v. 3.03.1995, Az.: 8 C 32/93 = BVerwGE 98, 58 = NJW 1996, 608.

177 Maurer/Waldhoff, Allgemeines Verwaltungsrecht, 19. Aufl. 2017, § 14 Rn. 49.

178 Maurer/Waldhoff, Allgemeines Verwaltungsrecht, 19. Aufl. 2017, § 14 Rn. 51.

179 Detterbeck, Allgemeines Verwaltungsrecht, 17. Aufl. 2019, Rn. 818.

180 Gellermann, DVBl. 2003, 481, $484 \mathrm{f}$.

181 BGH, Urt. v. 4.4.2003, Az.: V ZR 314/02 = EuZW 2003, 444; BGH, Urt. v. 20.1.2004, Az.: XI ZR 53/03 = EuZW 2004, 252; BGH, Urt. v. 5.12.2012, Az.: I ZR 92/11 = BGHZ 196, 254 = EuZW 2013, 753 (m. Anm. Bartosch). 
dass nach dem Grundsatz des effet utile dem europäischen Recht die Trennung zwischen öffentlichem und privatem Recht fremd ist; dann kann für verwaltungsrechtliche Verträge aufgrund des Grundsatzes der effektiven Rechtsdurchsetzung insoweit nichts anderes gelten. Diese Wertung muss sich also auch auf verwaltungsrechtliche Verträge auswirken. ${ }^{182}$ Es stellt sich jedoch die Frage, ob die generelle Nichtigkeit nach § 59 I i.V.m. § 134 BGB i.V.m. Art. 108 III AEUV bei fehlender Notifizierung generell das methodisch richtige Vorgehen darstellt. ${ }^{183}$ Nach überwiegender Ansicht in der Literatur ist ein solcher Fall jedoch nach § 58 II VwVfG analog wie eine fehlende Genehmigung einer anderen Behörde zu behandeln (s. Rn. 122). Diese Lösung ist vorzugswürdig, weil im Falle einer Genehmigung durch die Kommission, der Beihilfe gewährende Vertrag ex nunc wirksam wird. Nur wenn die Genehmigung durch die Kommission verweigert wird, wird der Vertrag endgültig unwirksam. ${ }^{184}$ Insofern ist eine Auslegung des Art. 108 III AEUV als Verbotsgesetz i.S.d. §134 BGB nicht überzeugend, weil die Nichtigkeit des Vertrages nicht zwingende Folge der Norm ist. ${ }^{185}$

Auch im Zusammenhang mit dem durch das Vergaberecht geregelten Aus- 118 schreibungsverfahren kommen mehrere Nichtigkeitstatbestände als Verbotsgesetze i.S.d. §134 BGB und dementsprechend auch als Nichtigkeitsgrund i.V.m. $\S 59$ I VwVfG in Frage. Grundsätzlich ist das Vergaberecht schon aufgrund seiner europarechtlichen Prägung vollumfänglich auf öffentlich-rechtliche Verwaltungsverträge anwendbar. Das Verhältnis der im Vergaberecht verankerten Unwirksamkeits- und Nichtigkeitsregelungen zu den $\S \S 58,59$ VwVfG ist jedoch noch nicht abschließend geklärt. ${ }^{186}$ Jedenfalls bei einem kollusiven Zusammenwirken von Auftragnehmer und Auftraggeber und einer darauf folgenden bewussten Missachtung des Vergaberechts, ist der Vertrag nach $\S 138$ BGB sittenwidrig. ${ }^{187}$ Außerdem führt auch der Verstoß gegen ein Zuschlagsverbot nach § 169 I 1 GWB i.V.m. § 134 BGB i.V.m. § 59 I VwVfG zur Nichtigkeit. ${ }^{188}$ Wenn ein öffentlicher Auftrag hingegen wegen inhaltlich unzulässiger Klauseln angegriffen wird, ist $\S 59$ II VwVfG vorrangig zu prüfen. ${ }^{189}$

182 Finck/Gurlit, Jura 2011, 87 (93); Gellermann, DVBl. 2003, 481, 485f.; Koenig, EuZW 2003, 417; Remmert, EuR 2000, 469, 477 f.; Pechstein, EuZW 2003, 447.

183 So z. B. Maurer/Waldhoff, Allgemeines Verwaltungsrecht, 19. Aufl. 2017, § 14 Rn. 53.

184 Gurlit, in: Ehlers/Pünder, Allgemeines Verwaltungsrecht, 15. Aufl. 2016, § 32 Rn. 27; Finck/ Gurlit, Jura 2011, 87; Detterbeck, Allgemeines Verwaltungsrecht, 17. Aufl. 2019, Rn. 818.

185 Gurlit, in: Ehlers/Pünder, Allgemeines Verwaltungsrecht, 15. Aufl. 2016, § 32 Rn. 26; Detterbeck, Allgemeines Verwaltungsrecht, 17. Aufl. 2019, Rn. 818.

186 Gurlit, in: Ehlers/Pünder, Allgemeines Verwaltungsrecht, 15. Aufl. 2016, § 32 Rn. 29.

187 Gurlit, in: Ehlers/Pünder, Allgemeines Verwaltungsrecht, 15. Aufl. 2016, § 32 Rn. 28.

188 Gurlit, in: Ehlers/Pünder, Allgemeines Verwaltungsrecht, 15. Aufl. 2016, § 32 Rn. 29.

189 Gurlit, in: Ehlers/Pünder, Allgemeines Verwaltungsrecht, 15. Aufl. 2016, § 32 Rn. 29. 


\section{d) Folgen der Nichtigkeit}

119 Ist der gesamte Vertrag nichtig, müssen gegebenenfalls darauf beruhende und bereits ausgetauschte Leistungen rückabgewickelt werden (s. Rn. $130 \mathrm{ff}$.). Sind Teile des Vertrags nichtig, stellt sich die Frage nach den Auswirkungen auf den gesamten Vertrag (aa)). Davon ist Frage nach einem aufgrund eines nichtigen Verwaltungsvertrags erlassenen Verwaltungsakt zu unterscheiden (bb)).

\section{aa) Teilnichtigkeit nach $§ 59$ III VwVfG}

$120 § 59$ III VwVfG enthält eine Auslegungsregel, die entsprechend §139 BGB festlegt, dass aus der Nichtigkeit eines Teils des Vertrags, im Zweifel die Gesamtnichtigkeit folgt. Diese gesetzliche Vermutung kann natürlich vertraglich widerlegt werden. Typischer Fall einer vertraglichen Regelung, die eine Gesamtnichtigkeit verhindern würde, ist die so genannte „salvatorische Klausel“ (lat. salvatorius „,bewahrend“, „erhaltend“). Unter dieser Überschrift wird beispielsweise im Vertrag verankert: „Sollten einzelne Bestimmungen dieses Vertrages unwirksam oder undurchführbar sein oder nach Vertragsschluss unwirksam oder undurchführbar werden, bleibt davon die Wirksamkeit des Vertrages im Übrigen unberührt." ${ }^{190}$

\section{bb) Unterscheidung zwischen nichtigem Verpflichtungs- und Verfügungsvertrag}

121 Ein nichtiger Verwaltungsvertrag entfaltet keine rechtliche Wirkung. Sollte mit dem Vertrag also ein Verwaltungsakt ersetzt werden, so entfällt diese Wirkung. Die Nichtigkeit kann dann mit einer Feststellungsklage gerichtlich festgestellt werden. Hatte sich die Behörde in dem nichtigen Vertrag zum Erlass eines Verwaltungsakts verpflichtet und hat sie diesen in der Annahme seiner Wirkung erlassen, so ist der Verwaltungsakt nach \$§ 48, 49 VwVfG zurückzunehmen. ${ }^{191}$ Im Gegenzug ist das Rücknahmeermessen der Behörde bei einem „schlicht rechtswidrigen Vertrag“ wegen dessen fortwährender Wirkung als Rechtsgrund auf Null reduziert, sodass sie den Verwaltungsakt dementsprechend nicht zurücknehmen darf. ${ }^{192}$

190 Peine/Siegel, Allgemeines Verwaltungsrecht, 12. Aufl. 2018, Rn. 798.

191 Korte, in: Wolf/Bachof/Stober/Kluth, Allgemeines Verwaltungsrecht, 13. Aufl. 2017, §54 Rn. 101; Bonk/Neumann/Siegel, in: Stelkens/Bonk/Sachs, VWVfG § 59 Rn. 49; Ziekow/Siegel, VerwArch 2004, 281 (297).

192 Bonk/Neumann/Siegel, in Stelkens/Bonk/Sachs, VWVfG § 59 Rn. 3; Ziekow/Siegel, VerwArch 2004, 281 (297). 


\section{e) Fehlende Zustimmung nach § $\mathbf{5 8}$ VwVfG}

Ein öffentlich-rechtlicher Verwaltungsvertrag, der in Rechte Dritter eingreift, ist 122 nach $\S 58$ I VwVfG erst mit schriftlicher Zustimmung des Dritten wirksam. Ein Anwendungsfall dieser Vorschrift ist die vertraglich erteilte Baugenehmigung, durch die in Rechte eines Nachbarn eingegriffen wird. ${ }^{193}$ Bis die Zustimmung vorliegt, ist der Vertrag also schwebend unwirksam. ${ }^{194}$ Nach überwiegender Ansicht gilt die Vorschrift über den direkten Wortlaut hinaus auch für Verpflichtungsverträge. Dies wird damit gerechtfertigt, dass auch diese zu Lasten eines Dritten gehen würden, weil eine Verpflichtungsklage auf den Erlass eines solchen Verwaltungsakt aufgrund eines wirksamen Vertrags wohl begründet wäre und den Dritten so zumindest einem erheblichen Risiko aussetzen würde. ${ }^{195}$

Ein ähnliches Zustimmungserfordernis statuiert §59 II VwVfG auch gegenüber den Mitwirkungsrechten anderer Behörden. Wenn für eine Regelung des Vertrags, wäre sie in Form eines Verwaltungsakts ergangen, die Genehmigung, die Zustimmung oder das Einvernehmen einer anderen Behörde erforderlich ist, so wird auch dieser nach $\S 58$ II VwVfG erst wirksam, nachdem die andere Behörde in der vorgeschriebenen Form mitgewirkt hat.

Umstritten ist (wie bereits erwähnt s. Rn. 117) die analoge Anwendung dieser 124 Vorschrift auf die Notifizierung von Beihilfen bei der Kommission nach Art. 108 AEUV. Wegen § 1 I, II VwVfG ist die Kommission zwar keine Behörde i.S.d.VwVfG, die Interessenlage ist allerdings vergleichbar. Die Kommission ist mit Aufgaben der öffentlichen Verwaltung beauftragt und hat ein Mitentscheidungsrecht. ${ }^{196}$ Gerade wegen der in Art. 108 II, III AEUV vorgesehenen Möglichkeit einer nachträglichen Genehmigung durch die Kommission und einer damit eintretenden Wirksamkeit ex nunc, kommt die analoge Anwendung von § 58 II VwVfG zu den sachgemäßeren Ergebnissen, wird auch der vom EuGH geforderten Durchsetzung des EU-Rechts gerecht und ist somit einer Anwendung von Art. 107, 108 AEUV i.V.m. § 134 BGB i.V.m. § 59 I VwVfG vorzuziehen. ${ }^{197}$

193 Peine/Siegel, Allgemeines Verwaltungsrecht, 12. Aufl. 2018, Rn. 762; Detterbeck, Allgemeines Verwaltungsrecht, 17. Aufl. 2019, Rn. 809.

194 Peine/Siegel, Allgemeines Verwaltungsrecht, 12. Aufl. 2018, Rn. 762.

195 Detterbeck, Allgemeines Verwaltungsrecht, 17. Aufl. 2019, Rn. 809; a. A. Peine/Siegel, Allgemeines Verwaltungsrecht, 12. Aufl. 2018, Rn. 762.

196 Gurlit, in: Ehlers/Pünder, Allgemeines Verwaltungsrecht, 15. Aufl. 2016, § 32 Rn. 2.

197 Gurlit, in: Ehlers/Pünder, Allgemeines Verwaltungsrecht, 15. Aufl. 2016, §32 Rn. 2; Detterbeck, Allgemeines Verwaltungsrecht, 17. Aufl. 2019, Rn. 818; a. A. Maurer/Waldhoff, Allgemeines Verwaltungsrecht, 19. Aufl. 2017, § 14 Rn. 53; BGH, Urt. v. 4.4. 2003, Az.: V ZR 314/02 = EuZW 2003, 444; BGH, Urt.v. 20.1.2004, Az.: XI ZR 53/03 = EuZW 2004, 252; BGH, Urt.v. 5.12.2012, Az.: I ZR 92/ 11 = BGHZ 196, 254 = EuZW 2013, 753 (m. Anm. Bartosch). 


\section{f) Das Rechtsregime des wirksamen öffentlich-rechtlichen Verwaltungsvertrags}

125 Ist der Vertrag rechtmäßig oder „schlicht rechtswidrig“, also wirksam, gelten die vertraglich vereinbarten Leistungsansprüche. ${ }^{198}$ Allerdings kann sich bei entsprechenden Anhaltspunkten die Frage stellen, wie die darauf folgenden Entwicklungen, seien es tatsächliche Ereignisse oder Erklärungen wie Vertragsänderungen oder eine Kündigung, zu behandeln sind. Die über die grundsätzliche Wirksamkeit des Vertrags hinausgehenden Fragen sind - mit Ausnahme von $\S 61$ VwVfG - kaum im VwVfG geregelt. So stellen sich beispielsweise bei Leistungsstörungen Fragen nach der ordnungsgemäßen Erfüllung, nach Schadensersatzansprüchen, bei Anfechtungen oder Rücktritten Fragen nach Rückabwicklungsverhältnissen oder auch Verjährungsfragen. Hier führt der Weg über $\S 62 \mathrm{~S} .2 \mathrm{VwVfG}$ in eine entsprechende Anwendung des Bürgerlichen Gesetzbuchs und somit in das Verwaltungsvertragsschuldrecht.

Durch § 62 VwVfG werden die Regelungen zum verwaltungsrechtlichen Vertrag im VwVfG abgeschlossen. Allerdings öffnet dieser "Schlussstein in der Architektur des Verwaltungsvertragsrechts (...) es zugleich für die Aufnahme von allgemeinem Verwaltungsverfahrensrecht, vor allem aber in großem Umfang für die Rezeption von bürgerlichem Recht, ohne das bei isolierter Betrachtung das in $\S \S 54$ bis 61 [VwVfG] geregelte Verwaltungsvertragsrecht nicht wirklich handhabbar und tragfähig wäre.“199 Der Aufbau der Regelung folgt einem dreistufigen Anwendungs- und Verweisungsmodell, das auf der ersten Stufe die Regelungen der §§54-61 VwVfG vorsieht, auf der zweiten Stufe die übrigen Vorschriften des VwVfG für anwendbar erklärt und auf der dritten Stufe ergänzend die entsprechende Geltung der Vorschriften des BGB anordnet. ${ }^{200}$ Die dynamische Verweisung auf die BGB Vorschriften, die zu Zeiten des Vertragsschlusses gelten, ist verfassungskonform. ${ }^{201}$ Insbesondere die mit dem Schuldrechtsmodernisierungsgesetz vom 29.11.2001 durchgeführte Schuldrechtsreform hat sich demnach auch maßgeblich auf das Verwaltungsvertragsrecht ausgewirkt. ${ }^{202}$ Es sind also die einschlägigen BGB Normen in der aktuellen Fassung anzuwenden, insofern sich nicht aus der öffentlich-rechtlichen Sonderkonstellation etwas anderes ergibt. ${ }^{203}$ Methodisch abweichend und etwas umständlich schlagen andere Stimmen in der Literatur vor, jede Regel daraufhin zu überprüfen, ob sie im jeweiligen Einzelfall

198 Grziwotz, JuS 1998, 807, 902, 1013 und 1113; sowie JuS 1999, 245.

199 Bauer, in: Schoch/Schneider, VwVfG i.E., § 62 Rn. 5.

200 Bauer, in: Schoch/Schneider, VwVfG i. E., § 62 Rn. 10, 17.

201 BVerwG, Beschl. v. 3.3.2005, Az.: 7 B 151/04 = NVwZ 2005, 699 (700).

202 Bonk/Neumann/Siegel, in: Stelkens/Bonk/Sachs, VwVfG 9. Aufl. 2018, § 62 Rn. 21.

203 Bauer, in: Schoch/Schneider, VwVfG i. E., § 62 Rn. 42. 
anwendbar ist. ${ }^{204}$ Jedenfalls handelt sich bei der Regelung um eine gesetzlich angeordnete Regelvermutung für die Analogie. ${ }^{205}$ Diese erstreckt sich nur auf das BGB, eine darüber hinausgehende analoge Anwendung sonstiger zivilrechtlicher Regelungen ist allerdings nicht ausgeschlossen, sofern die Voraussetzungen dafür vorliegen. ${ }^{206}$

Relativ hohe Bedeutung haben die Regelungen $\mathrm{zu}$ vorvertraglichen 127 Rechtsverhältnissen (§ 62 S. 2 VwVfG i.V.m. §§ 311 II und III, 241 II BGB analog) und Schadensersatzansprüchen (§62 S. 2 VwVfG i.V.m. $\S \S 280$ I, 311 II und III BGB analog). ${ }^{207}$ Die allgemeinen Vorschriften bezogen auf die Erfüllung der Leistung (§ 62 S. 2 VwVfG i.V.m. $§ 362$ BGB) ${ }^{208}$ das Leistungsstörungsrecht (§ 62 S. 2 VwVfG i.V.m. §§ 280 I, 275 BGB) ${ }^{209}$, damit verbunden die das Verschulden des Vertragspartners (§ 276 BGB analog), bezogen auf Vorsatz und Fahrlässigkeit von gesetzlichen Vertretern sowie Erfüllungsgehilfen (§§ 89, 31 BGB oder $\S 278$ BGB analog) und die Vorschriften über die Geschäftsfähigkeit (§§ 104ff. BGB). ${ }^{210}$ Wie bereits erläutert (s.o.), finden außerdem die Regeln über Willenserklärungen, über die Stellvertretung, über den Vertragsschluss (s.o.) und die Formvorschriften (s.o.) entsprechende Anwendung. Die Regeln über die Wirksamkeit des Vertrages (z.B. die Regeln zur Anfechtung, §§ 119ff., §123, §§ 142ff. BGB) finden grundsätzlich ebenfalls entsprechend Anwendung (s.o.). Die Anwendung über § 59 I VwVfG verdrängt allerdings die Anwendung über $\S 61$ S. 2 VwVfG. Seit der Schuldrechtsmodernisierung ist außerdem das AGB-Recht Teil des BGB ( $\S 3305 \mathrm{ff}$. BGB) und somit von der Verweisung in $§ 62$ VwVfG grundsätzlich erfasst, wenn auch umstritten. ${ }^{211}$

\section{Schadensersatzansprüche}

Wie bereits erläutert (s. Rn. 66), ist die Erfüllung der primären Leistungspflichten 128 des öffentlich-rechtlichen Verwaltungsvertrags (zur Abgrenzung zum privatrechtlichen s. Rn. 82) im Wege der Leistungsklage vor den Verwaltungsgerichten

204 Z. B. Bonk/Neumann/Siegel, in: Stelkens/Bonk/Sachs, VwVfG 9. Aufl. 2018, § 62 Rn. 34.

205 De Wall, Anwendbarkeit privatrechtlicher Vorschriften, S. 62; Bauer, in: Schoch/Schneider, VwVfG, 2019 i.E., § 62 Rn. 42.

206 Bauer, in: Schoch/Schneider, VwVfG i. E., § 62 Rn. 36.

207 Grundlegend: Keller, Vorvertragliche Rechtsverhältnisse im Verwaltungsrecht, 1997.

208 Maurer/Waldhoff, Allgemeines Verwaltungsrecht, 19. Aufl. 2017, § 14 Rn. 62.

209 Gurlit, in: Ehlers/Pünder, Allgemeines Verwaltungsrecht, 15. Aufl. 2016, § 33 Rn. 5; Korte, in: Wolf/Bachof/Stober/Kluth, Allgemeines Verwaltungsrecht, 13. Aufl. 2017, § 54 Rn. 104.

210 Bauer, in: Schoch/Schneider, VwVfG i. E., § 62 Rn. 36.

211 Ruttloff, DVBl. 2013, 1415.

Wolfgang Abromeit 
zu erstreiten. ${ }^{212}$ Das Gleiche gilt bei den dem öffentlichen Recht zuzuordnenden Verträgen für alle Ansprüche der Behörde gegen den Bürger und nach § 40 I 1 i.V.m. II 1 HS 1, 3. Var. VwGO auch für Schadensersatzansprüche wegen Vertragsverletzung. ${ }^{213}$ Der Aufbau ist auch in solchen Fällen am zivilrechtlichen Anspruchsaufbau zu orientieren, die Prüfung des Vertrags erfolgt inzident, bei der Frage nach einem (öffentlich-rechtlichen) vertraglichen Schuldverhältnis. Bei Schadensersatzansprüchen aus vorvertraglichen Pflichtverletzungen ist die Rechtswegfrage umstritten. Während $\mathrm{BGH}^{214}$ und - zumindest im Ergebnis übereinstimmend - auch BVerwG ${ }^{215}$ bei der Nähe zu Amtspflichtverletzungen wegen des Vorrangs von Art. 34 GG i.V.m. § 839 BGB auf den Zivilrechtsweg verweisen, hält der überwiegende Teil der Lehre den Verwaltungsrechtsweg für eröffnet. Dies ist überzeugend, da nach der Ansicht der Rechtsprechung bei weitgehend ähnlich gelagerten Fällen der Zufall über den Rechtsweg entscheiden würde. ${ }^{216}$

\section{Anpassungs- und Kündigungsrechte nach $\S 60 \mathrm{VwVfG}$}

$129 \S 60$ I VwVfG gewährt den Parteien bei tatsächlichen oder rechtlichen Veränderungen einen Vertragsanpassungsanspruch gegenüber dem Vertragspartner. Dafür müssen sich die rechtlichen oder tatsächlichen Verhältnisse, die für die Festsetzung des Vertragsinhalts maßgebend gewesen sind, so weitgehend verändert haben, dass einer Vertragspartei das Festhalten an der ursprünglichen vertraglichen Regelung nicht zuzumuten ist. Der Anspruch kann gerichtlich im Wege einer Leistungsklage erstritten werden, falls sich keine Einigung erzielen lässt. ${ }^{217}$ Wenn die Anpassung nicht möglich, oder nicht zumutbar ist, gewährleistet $§ 60$ I S. 1 VwVfG ein Kündigungsrecht. Eine wesentliche Änderung liegt vor, wenn bei einer Zugrundelegung neuer Umstände der Vertrag, aus Sicht eines verständigen Beobachters, nicht mit demselben Inhalt zustande gekommen wäre. ${ }^{218} \S 60$ I S. 1 VwVfG ist entgegen seines Wortlauts auch auf das ursprüngliche

212 Korte, in: Wolf/Bachof/Stober/Kluth, Allgemeines Verwaltungsrecht, 13. Aufl. 2017, §54 Rn. 107.

213 Detterbeck, Allgemeines Verwaltungsrecht, 17. Aufl. 2019, Rn. 823.

214 BGH, Urt. v. 3.10.1985, Az.: III ZR 60/84 = NJW 1986, 1109.

215 BVerwG, Beschl. v. 30.4.2002, Az.: 4 B 72/01 = NJW 2002, 2894.

216 Vgl. Maurer/Waldhoff, Allgemeines Verwaltungsrecht, 19. Aufl. 2017, § 14 Rn. 64; Peine/Siegel, Allgemeines Verwaltungsrecht, 12. Aufl. 2018, Rn. 799; Detterbeck, Allgemeines Verwaltungsrecht, 17. Aufl. 2019, Rn. 823; vgl. auch: Clausing, JuS 2003, 793.

217 Detterbeck, Allgemeines Verwaltungsrecht, 17. Aufl. 2019, Rn. 821; BVerwG, Urt. v. 26.1.1995, Az.: 3 C 21/93 = BVerwGE 98, 58 = NVwZ 1996, 171; BVerwG, Urt. v. 18.7. 2012, Az.: 8 C 4/11 = BVerwGE 143, $335 \mathrm{ff}=$ NVwZ 2013, 209.

218 Peine/Siegel, Allgemeines Verwaltungsrecht, 12. Aufl. 2018, Rn. 805.

Wolfgang Abromeit 
Fehlen der Geschäftsgrundlage anzuwenden. ${ }^{219} \S 60$ I S. 2 VwVfG enthält außerdem ein Sonderkündigungsrecht der Behörde, um schwere Nachteile für das Gemeinwohl zu verhüten oder $\mathrm{zu}$ beseitigen. Dieser Tatbestand ist allerdings eng auszulegen und nur im Notfall ${ }^{220}$ anzunehmen, „wenn besondere, erhebliche, überragende Interessen der Allgemeinheit die Auflösung des Vertrages gebieten“. ${ }^{221}$ Fiskalische Interessen reichen jedenfalls nicht als Kündigungsgrund im Sinne des $§ 60$ I S. 2 VwVfG aus. ${ }^{222}$ Nach $§ 60$ II VwVfG bedarf die Kündigung der Schriftform und einer Begründung.

\section{Ansprüche auf Rückabwicklung oder Folgenbeseitigung}

Klausurkonstellationen beziehen sich nicht immer auf die Durchsetzung der 130 vertraglichen Neben- oder Hauptleistungspflichten, sondern häufig auch auf die Beseitigung der Folgen von nichtigen Verträgen. Sind die umstrittenen Verträge nicht auf den Erlass eines Verwaltungsakts bezogen gewesen, ist wiederum regelmäßig die Leistungsklage einschlägig. Wenn die Parteien des Vertrags die Streitbeteiligten sind, ergibt sich der Anspruch aus einem (öffentlich-rechtlichen) Erstattungsanspruch. Die Prüfung der Wirksamkeit des öffentlich-rechtlichen Verwaltungsvertrags erfolgt unter dem Prüfungspunkt Rechtsgrund (für die Leistung/Vermögensverschiebung). Es gibt aber auch Konstellationen, in denen Dritte von den Auswirkungen eines nichtigen Vertrages belastet sind. Wenn beispielsweise eine religiöse Gemeinschaft von den Auswirkungen einer aufgrund eines Vertrags gewährten Leistung betroffen ist, ist ein öffentlich-rechtlicher Folgenbeseitigungsanspruch zu prüfen. Die Wirksamkeit des Vertrags sollte dann bei einer Duldungspflicht der Beeinträchtigung angesprochen werden.

Typische Klausurprobleme, die neben der Wirksamkeit des Vertrages in die- 131 sen Fällen (kurz) angesprochen werden sollten, sind die Herleitung der Anspruchsgrundlage (zum öffentlich-rechtlichen Erstattungsanspruch Rn. $189 \mathrm{ff}$./ zum Folgenbeseitigungsanspruch Rn. 169ff.) und die Abgrenzung zu privatrechtlichen Anspruchsgrundlagen, die regelmäßig akzessorisch zu der Charakterisierung des Vertrags zu entscheiden sind.

Im Rahmen der Prüfung des öffentlich-rechtlichen Erstattungsanspruchs 132 kann sich außerdem die Frage stellen, ob sich der Bürger rechtsmissbräuchlich

219 Gurlit, in: Ehlers/Pünder, Allgemeines Verwaltungsrecht, 15. Aufl. 2016, § 33 Rn. 3.

220 Maurer/Waldhoff, Allgemeines Verwaltungsrecht, 19. Aufl. 2017, § 14 Rn. 64.

221 Peine/Siegel, Allgemeines Verwaltungsrecht, 12. Aufl. 2018, Rn. 805.

222 Gurlit, in: Ehlers/Pünder, Allgemeines Verwaltungsrecht, 15. Aufl. 2016, § 33 Rn. 4.

Wolfgang Abromeit 
verhält, wenn oder gerade weil er seine Leistung bereits erhalten hat. Allerdings findet in einem solchen Fall § 817 S. 2 BGB keine entsprechende Anwendung. ${ }^{223}$

\section{Literaturhinweise}

133 Höfling/Krings, Der verwaltungsrechtliche Vertrag: Begriff, Typologie, Fehlerlehre, JuS 2000, 625; Voßkuhle/Kaiser, Grundwissen - Öffentliches Recht: Der öffentlich-rechtliche Vertrag, JuS 2013, 687; Bauer, § 36 Verwaltungsverträge, in: Hoffmann-Riem/Schmidt-Aßmann/Hoffmann-Riem (Hrsg.), Grundlagen des Verwaltungsrechts, 2. Aufl. 2012, $1255 \mathrm{ff}$;; Gurlit, Grundlagen des Verwaltungsvertrages, Jura 2001, 659, 731; Breuer, Das rechtsstaatliche Koppelungsverbot, NVwZ 2017, 112; Drechsler, Städtebauliche Verträge (§ 11 BauGB), Jura 2017, 413; Decker, Ausgewählte examensrelevante Probleme des städtebaulichen Vertrages nach § 11 BauGB, JA 2012, 286; Finck/Gurlit, Die Rückabwicklung formell unionsrechtswidriger Beihilfen, Jura 2011, 87; Stelkens, ,Hinkende‘ Verwaltungsverträge Wirkungen und Rechtsnatur, DÖV 2009, 850; Grziwotz, Einführung in die Vertragsgestaltung im Öffentl. Recht, JuS 1998, 807 ff., $902 \mathrm{ff}$., $1013 \mathrm{ff}$. und 1113ff. sowie JuS 1999, $245 \mathrm{ff}$.

Falllösung: Fall 9 in: Eisentraut, Fälle zum Verwaltungsrecht, 2020

\section{Der öffentlich-rechtliche Abwehr- und Unterlassungsanspruch (Jana Himstedt)}

134 Begehrt der Kläger, einen hoheitlichen Eingriff in seinen individuellen Rechtskreis abzuwehren, ohne dass ihm hierfür eine spezialgesetzliche Anspruchsgrundlage zur Verfügung steht, kann er insbesondere auf den allgemeinen öffentlich-rechtlichen Abwehr- und Unterlassungsanspruch zurückgreifen. Dieser ist grundsätzlich im Wege der allgemeinen Unterlassungsklage als Unterform der allgemeinen Leistungsklage (vgl. §§ 43 II 1, 111 1, 113 IV VwGO) durchzusetzen.

Prozessuale Besonderheiten gelten demgegenüber für den vorbeugenden Unterlassungsanspruch (dazu sogleich Rn. 137). ${ }^{224}$ Als Rechtsbehelf in der Hauptsache ist hier insbesondere die sog. vorbeugende Unterlassungsklage statthaft. Diese erfordert vor allem ein „qualifiziertes“ Rechtsschutzbedürfnis, welches nur dann gegeben ist, wenn dem Kläger ausnahmsweise ein Abwarten

223 BVerwG, Urt. v. 26.3.2003, Az.: 9 C 4/02 = NVwZ 2003, 993.

224 Peine/Siegel, Allgemeines Verwaltungsrecht, 12. Aufl. 2018, § 25 Rn. 911.

Wolfgang Abromeit/Jana Himstedt 
der drohenden Maßnahme nicht zumutbar ist, weil diese sich bereits konkret abzeichnet und z. B. irreversible, schwere Beeinträchtigungen herbeiführen wird (s. auch Rn. 47).225

In beiden Varianten des Anspruchs ist bei seiner Durchsetzung stets auch an einen Antrag auf einstweilige Anordnung gem. § 123 I VwGO (ggf. in Form des „vorläufigen vorbeugenden Rechtsschutzes“226) $\mathrm{zu}$ denken. ${ }^{227}$

\section{Anspruchsziele}

Der Anspruch kann sich dabei gegen gegenwärtige wie auch bevorstehende 135 hoheitliche Eingriffe richten.

\section{a) (Negatorischer) Störungsabwehranspruch}

Bei gegenwärtigen - also bereits eingetretenen und noch fortdauernden - Ein- 136 griffen spricht man vom sog. Störungsabwehranspruch oder „schlichten“228 Abwehr- und Unterlassungsanspruch.

Beispiel: Die Wohnung des K liegt neben einer städtischen Müllverbrennungsanlage, von der permanente Geruchsbelästigungen für die umliegenden Gebäude ausgehen. $\mathrm{K}$ möchte sich hiergegen wehren.

\section{b) Vorbeugender Unterlassungsanspruch}

Steht die (behauptete) Beeinträchtigung durch einen Hoheitsträger hingegen erst 137 bevor, handelt es sich um den sog. vorbeugenden Unterlassungsanspruch. ${ }^{229}$

Beispiel: ${ }^{230}$ Der eher konservative K erfährt aus den Medien, dass die Bundesregierung plant, zum anstehenden Christopher Street Day vor den Dienstgebäuden einiger Ministerien die sog.

225 Kratzlmeier, Jura 2018, 1239 (1241); Sodan/Ziekow, Grundkurs Öffentliches Recht, 8. Aufl. 2018, § 100 Rn. 4.

226 Pietzcker in: Schoch/Schneider/Bier, VwGO, 36. EL Februar 2019, § 42 Rn. 162.

227 Aktuelle Übungsfälle zum Antrag nach §123 I VwGO in Verbindung mit dem öffentlichrechtlichen Abwehr- und Unterlassungsanspruch bei Ferreau, JuS 2017, 758 (Äußerung eines Oberbürgermeisters auf Facebook); Frank, JuS 2018, 56 (hoheitliche Immissionen durch Bolzplatz); Peters, Jura 2014, 752 (amtliche Veröffentlichung lebensmittelrechtlicher Verstöße in Gastronomiebetrieben); Barczak, JuS 2014, 932 (amtliche Warnung vor E-Zigaretten).

228 Kaiser/Köster/Seegmüller, Materielles Öffentliches Recht im Assessorexamen, 4. Aufl. 2018, Rn. 51.

229 Gersdorf, Verwaltungsprozessrecht, 6. Aufl. 2019, Rn. 63.

230 Nach VG Berlin, Urt. v. 3.6.2015, Az.: 33 K 332.14. 
Regenbogenflagge zu hissen. Da K hierin eine Verletzung seiner negativen Weltanschauungsfreiheit sowie der staatlichen Neutralitätspflicht sieht, möchte er dies von Vornherein auf dem Klageweg verhindern.

138 Unterschiedlich wird beurteilt, ob im Falle iterativer - also mehrerer gleichartiger und aufeinander folgender - Eingriffe der vorbeugende Unterlassungsanspruch $^{231}$ oder nicht vielmehr der „einfache“ Störungsabwehranspruch einschlägig ist. Denn teilweise wird für den vorbeugenden Unterlassungsanspruch einschränkend das erstmalige Bevorstehen einer hoheitlichen Handlung verlangt. ${ }^{232}$ In der Klausur ist folglich beides vertretbar.

\section{c) Bedeutung der Unterscheidung}

139 Die Differenzierung zwischen den genannten Unterformen des Anspruchs hat vor allem zwei Konsequenzen:

Erstens ist der Störungsabwehranspruch mittels „normaler“ allgemeiner Leistungsklage geltend $\mathrm{zu}$ machen, der vorbeugende Unterlassungsanspruch hingegen im Wege der vorbeugenden Unterlassungsklage, für die qualifizierte Anforderungen vor allem im Hinblick auf das Rechtsschutzbedürfnis gelten (s. Rn. 47, 134).

Zweitens kann sich der schlichte Abwehr- und Unterlassungsanspruch ausschließlich gegen Tathandeln eines Hoheitsträgers, also Grundrechtsbeeinträchtigungen in Form von Realakten, richten, wohingegen der vorbeugende Unterlassungsanspruch prinzipiell auch gegen rechtsförmige Hoheitsakte (insbesondere: Verwaltungsakte) einzugreifen vermag. ${ }^{233}$ Dessen Reichweite ist mithin größer, die Voraussetzungen an seine gerichtliche Durchsetzung jedoch auch höher.

231 Dafür: Detterbeck, Allgemeines Verwaltungsrecht, 17. Aufl. 2019, Rn. 1443f.; Gersdorf, Verwaltungsprozessrecht, 6. Aufl. 2019, Rn. 63; aus der Rechtsprechung etwa BVerwG, Urt. v. 23.5. 1989, Az.: 7 C 2/87 = BVerwGE 82, 76 (Rn. 46); Urt. v. 22.10.2014, Az.: 6 C 7/13 = NVwZ 2015, 906 (907); OVG Münster, Beschl.v. 17.10.2017, Az.: 4 B 786/17 -, juris-Rn. 7.

232 So Peine/Siegel, Allgemeines Verwaltungsrecht, 12. Aufl. 2018, Rn. 909; Sodan/Ziekow, Grundkurs Öffentliches Recht, 8. Aufl. 2018, § 90 Rn. 12; Kaiser/Köster/Seegmüller, Materielles Öffentliches Recht im Assessorexamen, 4. Aufl. 2018, Rn. 51.

233 Kaiser/Köster/Seegmüller, Materielles Öffentliches Recht im Assessorexamen, 4. Aufl. 2018, Rn. 49. Denn: Anspruchsziel ist bloßes Untätigwerden des Staates, vgl. Erbguth/Guckelberger, Allgemeines Verwaltungsrecht, 9. Aufl. 2018, welches dem Kläger im Falle eines bereits rechtswirksam erlassenen Verwaltungsakts nicht hilft, wohl aber, wenn der Erlass des streitigen Rechtsakts erst noch bevorsteht. Zudem sieht das Gesetz im Hinblick auf bereits erlassene Verwaltungsakte speziellere Abwehrmechanismen wie etwa den kassatorischen Urteilsspruch der Anfechtungsklage vor. 


\section{d) Abgrenzung zum Folgenbeseitigungsanspruch}

Schwierig kann sich vor allem die Abgrenzung des öffentlich-rechtlichen Abwehr- 140 und Unterlassungsanspruchs vom Folgenbeseitigungsanspruch (dazu unten Rn. 169 ff.) gestalten. Denn beide Institute haben identische Rechtsgrundlagen ${ }^{234}$ und sind funktional darauf gerichtet, den grundrechtlichen status negativus des Anspruchstellers wiederherzustellen bzw. zu bewahren. ${ }^{235}$

In zeitlicher Hinsicht unterscheidet sich der Folgenbeseitigungsanspruch zunächst insoweit vom öffentlich-rechtlichen Unterlassungsanspruch, als dass der betreffende Eingriff bereits abgeschlossen ist und in der Vergangenheit liegt, während der Unterlassungsanspruch gegenwärtige oder bevorstehende Eingriffe zum Gegenstand hat. ${ }^{236}$

Beispiel: Nach einer rechtswidrigen öffentlichen Äußerung durch einen Hoheitsträger begehrt der Kläger

1. den Widerruf der bereits getätigten Äußerung sowie

2. dass der Beklagte es zukünftig unterlässt, vergleichbare Äußerungen zu tätigen.

Grundlage des erstgenannten Klageziels ist der Folgenbeseitigungsanspruch; das letztere, zukunftsgerichtete Begehren lässt sich hingegen auf den öffentlich-rechtlichen Unterlassungsanspruch stützen. ${ }^{237}$

Dieser zeitliche Aspekt allein hilft jedoch meist nicht weiter, wenn gerade die $\mathbf{1 4 2}$ Abgrenzung zwischen dem Eingriff selbst, gegen welchen sich der Unterlassungsanspruch richtet, und den Eingriffsfolgen, auf deren Rückgängigmachung der Folgenbeseitigungsanspruch abzielt, in Frage steht. Problematisch ist dies besonders im Falle hoheitlich hervorgerufener Immissionen.

Beispiel: Unmittelbar angrenzend an das Grundstück des $K$ wird durch die Gemeinde ein
Bolzplatz errichtet und betrieben, von welchem in der Folgezeit erhebliche Lärmemissionen
ausgehen. A fühlt sich durch letztere gestört. Man kann hier einerseits die gegenwärtigen
Immissionen selbst der öffentlichen Hand zurechnen und diese als hoheitlichen Eingriff werten
( $\rightarrow$ Unterlassungsanspruch). Denkbar wäre andererseits, auf die in der Vergangenheit ab-
geschlossene hoheitliche Errichtung des Bolzplatzes abzustellen und die von ihm ausgehenden
Emissionen als absehbare Eingriffsfolgen werten ( $\rightarrow$ Folgenbeseitigungsanspruch). ${ }^{238}$ Indes
werden von „,hoher Hand“ zurechenbar hervorgerufene Immissionen überwiegend als eigen-

234 Erbguth/Guckelberger, Allgemeines Verwaltungsrecht, 9. Aufl. 2018, § 41 Rn. 18.

235 Schoch, Jura 1993, 478 (481); Ossenbühl/Cornils, Staatshaftungsrecht, 6. Aufl. 2013, S. 359.

236 Peine/Siegel, Allgemeines Verwaltungsrecht, 12. Aufl. 2018, § 25 Rn. 909.

237 So etwa bei VGH Kassel, Beschl. v. 11.7.2017, Az.: 8 B 1144/17 = DÖV 2017, 920 (LS); Barczak, JuS 2014, 932.

238 Frank, JuS 2018, 56 (58). 
ständiger Eingriff gewertet und der Immissionsabwehranspruch somit dem Unterlassungsanspruch zugeordnet. ${ }^{239}$

In derartigen Klausurfällen muss also zunächst durch Sachverhaltsauslegung ermittelt werden, ob es sich um eine einzige Störungsquelle mit unselbständiger Störungsfolge handelt ${ }^{240}$ oder vielmehr zwei trennbare Störungsquellen vorliegen (hier: Errichtung des Platzes einerseits und sein Betrieb andererseits). Sodann ist nach dem Klägerbegehren zu ermitteln, gegen welchen beider Akte sich der Anspruch richtet, wobei zu beachten ist, dass Rechtsfolge des Unterlassungsanspruchs allein behördliches Untätigwerden oder -bleiben sein kann, die des Folgenbeseitigungsanspruchs hingegen auch (aktives) Tätigwerden des Hoheitsträgers. ${ }^{241}$

Zum Beispiel aus Rn. 142: Hätte K hier nicht nur eine Abstellung des Lärms, sondern eine Beseitigung der Anlage selbst begehrt, wäre der Errichtungsakt der maßgebliche Eingriff gewesen. Da die Errichtung des Platzes in der Vergangenheit liegt und anders als sein fortdauernder Betrieb nicht durch bloßes Unterlassen (Betriebseinstellung) erreicht werden kann, sondern es aktiver Baumaßnahmen bedürfte, wäre hier der Folgenbeseitigungsanspruch einschlägig.

Es bedarf also letztlich stets einer guten Argumentation im Einzelfall - eine „Universalabgrenzung“ zwischen Unterlassungs- und Folgenbeseitigungsanspruch ist leider nicht möglich. ${ }^{242}$

\section{Dogmatische Herleitung}

143 Der öffentlich-rechtliche Unterlassungsanspruch wurde von den Gerichten ursprünglich in Anlehnung an zivilrechtliche Vorschriften entwickelt und wird von dieser teils bis heute auf eine Analogie zu den \$§ 12, 906, 1004 BGB gestützt. ${ }^{243}$ Nach anderer Auffassung entspringt dieses Rechtsinstitut der Abwehrfunktion der Grundrechte ${ }^{244}$, die teils auch - da der Anspruch auf die Wahrung bzw. Wiederherstellung rechtmäßiger Zustände gerichtet ist - i.V.m. dem Prinzip der Gesetzmäßigkeit der Verwaltung (Art. 20 Abs. 3 GG) herangezogen werden. ${ }^{245}$

239 Baldus/Grzeszick/Wiehues, Staatshaftungsrecht, 5. Aufl. 2018, Rn. 79.

240 Vgl. OVG Münster, Urt. v. 28.4.1983, Az.: 11 A 424/82 = NJW 1984, 1982.

241 Mehde, Jura 2017, 783 (783).

242 Schwarz/Wendel, ZJS 2017, 328 (332).

243 Ossenbühl/Cornils, Staatshaftungsrecht, 6. Aufl. 2013, S. 352, 355.

244 Erbguth/Guckelberger, Allgemeines Verwaltungsrecht, 9. Aufl. 2018, § 41 Rn. 18.

245 Barczack, JuS 2014, 932 (934); Peine/Siegel, Allgemeines Verwaltungsrecht, 12. Aufl. 2018, $\S 25$ Rn. 899.

Jana Himstedt 
In jedem Fall ist der Anspruch aber gewohnheitsrechtlich anerkannt und ein Streitentscheid in der verwaltungsrechtlichen Klausur daher nicht angezeigt. ${ }^{246}$

\section{Anspruchsvoraussetzungen}

Der Anspruch erfordert insbesondere, dass durch öffentlich-rechtliches Han- 144 deln in ein subjektives öffentliches Recht des Klägers eingegriffen wird und dieser Eingriff rechtswidrig ist.

\section{a) Eingriff in ein subjektives öffentliches Recht des Klägers}

Notwendig ist also zunächst ein Eingriff in ein subjektives öffentliches Recht 145 des Klägers; die Verletzung solcher Vorschriften, die ausschließlich im Gemeininteresse erlassen wurden, genügt insofern nicht. ${ }^{247}$ Die (Unions-)Grundrechte, ${ }^{248}$ aber auch einfachgesetzliche Normen und öffentlich-rechtliche Sonderbeziehungen können jenes klägerische Recht begründen. ${ }^{249}$ Für den Eingriffsbegriff gelten die allgemeinen, aus der Grundrechtslehre bekannten Grundsätze. In den - durchaus klausurrelevanten - Fällen staatlichen Informationshandelns ist insofern auch die diesbezügliche spezielle Eingriffsdogmatik des BVerfG ${ }^{250}$ hinsichtlich der Berufsfreiheit zu beachten (näher der Fall 10 in: Eisentraut, Fälle zum Verwaltungsrecht, 2020).

\section{b) Durch öffentlich-rechtliches Handeln}

Zudem setzt der Unterlassungsanspruch ein öffentlich-rechtliches Handeln 146 des betreffenden Hoheitsträgers voraus. Die Abgrenzung zu zivilrechtlichem Tätigwerden - gegen welches unmittelbar auf Grundlage der §§ 906, 1004 BGB vorzugehen wäre - kann nach allgemeinen Abgrenzungskriterien, insbesondere dem Zweck und Sachzusammenhang des Staatshandelns ${ }^{251}$, erfolgen.

Störende Handlungen privater Dritter, die im Kontext einer öffentlichen Einrichtung vorgenommen werden, können einem Hoheitsträger insbesondere dann zugerechnet werden, wenn sie durch bestimmungsgemäße Nutzung der

246 Mehde, Jura 2017, 783.

247 Peine/Siegel, Allgemeines Verwaltungsrecht, 12. Aufl. 2018, § 25 Rn. 902.

248 Peters, Jura 2014, 752 (756).

249 Kaiser/Köster/Seegmüller, Materielles Öffentliches Recht im Assessorexamen, 4. Aufl. 2018, Rn. 51.

250 BVerfG, Beschl. vom 21.3.2018, Az.: 1 BvF 1/13 = NJW 2018, 2109 (2110f.)

251 Erbguth/Guckelberger, Allgemeines Verwaltungsrecht, 9. Aufl. 2018, § 41 Rn. 4.

Jana Himstedt 
Einrichtung entstehen. ${ }^{252}$ Selbst hierüber hinausgehende Nutzungen können jedoch zurechenbar sein, soweit der Hoheitsträger es unterlassen hat, diesbezüglich zumutbare Schutzmaßnahmen vorzunehmen (etwa: ein Schild mit der Nutzungsordnung nicht in lesbarem Zustand erhält) oder soweit der von ihm gewählte Standort im Hinblick auf Emissionen per se ungeeignet ist. ${ }^{253}$

Im Beispiel in Rn. 142 sind die vom kommunal betriebenen Bolzplatz ausgehenden Lärmemissionen also der Gemeinde grundsätzlich zurechenbar, soweit sie sich im Rahmen der - am Eingang ordnungsgemäß verkündeten - Benutzungsordnung halten. ${ }^{254}$

\section{c) Unmittelbar bevorstehend oder andauernd}

147 Der Eingriff muss ferner noch andauern oder unmittelbar bevorstehen. Soweit es sich also um keine noch gegenwärtige Dauerstörung (etwa: konstante Geruchsimmissionen) handelt, muss der Kläger eine konkrete Wiederholungs- oder Erstbegehungsgefahr darlegen. ${ }^{255}$

Die Wiederholungsgefahr ist dabei grundsätzlich durch einen bereits erfolgten, gleichartigen Eingriff indizier ${ }^{256}$, kann aber in besonderen Einzelfällen fehlen, etwa wenn sich der Rechtsstandpunkt der Behörde oder die tatsächlichen Umstände verändert haben. ${ }^{257}$

\section{d) Rechtswidrigkeit}

148 Letztlich muss der Eingriff rechtswidrig sein. Spezielle Maßstäbe sind hier insbesondere in den bereits angesprochenen Immissionsfällen wie auch im Falle amtlicher Warnungen $\mathrm{zu}$ beachten:

\section{aa) Hoheitlich herbeigeführte Immissionen}

149 Öffentlich-rechtliche Immissionen sind nur insoweit rechtswidrig, als sie die rechtlichen Duldungspflichten des Anspruchstellers übersteigen. Solche können sich zunächst aus öffentlichem Recht, insbesondere § $22 \mathrm{BImSchG}$ und den

252 Frank, JuS 2018, 56 (59).

253 Kaiser/Köster/Seegmüller, Materielles Öffentliches Recht im Assessorexamen, 4. Aufl. 2018, Rn. 51.

254 Frank, JuS 2018, 56 (59).

255 Vgl. Kaiser/Köster/Seegmüller, Materielles Öffentliches Recht im Assessorexamen, 4. Aufl. 2018, Rn. 51.

256 Ossenbühl/Cornils, Staatshaftungsrecht, 6. Aufl. 2013, S. 367.

257 BVerwG, Urt. v. 24.10.2013, Az.: 7 C 13/12 -, Rn. 44.

Jana Himstedt 
ihn konkretisierenden Verwaltungsvorschriften TA Lärm und TA Luft ergeben. ${ }^{258}$ Im Übrigen kann entsprechend auf $§ 906$ BGB zurückgegriffen werden. ${ }^{259}$

\section{bb) Staatliche Informationstätigkeit}

Gewissermaßen „modifizierte“ Rechtmäßigkeitsanforderungen gelten auch für 150 amtliche Warnungen (s. dazu auch den Fall 10 in: Eisentraut, Fälle zum Verwaltungsrecht, 2020 260):

Erstens ist nach der Rechtsprechung des BVerfG eine formell-gesetzliche Ermächtigungsgrundlage lediglich bei „klassischen“, also insbesondere final beeinträchtigenden Eingriffen erforderlich. Für „nur“ mittelbar-faktische Eingriffe soll es hingegen ausreichen, dass der betreffende Hoheitsträger im Rahmen seiner (grund-)gesetzlichen Aufgabenzuweisung tätig wird.

Zweitens ist im Rahmen der Verhältnismäßigkeitsprüfung insbesondere das Sachlichkeitsgebot zu beachten: So muss der Hoheitsträger vor der Äußerung eine hinreichende Sachverhaltsaufklärung betrieben haben und die Warnung darf ausschließlich auf wahren, vertretbar begründbaren Tatsachen basieren. ${ }^{261}$

\section{Abschließender Überblick: Öffentlich-rechtlicher Abwehr- und Unterlassungsanspruch}

Grundlage: $\S \S 12,906,1004$ BGB analog oder Verfassungsrecht (Grundrechte, 151 Rechtsstaatsprinzip), jedenfalls gewohnheitsrechtlich anerkannt

Voraussetzungen:

1 Eingriff in ein subjektives öffentliches Recht des Klägers

2 Hoheitlichkeit des Eingriffs

3 Rechtswidrigkeit des Eingriffs

Rechtsfolge: Unterlassungsanspruch hinsichtlich eines gegenwärtigen oder bevorstehenden Verwaltungshandelns

258 Vgl. Frank, JuS 2018, 56 (61f.).

259 Kranz, NVwZ 2018, 864; Erbguth/Guckelberger, Allgemeines Verwaltungsrecht, 9. Aufl. 2018, $\S 41$ Rn. 6.

260 Weitere aktuelle Übungsfälle zum Unterlassungsanspruch gegen hoheitliches Informationshandeln bei Ferreau, JuS 2017, 758 (Äußerung eines Oberbürgermeisters auf Facebook); Burgi/ Tjardes, GewArch 2014, 348 (Äußerungen der IHK); Barczak, JuS 2014, 932 (amtliche Warnung vor E-Zigaretten); Peters, Jura 2014, 752 (amtliche Veröffentlichung lebensmittelrechtlicher Verstöße in Gastronomiebetrieben).

261 Schwarz/Wendel, ZJS 2017, 328 (337). 


\section{Literaturhinweise}

152 Ausbildungsaufsätze: Köckerbauer/Büllesbach, Der öffentlich-rechtliche Unterlassungsanspruch, JuS 1991, 373; vertiefend zur Verjährung des Unterlassungsanspruchs Kranz, Verjährung von öffentlich-rechtlichen Unterlassungsansprüchen, NVwZ 2018, 864.

Übungsklausuren und -hausarbeiten: Frank, Referendarexamensklausur Öffentliches Recht: Verwaltungsrecht - Das Eigentor, JuS 2018, 56; Ferreau, Fortgeschrittenenklausur - Öffentliches Recht: Staatsorganisations-, Kommunal-, Verwaltungsprozessrecht - Disharmonie um Kommunalwahlkampf, Jus 2017, 758; Barczak, Referendarexamensklausur - Öffentliches Recht: Grundrechte, Staatshaftungsrecht und Besonderes Verwaltungsrecht - Behördliche Warnung vor EZigaretten, JuS 2014, 932; Peters, Der „Ekel“-Pranger, Jura 2014, 753 (Examensklausur); Burgi/Tjardes, Schwerpunktbereichsklausur - Wirtschaftsverwaltungsrecht: Äußerungen der IHK - verfassungsrechtliche Zulässigkeit von Privatisierungen, GewArch 2014, 348.

\section{Ansprüche auf öffentliche Ersatzleistungen (Jana Himstedt)}

153 Die auf Durchsetzung des soeben behandelten öffentlich-rechtlichen Unterlassungsanspruchs gerichtete Leistungsklage ist ein klassisches Mittel des sog. Primärrechtsschutzes, also solcher Rechtsbehelfe, die rechtswidrige hoheitliche (Grund-)Rechtseingriffe von Vornherein abzuwehren suchen. ${ }^{262}$ In zahlreichen Fällen allerdings erweisen sich solche primären Rechtsbehelfe als wirkungslos. Dies gilt entweder, weil sie zu spät kommen und die öffentliche Hand bereits irreversibel einen Zustand geschaffen hat, der mit der Rechtsordnung unvereinbar ist, ${ }^{263}$ oder weil sich der hoheitliche Eingriff gerade als rechtmäßig erweist.

Hier setzen die sog. sekundären Ansprüche an: Sie können einerseits darauf abzielen, einen durch rechtswidriges Hoheitshandeln herbeigeführten status quo zu beseitigen oder jedenfalls finanziell auszugleichen (Unrechtshaftung ${ }^{264}$ ), andererseits auch darauf, eine übermäßige Inanspruchnahme des Einzelnen durch eine an sich rechtmäßige Situation zu kompensieren (Sonderopferentschädigung $\left.^{265}\right) .{ }^{266}$ Soweit diese sekundäre Verantwortlichkeit der öffentlichen Hand auf

262 Erbguth/Guckelberger, Allgemeines Verwaltungsrecht, 9. Aufl. 2018, § 36 Rn. 1.

263 Ipsen, Allgemeines Verwaltungsrecht, 11. Aufl. 2019, Rn. 1239.

264 Vgl. Papier in: Isensee/Kirchhof, Handbuch des Staatsrechts VIII, 3. Aufl. 2010, § 180 Rn. 2.

265 Vgl. Papier in: Isensee/Kirchhof, Handbuch des Staatsrechts VIII, 3. Aufl. 2010, § 180 Rn. 74.

266 Wolff/Bachof/Stober/Kluth, Verwaltungsrecht II, 7. Aufl. 2010, § 66 Rn. 3, 7; Lege, JA 2016, 81 (82). 
der Ausübung öffentlicher Gewalt und nicht privatrechtlichen Handlungen beruht, wird sie regelmäßig unter den Begriffen „Staatshaftungsrecht“ oder „öffentliche Ersatzleistungen“ zusammengefasst ${ }^{267}$ und soll im Folgenden behandelt werden.

Im Übrigen wird an den Bezeichnungen „Primär-“ und „Sekundärrechts- 154 schutz“ bereits das Verhältnis zwischen den ihnen zuzuordnenden Anspruchsgrundlagen ersichtlich. ${ }^{268}$ So hat sich der Bürger im Grundsatz vorrangig mit dem Primärrechtsschutz, also der Abwehr staatlicher Eingriffe, zu behelfen. Restitution und vor allem finanzielle Entschädigung kann er erst verlangen, wenn jene scheitert (sog. „Vorrang des Primärrechtsschutzes“). ${ }^{269}$ Auf die speziellen gesetzlich wie richterrechtlich begründeten - Ausprägungen dieses Grundsatzes wird im Kontext der jeweiligen Anspruchsgrundlagen zurückzukommen sein.

\section{Die Struktur des Staatshaftungsrechts: Systematisierungsansätze}

Die heute anerkannten Ansprüche auf öffentliche Ersatzleistungen unterliegen

freilich keiner sofort zugänglichen Systematik. Vielmehr handelt es sich um einen historisch nach Bedarf gewachsenen, stark richterrechtlich geprägten Bestand, ${ }^{270}$ dessen Zusammenfassung und Systematisierung durch den Gesetzgeber nicht in absehbarer Zeit zu erwarten ist, gleichwohl dieses Vorhaben in der Vergangenheit regelmäßig Eingang in die Koalitionsverträge gefunden hat. ${ }^{271}$ In prozessualer Hinsicht ist überdies eine Rechtswegspaltung durch das Staatshaftungsrecht zu verzeichnen, die letzteres weiter verkompliziert (näher Rn. $161 \mathrm{ff}$.).

\section{a) Das materielle Anspruchssystem}

In materieller Hinsicht hält die Literatur ${ }^{272}$ indes einige Strukturierungsansätze 156 bereit, die im Folgenden kurz aufgegriffen werden sollen - dies vor allem mit dem Zweck einer verbesserten Einprägsamkeit der danach erörterten Ansprüche für die verwaltungsrechtliche Klausur.

267 Lege, JA 2016, 81; Baldus/Grzeszick/Wienhues, Staatshaftungsrecht, 5. Aufl. 2018, Rn. 6 f. 268 Ipsen, Allgemeines Verwaltungsrecht, 11. Aufl. 2019, § 20 Rn. 1252.

269 Kratzlmeier, Jura 2018, 1239 (1248); Papier in: Isensee/Kirchhof, Handbuch des Staatsrechts VIII, 3. Aufl. 2010, § 180 Rn. 14.

270 Vgl. Ossenbühl/Cornils, Staatshaftungsrecht, 6. Aufl. 2013, S. 5 f.

271 Vgl. etwa Koalitionsvertrag der 18. Legislaturperiode des Bundestages vom 16.12. 2013, S. 107.

272 Jüngst etwa Kratzlmeier, Jura 2018, 1239; Lege, JA 2016, 81. 


\section{aa) Unrechtshaftung vs. Sonderopferentschädigung}

157 Zunächst lassen sich die Ansprüche funktional ${ }^{273}$ in diejenigen unterteilen, die der Haftung für rechtswidrige Zustände dienen (Unrechtshaftung), und jene, die eine rechtmäßige, aber übermäßige Inanspruchnahme des Anspruchstellers kompensieren sollen (sog. Sonderopferentschädigung). ${ }^{274}$

158 Der Unrechtshaftung sind dabei zuzuordnen:

1. Folgenbeseitigungsansprüche,

2. öffentlich-rechtliche Erstattungsansprüche,

3. Amtshaftungsansprüche sowie

4. Ansprüche aus verwaltungsrechtlichen Schuldverhältnissen.

Zur Haftung wegen übermäßiger Inanspruchnahme zählen hingegen:

1. alle eigentumsspezifischen Ansprüche (Enteignungsentschädigung, enteignender und enteignungsgleicher Eingriff, Ausgleich für Inhalts- und Schrankenbestimmungen) sowie

2. der allgemeine Aufopferungsanspruch. ${ }^{275}$

159 Diese Unterschiede im Haftungsgrund schlagen sich letztlich in den Anspruchsvoraussetzungen nieder: So setzen Ansprüche der Sonderopferentschädigung naheliegender Weise - regelmäßig das Vorliegen eines Sonderopfers voraus, solche der Unrechtshaftung hingegen einen rechtswidrigen (Vermögens-)Zustand oder Eingriff.

\section{bb) Verschuldenshaftung}

160 Nimmt man hingegen eine Differenzierung der Ansprüche danach vor, ob sie ein Verschulden des betreffenden Amtswalters oder Hoheitsträgers voraussetzen, fällt unmittelbar auf, dass dies allein im Rahmen der der Zivilgerichtsbarkeit zugewiesenen Unrechtshaftung, also der Amtshaftungsansprüche sowie der Haftung im Verwaltungsschuldverhältnis der Fall ist. Bereits insofern nehmen diese genuin zivilrechtlichen Institute in der Staatshaftung eine Sonderstellung ein; in der Konsequenz reicht aber auch ihre Rechtsfolge - nämlich „echter“ Schadensersatz nach den Grundsätzen der Totalreparation und Naturalrestitution - deutlich weiter als die der übrigen Ansprüche. Die Sonderopferhaftung

273 Vgl. Wolff/Bachof/Stober/Kluth, Verwaltungsrecht II, 7. Aufl. 2010, § 66 Rn. 3.

274 Lege, JA 2016, 81 (82ff.); Erbguth/Guckelberger, Allgemeines Verwaltungsrecht, 9. Aufl. 2018, $\S 36$ Rn. 3.

275 Insgesamt Erbguth/Guckelberger, Allgemeines Verwaltungsrecht, 9. Aufl. 2018, § 36 Rn. 3. Jana Himstedt 
setzt demgegenüber - ihrem Haftungsgrund entsprechend - nie Verschulden voraus, ebenso wenig alle (sonstigen) vor den Verwaltungsgerichten zu verhandelnden Ansprüche auf öffentliche Ersatzleistungen. Systematisch gesehen bildet das privatrechtlich verwurzelte Kriterium der persönlichen Vorwerfbarkeit einer Schädigungshandlung deshalb in der öffentlich-rechtlichen Haftung lediglich die Ausnahme. In der Folge wurde es vor allem im Rahmen der Amtshaftung immer weiter „entschärft“ und objektiviert (näher § 11 Rn. 17).

\section{b) Rechtswegsystematik}

Die so kategorisierten Anspruchsgrundlagen sollen allesamt durch hoheitliches 161 Handeln herbeigeführte Rechts- oder Vermögenszustände korrigieren und wären hiernach grundsätzlich dem öffentlichen Recht zuzuordnen. ${ }^{276}$ Gleichwohl wird ihr überwiegender Teil vor den Zivilgerichten verhandelt, weil das Recht der Staatshaftung von diversen Sonderzuweisungen durchdrungen wird (Stichwort: Rechtswegspaltung $\left.^{277}\right)$.

\section{aa) $\$ 40$ II 1 VwGO}

Die wohl relevanteste Sonderzuweisung bildet $\$ 40$ II 1 VwGO, die insbesondere 162 Ansprüche aus Amtshaftung gem. § 839 BGB i.V.m. Art. 34 GG betrifft (§ 40 I 1 Var. 3 VwGO) und insoweit durch Art. 34 S. 3 GG explizit verfassungsrechtlich geboten ist. ${ }^{278}$ Über diese verfassungsrechtliche Vorgabe reicht $§ 40$ II 1 VwGO jedoch hinaus und drängt allgemein Streitigkeiten für vermögensrechtliche Ansprüche aus Aufopferung für das gemeine Wohl (Var. 1), aus öffentlich-rechtlicher Verwahrung (Var. 2) sowie für Schadensersatzansprüche aus der Verletzung nichtvertraglicher öffentlich-rechtlicher Pflichten (Var. 3) auf den ordentlichen Rechtsweg ab. Damit erfasst sie neben der Amtshaftung Rechtsstreitigkeiten auf Grundlage

a) des allgemeinen Aufopferungsanspruchs (Var. 1) ${ }^{279}$,

b) des enteignenden Eingriffs (Var. 1) ${ }^{280}$,

c) des enteignungsgleichen Eingriffs (Var. 1 oder 3, streitig) ${ }^{\mathbf{2 8 1}}$,

276 Baldus/Grzeszick/Wienhues, Staatshaftungsrecht, 5. Aufl. 2018, Rn. 6 f.

277 Vgl. Tremml/Karger/Luber, Der Amtshaftungsprozess, 4. Aufl. 2013, Rn. $526 \mathrm{ff}$.

278 Papier in: Maunz/Dürig, GG, 86. Aufl. 2019, Art. 34 Rn. 305.

279 Grzeszick in: Ehlers/Pünder, Allgemeines Verwaltungsrecht, 15. Aufl. 2015, § 45 Rn. 110.

280 Peine/Siegel, Allgemeines Verwaltungsrecht, 12. Aufl. 2018, § 28 Rn. 1040.

281 Die Zuordnung zum Aufopferungsrecht (Var. 1) kann in Anbetracht der Rechtswidrigkeit des Eingriffs bezweifelt werden; auch andernfalls handelt es sich jedoch um einen „Schadenser- 
d) nichtvertraglicher Verwaltungsschuldverhältnisse (Var. 3 bzw. Var. 2, soweit es um den speziellen Unterfall eines Verwahrungsverhältnisses geht) ${ }^{282}$, und

e) der unionsrechtlichen Amtshaftung deutscher Hoheitsträger (Var. 3) ${ }^{283}$.

163 Streitigkeiten um das Bestehen und die Höhe eines Ausgleichsanspruchs für Inhalts- oder Schrankenbestimmungen i. S.d. Art. 14 I S. 2 GG sind von § 40 II 1 VwGO mit dessen letztem Halbsatz explizit ausgenommen, sodass für sie nach der Generalklausel des § 40 I 1 VwGO der Verwaltungsrechtsweg eröffnet ist. ${ }^{284}$

Insgesamt greift $§ 40$ II 1 VwGO ausschließlich, soweit der Anspruchsgegner ein Hoheitsträger ist, also insbesondere nicht bei Ansprüchen des Staates gegen den Bürger. ${ }^{285}$ Dies ergibt sich aus der Entstehungsgeschichte der Vorschrift: So sollten Streitigkeiten um all jene Ansprüche, die in starker Nähe zur Amtshaftung und Enteignungsentschädigung stehen, mit letzteren einem einheitlichen Rechtsweg zugwiesen werden. Ansprüchen des Staates gegen den Bürger fehlt es aber am erforderlichen Sachzusammenhang mit diesen klassischen Instituten der Staatshaftung. ${ }^{286}$ Trotz dieser Einschränkung drängt die Vorschrift im Ergebnis einen großen Teil des staatshaftungsrechtlichen Streitstoffs an die Zivilgerichte $\mathrm{ab}$.

bb) Art. 14 Abs. 3 S. 4 GG

165 Außerdem entscheiden die Zivilgerichte über Streitigkeiten um die Höhe einer Enteignungsentschädigung; Art. 14 Abs. 3 S. 4 GG bildet insoweit eine unmittelbar verfassungsrechtliche Sonderzuweisung. ${ }^{287}$

\section{cc) Examenswissen: Rechtswegübergreifende Entscheidungskompetenz des § 17 || 1 GVG}

166 Daneben kann auch die Vorschrift des $\S 17$ II GVG für die Bestimmung des Rechtswegs im Staatshaftungsrecht relevant werden. ${ }^{288}$ Hiernach hat das Gericht des zulässigen Rechtswegs den Streit „unter allen in Betracht kommenden rechtlichen Gesichtspunkten“ zu entscheiden. Wird ein

satzanspruch aus der Verletzung öffentlich-rechtlicher Pflichten“ gem. Var. 3; s. Ehlers/Schneider in: Schoch/Schneider/Bier, VwGO, 36. EL Februar 2019, § 40 Rn. 527.

282 Maurer/Waldhoff, Allgemeines Verwaltungsrecht, 19. Aufl. 2017, § 29 Rn. 11.

283 Peine/Siegel, Allgemeines Verwaltungsrecht, 12. Aufl. 2018, § 27 Rn. 987.

284 Erbguth/Guckelberger, Allgemeines Verwaltungsrecht, 9. Aufl. 2018, § 39 Rn. 29.

285 Ehlers/Schneider in: Schoch/Schneider/Bier, VwGO, 36. EL Februar 2019, § 40 Rn. 520 f.

286 Ehlers in: Ehlers/Schoch, Rechtsschutz im Öffentlichen Recht, 2009, § 21 Rn. 109.

287 Grzeszick, in: Ehlers/Pünder, Allgemeines Verwaltungsrecht, 15. Aufl. 2015, § 45 Rn. 36.

288 Vgl. Ossenbühl/Cornils, Staatshaftungsrecht, 6. Aufl. 2013, S. 122.

Jana Himstedt 
Anspruch also auf mehrere materiell-rechtliche Grundlagen gestützt, prüft das zuerst angerufene Gericht diese insgesamt - selbst wenn einzelne von ihnen per se vor einer anderen Gerichtsbarkeit zu verhandeln wären. ${ }^{289}$

Dies kann einerseits dazu führen, dass Zivilgerichte die öffentliche Hand zu Ersatzleistungen verpflichten, deren Rechtsgrundlagen eigentlich im öffentlichen Recht liegen und somit isoliert betrachtet Gegenstand der Verwaltungsgerichtsbarkeit wären. ${ }^{290}$ Umgekehrt können Verwaltungsgerichte etwa auf Grundlage von Vorschriften entscheiden, die an sich der abdrängenden Sonderzuweisung des § 40 II 1 VwGO unterfallen (§ 1731 VwGO i.V.m. § 17 II 1 GVG). ${ }^{291}$

Beispiel: Wird eine Sache zu Unrecht beschlagnahmt, kann der Betroffene seinen Herausgabeanspruch sowohl auf den Folgenbeseitigungsanspruch ( $\rightarrow$ Verwaltungsrechtsweg, \& 40 I 1 $V w G O)$ als auch ein öffentlich-rechtliches Verwahrungsverhältnis ( $\rightarrow$ Zivilgerichtsbarkeit, $\S 40$ II 1 Var. 2 VwGO) stützen. Im Klagefall würde gem. § 17 II 1 GVG dasjenige Gericht, bei welchem der Rechtsstreit zuerst anhängig wird, beide Ansprüche prüfen. ${ }^{292}$

Für die Verwaltungsgerichtsbarkeit gilt hierbei indes die Einschränkung des § 17 II S. 2 GVG. So bleiben ihr Entscheidungen über Amtshaftungsansprüche und die Höhe von Enteignungsentschädigungen infolge der verfassungsrechtlichen Vorschriften in Art. 34 S. 3 und Art. 14 Abs. 3 S. 4 GG entzogen; eine rechtswegübergreifende Entscheidungskompetenz nach § 17 II 1 GVG ist insoweit ausgeschlossen. ${ }^{293}$

\section{dd) Schlussfolgerungen für die verwaltungsrechtliche Klausur}

Für den Verwaltungsrechtsweg verbleiben somit insbesondere

- die Folgenbeseitigungsansprüche;

- öffentlich-rechtliche Erstattungsansprüche und

- Ausgleichsansprüche für Inhalts- und Schrankenbestimmungen nach Art. 14 I S. 2 GG.

Diese sind in der verwaltungsrechtlichen (Examens-)Klausur ohne weiteres zu erwarten und werden im Folgenden ausführlich behandelt. Die übrigen Ansprüche (zu diesen unten § 11) können in öffentlich-rechtlichen Klausuren insbesondere im Wege von Zusatzfragen abgeprüft werden. ${ }^{294}$ Staatshaftungsrechtliche Klausurfälle in zivilprozessualer Einkleidung oder ganz ohne Zulässigkeitsprüfung haben aus Prüfersicht demgegenüber den erheblichen Nachteil, keine

289 Tremml/Karger/Luber, Der Amtshaftungsprozess, 4. Aufl. 2013, Rn. $543 \mathrm{ff}$.

290 BGH, Urt. v. 25.2.1993, Az.: III ZR 9/92 = NJW 1993, 1799.

291 Vgl. Rathmann, in: Saenger, ZPO, 7. Aufl. 2017, § 17 GVG Rn. 2.

292 So etwa bei BGH, Urt. v. 3.2.2005, Az.: III ZR 271/04 = NJW 2005, 988; umgekehrt VG Neustadt (Weinstraße), Beschl. v. 11.11.2013, Az.: 4 K 847/13.NW.

293 Wittschier, in: Musielak/Voit, ZPO, 16. Aufl. 2019, § 17 GVG Rn. 11.

294 Vgl. Ahrens, Staatshaftungsrecht, 3. Aufl. 2018, Rn. 1; beispielhaft Schaks, ZJS 2015, 409. 
Kenntnisse öffentlichen Prozessrechts abfragen zu können. Ganz undenkbar sind derartige Fälle leider dennoch selbst im Examen nich ${ }^{295}$. In der Folge müssen die materiell-rechtlichen Anspruchsgrundlagen im Ergebnis unabhängig vom einschlägigen Rechtsweg beherrscht werden.

\section{ee) Schaubild/Überblick}

168

Gerichtsbarkeit

Anspruchsgrundlage

Typischerweise einschlägiger

Rechtsbehelf

\begin{tabular}{|c|c|c|}
\hline \multirow{6}{*}{$\begin{array}{l}\text { Ordentliche } \\
\text { (§13 GVG) }\end{array}$} & Amtshaftungsanspruch & \multirow[t]{6}{*}{ Leistungsklage (ZPO) } \\
\hline & $\begin{array}{l}\text { Unionsrechtlicher Staats- } \\
\text { haftungsanspruch }\end{array}$ & \\
\hline & Enteignungsentschädigung & \\
\hline & $\begin{array}{l}\text { Enteignender und enteig- } \\
\text { nungsgleicher Eingriff }\end{array}$ & \\
\hline & Aufopferungsansprüche & \\
\hline & $\begin{array}{l}\text { Verwaltungsrechtliches } \\
\text { Schuldverhältnis } \\
\text { Ausnahme: öffentlich-rechtli- } \\
\text { cher Vertrag (s. § } 40 \text { II } 1 \text { VwG0) }\end{array}$ & \\
\hline \multirow[t]{3}{*}{$\begin{array}{l}\text { Verwaltungsgerichtsbarkeit } \\
(\S 40 \text { I } 1 \text { VwG0) }\end{array}$} & $\begin{array}{l}\text { Erstattungsanspruch aus } \S 49 a \\
\text { I VwVfG } \\
\text { allgemeiner öffentlich-recht- } \\
\text { licher Erstattungsanspruch }\end{array}$ & \multirow[t]{2}{*}{$\begin{array}{l}\text { Allgemeine Leistungsklage (vgl. } \\
\S \S 43 \text { II 1, } 1111,113 \text { Abs. } 4 \\
\text { VwG0) }\end{array}$} \\
\hline & $\begin{array}{l}\text { Ausgleichsansprüche für } \\
\text { Inhalts- und Schrankenbestim- } \\
\text { mungen }\end{array}$ & \\
\hline & $\begin{array}{l}\text { Allgemeiner Folgenbeseiti- } \\
\text { gungsanspruch }\end{array}$ & $\begin{array}{l}\text { s.o.; bei Vollzugsfolgen-FBA } \\
\S 113 \text { । S. } 2,3 \text { VwGO beachten }\end{array}$ \\
\hline
\end{tabular}

\section{Der Folgenbeseitigungsanspruch}

169 Der Folgenbeseitigungsanspruch bildet die sekundärrechtliche Dimension (auch) des öffentlich-rechtlichen Abwehr- und Unterlassungsanspruchs: Konnte

295 Vgl. Heinze, Systematisches Fallrepetitorium Besonderes Verwaltungsrecht, S. 123ff. und die unter BayVbl 1989, 669 veröffentlichte bayerische Staatsexamensklausur. 
das streitige Verwaltungshandeln nicht ex ante mittels Unterlassungsklage ${ }^{296}$ abgewehrt werden, muss dem Beeinträchtigten zumindest ein Anspruch auf Beseitigung des hieraus resultierenden rechtswidrigen Zustands zustehen. ${ }^{297}$ Dementsprechend kann hinsichtlich der rechtlichen Grundlagen des allgemeinen Folgenbeseitigungsanspruchs auf die obigen Ausführungen zum öffentlichrechtlichen Abwehr- und Unterlassungsanspruch (Rn. 143) verwiesen werden.

Auch der Folgenbeseitigungsanspruch ist vor den Verwaltungsgerichten re- 170 gelmäßig im Wege der allgemeinen Leistungsklage geltend $\mathrm{zu}$ machen. ${ }^{298}$

Examenswissen: Ausnahmsweise kann die Folgenbeseitigung auch den Erlass eines Verwaltungsakts erfordern mit der Folge, dass die Verpflichtungsklage statthaft ist. Im klassischen Beispiel der Wohnungseinweisung Obdachloser etwa (s. unten Rn. 174) muss der Hoheitsträger zunächst eine Anordnung an die Bewohner erlassen, die Wohnung zu räumen. ${ }^{299}$ Denn erst auf dieser Grundlage könnte eine zwangsweise Räumung im Wege des Verwaltungsvollstreckungsrechts erfolgen. ${ }^{300}$

Prozessuale Besonderheiten gelten für den Vollzugsfolgenbeseitigungsanspruch (dazu 172 $\S 2$ Rn. 1387).

\section{a) Anspruchsziel: Herstellung des „status quo ante in natura“}

Ziel des Folgenbeseitigungsanspruchs ist die Wiederherstellung desjenigen Zu- 173 stands, der ursprünglich vor Eintritt der rechtswidrigen Eingriffsfolgen bestand (status quo ante $\left.{ }^{301}\right) .{ }^{302}$ Er soll folglich der „Unrechtslast“303 des Bürgers abhelfen. Der Anspruch gewährt hingegen keine Naturalrestitution und grundsätzlich keine monetäre Entschädigung. ${ }^{304}$ Naturalrestitution nämlich zielt auf die Herstellung eines hypothetischen Zustands ab, der - aktuell - bestünde, wenn der Haftungstatbestand nie eingetreten wäre ${ }^{305}$ und unterscheidet sich somit grund-

\footnotetext{
296 Im Falle eines Verwaltungsakts aber natürlich vor allem mithilfe der Anfechtungsklage.

297 Vgl. Ellerbrok, Jura 2016, 125 (128).

298 Sodan/Ziekow, Grundkurs Öffentliches Recht, 8. Aufl. 2018, § 89 Rn. 11.

299 Vgl. Ipsen, Allgemeines Verwaltungsrecht, 11. Aufl. 2019, § 22 Rn. 1360.

300 Zum Vorgehen der Polizei- und Ordnungsbehörden in solchen Fällen etwa Lindner in: Möstl/ Schwabenbauer, Beck’scher Onlinekommentar Polizei- und Sicherheitsrecht Bayern, 9. Ed. 2019, Art. 9 LStVG Rn. 47.4.

301 Mehde, Jura 2017, 783 (786f.).

302 Maurer/Waldhoff, Allgemeines Verwaltungsrecht, 19. Aufl. 2017, § 30 Rn. 13.

303 Vgl. Hartmann, Öffentliches Haftungsrecht, 2013, S. 76.

304 Sodan/Ziekow, Grundkurs Öffentliches Recht, 8. Aufl. 2018, § 89 Rn. 7.

305 Mehde, Jura 2017, 783 (785).
} 
legend vom hier maßgeblichen status quo ante, der zwar einen vergangenen, aber realen Zustand beschreibt. ${ }^{306}$

174 Eine besondere Form des Folgenbeseitigungsanspruchs stellt der Vollzugsfolgenbeseitigungsanspruch dar. Dieser liegt vor, wenn der rechtswidrige $\mathrm{Zu}$ stand durch den Vollzug eines rechtswidrigen Verwaltungsakts entstanden ist. ${ }^{307}$ Im Hinblick auf die Anspruchsvoraussetzungen gelten keine Besonderheiten gegenüber dem allgemeinen Folgenbeseitigungsanspruch; lediglich bei seiner gerichtlichen Durchsetzung ist die Spezialvorschrift des § 113 I S. 2, 3 VwGO zu beachten.

Das klassische Beispiel des Vollzugsfolgenbeseitigungsanspruchs bildet die Wohnungseinweisung Obdachloser: In der Wohnungsnot der Nachkriegszeit weist die Stadt S eine obdachlose Familie vorübergehend in die gerade unvermietete Wohnung des K ein. Nach Ablauf des Einweisungszeitraums verweigert die Familie jedoch den Auszug, sodass $K$ sich an die verursachende Stadt wendet und von dieser Wiederherstellung des ursprünglichen (unbewohnten) Zustands verlangt. ${ }^{308}$

175 Ein aktuelles Pendant dieser Fallgruppe stellen hoheitlich angeordnete Flüchtlingsunterbringungen in private Immobilien dar. ${ }^{309}$

\section{b) Anspruchsvoraussetzungen}

176 Auch der Tatbestand des Folgenbeseitigungsanspruchs ähnelt dem des öffentlichrechtlichen Unterlassungsanspruchs. Einige Besonderheiten gilt es gleichwohl zu beachten.

\section{aa) Keine spezialgesetzliche Regelung}

177 Zunächst kommt der allgemeine (Vollzugs-)Folgenbeseitigungsanspruch nur dann zum Tragen, wenn es an einer spezialgesetzlichen Regelung der Folgenbeseitigung fehlt. $\mathrm{Zu}$ beachten sind insoweit z. B. polizeirechtliche Regelungen zur Herausgabe einer beschlagnahmten Sache nach Wegfall des Sicherstellungsgrundes (in Berlin: § 41 I 1 ASOG) oder der Anspruch auf Löschung personenbezogener Daten nach $\S 17$ DSGVO. ${ }^{310}$

306 Baldus/Grzeszick/Wienhues, Staatshaftungsrecht, 5. Aufl. 2018, Rn. 21.

307 Mehde, Jura 2017, 783 (784).

308 Nach BGH, Urt. v. 13.7.1995, Az.: III ZR 160/94 = NJW 1995, 2918.

309 Übungsfall bei Daiber, JA 2016, 760.

310 Peine/Siegel, Allgemeines Verwaltungsrecht, 12. Aufl. 2018, § 25 Rn. 899.

Jana Himstedt 


\section{bb) Hoheitlicher Eingriff in ein subjektives Recht}

Auch insoweit gilt das zum Abwehr- und Unterlassungsanspruch (Rn. 145f.) Ge- 178 sagte entsprechend.

$\mathrm{Zu}$ bemerken ist indes, dass das BVerwG in seiner neueren Rechtsprechung gesetzesförmiges Handeln der Legislative - sprich: verfassungswidrige Gesetze - wie auch dessen vorschriftsgemäßen Vollzug durch die Exekutive explizit vom Anwendungsbereich des Folgenbeseitigungsanspruchs ausnimmt. ${ }^{311}$ Zur Begründung führt das Gericht an, dass die Gewährung derartiger Ausgleichsansprüche dem Gesetzgeber selbst vorbehalten blieben müsse. Die Literatur verweist demgegenüber auf die grundrechtlichen wie rechtstaatlichen Wurzeln des Folgenbeseitigungsanspruchs und die hieraus resultierende verfassungsrechtliche Pflicht aller Staatsgewalten, die rechtswidrigen Folgen ihres hoheitlichen Handelns rückgängig zu machen. ${ }^{312}$

\section{cc) Andauernder rechtswidriger Zustand}

Als zentrales Merkmal des Folgenbeseitigungsanspruchs ist sodann das Vorlie- 179 gen eines andauernden rechtswidrigen Zustands zu prüfen. Nur soweit die vom Kläger gerügten tatsächlichen Umstände mit der Rechtsordnung unvereinbar sind, liegt die oben angesprochene Unrechtslast vor. Die Rechtswidrigkeit des vorangegangenen hoheitlichen Eingriffs ist dabei irrelevant; auch ein ursprünglich rechtmäßiger Eingriff kann rechtswidrige Folgen herbeiführen. ${ }^{313}$

Beispiel: In unserem obigen Beispiel (Rn. 174) erfolgte die Wohnungseinweisung der obdachlosen Familie ursprünglich rechtmäßig. Die befristete Verfügung verlor jedoch durch Zeitablauf ihre Legalisierungswirkung, sodass der aus ihr resultierende Zustand (tatsächliche Sachherrschaft der Familie über die Wohnung) nunmehr rechtswidrig ist.

Die sog. Legalisierungswirkung des Verwaltungsakts ${ }^{314}$ - ein tatsächlicher 180 Zustand entspricht dem Inhalt eines rechtswidrigen, aber wirksamen Verwaltungsakts und ist deshalb als rechtmäßig anzusehen - gilt es vor allem nach Eintritt der formellen Bestandskraft zu beachten. Bestehen gegen einen rechtswidrigen Verwaltungsakt wegen Ablaufs der Widerspruchs- und Klagefrist keine

311 BVerwG, Urt. v. 11.10.2016, Az.: 2 C 11/15 = NVwZ 2017, 481 (484).

312 So Detterbeck, NVwZ 2019, 97 (99f.).

313 Kratzlmeier, Jura 2018, 1239 (1240); Baldus/Grzeszick/Wienhues, Staatshaftungsrecht, 5. Aufl. 2018, Rn. 53.

314 Zum Begriff Ruffert in: Ehlers/Pünder, Allgemeines Verwaltungsrecht, 15. Aufl. 2015, § 22 Rn. 20; Mehde, Jura 2017, 783 (786). 
Rechtsbehelfe mehr, kann auch keine Beseitigung seiner Folgen im Wege des Vollzugsfolgenbeseitigungsanspruchs verlangt werden. Andernfalls würde die gesetzlich angeordnete Bestandskraft von Verwaltungsakten umgangen. ${ }^{315}$ Dieser Anspruchsausschluss ist letztlich eine Ausprägung des Grundsatzes „Primär- vor Sekundärrechtsschutz“.316

181 Der rechtswidrige Zustand dauert an, wenn er im Zeitpunkt der letzten mündlichen Verhandlung vor Gericht fortbesteht. ${ }^{317}$

\section{dd) Unmittelbarkeit der Eingriffsfolgen (Zurechnungszusammenhang)}

182 Der Anspruch setzt außerdem voraus, dass der zu beseitigende Zustand unmittelbare Folge des hoheitlichen Eingriffs ist, d.h. in einem hinreichenden Zurechnungszusammenhang mit diesem steht. ${ }^{318}$ Für diese Beurteilung bedarf es einer wertenden Betrachtung des Sachverhalts unter Heranziehung der Adäquanztheorie. ${ }^{319}$ Probleme können sich dabei insbesondere aus dazwischentretenden Handlungen privater Dritter ergeben. ${ }^{320}$

Beispiel: Die in die Wohnung des K eingewiesene Familie (s. Rn. 174) verbleibt nicht nur über die behördliche Anordnung hinaus in der Wohnung, sondern hat überdies größere Schäden an der Einbauküche verursacht. ${ }^{321}$

In derartigen Fällen kann eine Risikozurechnung zum Staat jedenfalls bei von diesem intendiertem und objektiv vorhersehbarem, also typischem Folgeverhalten des/r Dritten, welches der Hoheitsträger mindestens billigend in Kauf genommen hat, erfolgen. ${ }^{322}$ Nicht vorhersehen muss der veranlassende Hoheitsträger dabei insbesondere rechtswidrige Verhaltensweisen des privaten Dritten. ${ }^{323}$

Beispiel: Da die Beschädigung der Küche im obigen Beispiel nicht nur kein sozialadäquates und -typisches Verhalten der Nutzer darstellt, sondern eine rechtmäßige Wohnnutzung zudem überschreitet, kann A keine Reparatur der Küche auf Grundlage des Folgenbeseitigungsanspruchs verlangen.

315 Zum Ganzen Baldus/Grzeszick/Wienhues, Staatshaftungsrecht, 5. Aufl. 2018, Rn. 55.

316 Kratzlmeier, Jura 2018, 1239 (1248).

317 Pietzko, Der materiell-rechtliche Folgenbeseitigungsanspruch, 1994, S. 303.

318 Ellerbrok, Jura 2016, 125; Daiber, JA 2016, 760 (762).

319 Eingehend Ellerbrok, Jura 2016, 125 (128ff.).

320 Kaiser/Köster/Seegmüller, Materielles Öffentliches Recht im Assessorexamen, 4. Aufl. 2018, Rn. 58.

321 Vgl. Maurer/Waldhoff, Allgemeines Verwaltungsrecht, 19. Aufl. 2017, § 30 Rn. 18.

322 Ellerbrok, Jura 2016, 125 (131f.).

323 Ellerbrok, Jura 2016, 125 (132).

Jana Himstedt 


\section{ee) Kein Ausschluss/Umwandlung in den „Folgenentschädigungsanspruch“}

Doch selbst bei Vorliegen der vorbenannten Voraussetzungen ist der Folgenbeseitigungsanspruch in folgenden Fällen ausgeschlossen:

Die Folgenbeseitigung ist

1. rechtlich unzulässig,

2. tatsächlich unmöglich oder

3. dem Verwaltungsträger unzumutbar. ${ }^{324}$

Unzumutbarkeit liegt vor, wenn die Wiederherstellung des status quo ante mit $\mathbf{1 8 4}$ unverhältnismäßig hohem Aufwand verbunden wäre, welcher „,zu dem erreichbaren Erfolg in keinem vernünftigen Verhältnis [stünde]“.325

Folge dieses Ausschlusses ist nach wohl überwiegender Auffassung ${ }^{326}$ aller185 dings nicht, dass der Kläger anspruchslos gestellt wird, sondern vielmehr die Umwandlung des Folgenbeseitigungsanspruchs in einen sog. Folgenentschädigungsanspruch. Hierfür lässt sich insbesondere der Rechtsgedanke des § 251 II 1 BGB anführen. ${ }^{327}$ Dieser modifizierte Anspruch ist dann anders als der Folgenbeseitigungsanspruch auf eine Entschädigung des Anspruchstellers in Geld gerichtet. $^{328}$

\section{c) Exkurs: Die Folgenbeseitigungslast}

Als spezifische Rechtsfolge des Folgenbeseitigungsanspruchs kann beim an- 186 spruchsverpflichteten Hoheitsträger eine sog. Folgenbeseitigungslast entstehen. ${ }^{329}$ Insbesondere kann etwaiges Ermessen der Behörde im Verhältnis zum Anspruchsberechtigten durch das rechtswidrige Vorverhalten des Staates auf Null reduziert sein.

Beispiel: Für die von A begehrte „Exmittierungsverfügung“ an die Familie (s. Rn. 174) steht der Behörde die polizeiliche Generalklausel (s. zu den polizeilichen Generalklauseln § 2 Rn. 1052ff.) zur Verfügung. Diese räumt dem Hoheitsträger aber grundsätzlich Ermessen darüber ein, ob er

324 Peine/Siegel, Allgemeines Verwaltungsrecht, 12. Aufl. 2018, § 25 Rn. 904.

325 BVerwG, Beschl. v. 12.7.2004, Az.: 7 B 86/04 = NVwZ 2004, 1511.

326 Erbguth/Guckelberger, Allgemeines Verwaltungsrecht, 9. Aufl. 2018, § 41 Rn. 10; Maurer/ Waldhoff, Allgemeines Verwaltungsrecht, 19. Aufl. 2017, § 30 Rn. 18; Peine/ Siegel, Allgemeines Verwaltungsrecht, 12. Aufl. 2018, § 25 Rn. 904; Baldus/ Grzeszick/Wienhues, Staatshaftungsrecht, 5. Aufl. 2018, Rn. 64; Mehde, Jura 2017, 783 (789).

327 Maurer/Waldhoff, Allgemeines Verwaltungsrecht, 19. Aufl. 2017, § 30 Rn. 18.

328 Baldus/Grzeszick/Wienhues, Staatshaftungsrecht, 5. Aufl. 2018, Rn. $266 \mathrm{f}$.

329 Eingehend Blanke/Peilert, Die Verwaltung 31 (1998), 29. 
im Einzelfall tätig wird (vgl. Opportunitätsprinzip). Damit die Norm in Dreieckskonstellationen einen Anspruch auf polizeiliches Einschreiten gewährt, bedarf es daher einer Ermessensreduzierung „auf Null“. Diese ergibt sich hier daraus, dass der Verwaltungsträger den rechtswidrigen Zustand selbst geschaffen hat und daher ein Folgenbeseitigungsanspruch gegen ihn besteht (= Folgenbeseitigungslast) ${ }^{330}$

Die Folgenbeseitigungslast entsteht unabhängig von etwaigen Ausschlussgründen für den Folgenbeseitigungsanspruch, ${ }^{331}$ also sobald die oben unter aa) - dd) genannten Voraussetzungen erfüllt sind.

\section{d) Abschließender Überblick: Der Folgenbeseitigungsanspruch}

187 Grundlage: §§ 12, 906, 1004 BGB analog oder Verfassungsrecht (Grundrechte, Rechtsstaatsprinzip), jedenfalls gewohnheitsrechtlich anerkannt.

\section{Voraussetzungen:}

1. Eingriff in ein subjektives öffentliches Recht des Klägers

2. Hoheitlichkeit des Eingriffs

3. Andauernder rechtswidriger Zustand

4. Unmittelbarkeit der Eingriffsfolgen/Zurechnungszusammenhang

5. Kein Ausschluss

Rechtsfolge: Anspruch auf Wiederherstellung des „status quo ante in natura“; bei Anspruchsausschluss „Umwandlung“ des Folgenbeseitigungs- in den Folgenentschädigungsanspruch (= Geldentschädigung)

\section{e) Literaturhinweise}

188 Ausbildungsaufsätze: Mehde, Der Folgenbeseitigungsanspruch, Jura 2017, 783; Voßkuhle/Kaiser, Grundwissen - Öffentliches Recht: Der Folgenbeseitigungsanspruch, JuS 2012, 1079; vertiefend Ellerbrok, Die Grenzen der Zurechnung im Rahmen des Folgenbeseitigungsanspruchs, Jura 2016, 125 und Detterbeck, Folgenbeseitigungs- und polizeirechtlicher Ausgleichsanspruch beim Vollzug rechtswidriger Gesetze, NVwZ 2019, 97.

330 Vgl. BGH, Urt. v. 13.7.1995, Az.: III ZR 160/94 = NJW 1995, 2918 (2919).

331 Uerpmann-Wittzack, Examens-Repetitorium Allgemeines Verwaltungsrecht mit Verwaltungsprozessrecht, 5. Aufl. 2018, § 23 Rn. 414. 
Übungsklausuren und -hausarbeiten: Daiber, Flüchtlingsunterbringung, JA 2016, 760; Schwarz/Wendel, Hausarbeit: Bürgermeisterin bekennt Farbe - Behördlicher Aufruf zum Versammlungsboykott, ZJS 2017, 328

\section{Der allgemeine öffentlich-rechtliche Erstattungsanspruch}

Erstattungsansprüche richten sich im Gegensatz zu Folgenbeseitigungs- und

Entschädigungsansprüchen nicht auf die Beseitigung oder Kompensation eines „Minus“ - also einer Einbuße an Rechtsgütern - beim Anspruchsteller, sondern auf die Abschöpfung eines „Plus“ beim Anspruchsgegner. ${ }^{332}$ Ihnen kommt mithin die Funktion zu, rechtsgrundlose Vermögensverschiebungen rückabzuwickeln $^{333}$, womit sie das öffentlich-rechtliche Pendant zu den Bereicherungsansprüchen nach $\S \S 812 \mathrm{ff}$. BGB bilden. ${ }^{334}$

\section{a) Die Rückabwicklung rechtswidriger Vermögenslagen im öffentlichen Recht}

Das öffentliche Recht hält hierzu vor allem den sog. allgemeinen öffentlich- 190 rechtlichen Erstattungsanspruch bereit. Auch dieser wird regelmäßig mittels der allgemeinen Leistungsklage durchgesetzt. ${ }^{335}$ Dies gilt weitgehend uneingeschränkt für Ansprüche des Bürgers gegen den Staat und zwischen Hoheitsträgern untereinander. Erstattungsansprüche des Staates gegen den Bürger können jedoch nur dann im Wege der ,behördlichen“ Leistungsklage geltend gemacht werden, wenn der Verwaltung keine Verwaltungsaktbefugnis zusteht (zu dieser unten Rn. 209); andernfalls fehlt es der Klage am allgemeinen Rechtsschutzbedürfnis. ${ }^{336}$

Die Rechtsgrundlagen des allgemeinen öffentlich-rechtlichen Erstattungsanspruchs werden teils in einer Analogie zu den $\S \S 812 \mathrm{ff}$. BGB gesehen; ${ }^{337}$ überwiegend aber wird der Anspruch als eigenständiges öffentlich-rechtliches Institut anerkannt, das im Grundsatz der Gesetzmäßigkeit der Verwaltung wurzelt ${ }^{338}$ oder

332 Kratzlmeier, Jura 2018, 1239 (1242).

333 Sodan/Ziekow, Grundkurs Öffentliches Recht, 8. Aufl. 2018, § 90 Rn. 9.

334 Peine/Siegel, Allgemeines Verwaltungsrecht, 12. Aufl. 2018, § 26 Rn. 914.

335 Sodan/Ziekow, Grundkurs Öffentliches Recht, 8. Aufl. 2018, § 90 Rn. 15.

336 Hartwig/Himstedt/Eisentraut, DÖV 2018, 901 (908f.).

337 VGH München, Beschl. v. 7.11.2016, Az.: 4 ZB 15.2809 = BayVBl 2017, 276 (277).

338 BVerwG, Urt. v. 30.6.2016, Az.: 5 C 1/15 = BVerwGE 155, 357 (359); OVG Berlin-Brandenburg, Urt. v. 13.9.2016, Az.: OVG 6 B 87.15 = NJW 2017, 421 (423). 
jedenfalls gewohnheitsrechtlich anerkannt ist ${ }^{339}$. Da über Existenz und Voraussetzungen des Anspruchs jedoch Einigkeit besteht, bedarf dieser Streit in der verwaltungsrechtlichen Klausur keiner Entscheidung.

Vorrangig sind allerdings stets die gesetzlich kodifizierten Ausprägungen des Erstattungsanspruchs zu prüfen. Dazu zählt insbesondere § 49a I VwVfG, der die Erstattung solcher Leistungen regelt, deren Rechtsgrundlage ein nunmehr zurückgenommener, widerrufener oder infolge einer auflösenden Bedingung unwirksam gewordener Verwaltungsakt dargestellt hat (dazu sogleich Rn. 192ff.) Auch bestimmte Vorschriften des Beamtenrechts (§§ 12 II BBesG, 52 II BeamtVG, 84a BBG) und im Recht der Ausbildungsförderung (§ 20 BAföG) regeln die Rückabwicklung rechtsgrundlos erbrachter Leistungen bereits speziell. ${ }^{340}$ In diesen Fällen ist der allgemeine Erstattungsanspruch als lex generalis nicht anwendbar.

\section{b) Exkurs: § 49a I VwVfG}

192 Von besonderer Bedeutung für die Rückabwicklung fehlgeschlagener Subventionen $^{341}$ - und damit eine beliebte Klausurkonstellation - ist die Rückforderungsvorschrift des § 49a I VwVfG (s. dazu bereits § 2 Rn. 989f.). Grundsätzlich enthalten alle Landes-VwVfG entsprechende Regelungen oder dynamische Verweisungen in das Bundesrecht; Abweichungen finden sich lediglich im Hinblick auf Einzelheiten. ${ }^{342}$

\section{aa) Anspruchsvoraussetzungen}

193 Der Tatbestand des § 49 I 1 VwVfG setzt voraus:

1. Eine „bereits erbrachte Leistung“

2. auf Grundlage eines Verwaltungsakts

3. Rücknahme, Widerruf oder Unwirksamkeit infolge einer auflösenden Bedingung

4. mit Wirkung für die Vergangenheit (ex tunc).

339 OVG Münster, Urt. v. 16. 2. 2016, Az.: 15 A 1035/14 = NVwZ-RR 2016, 554 (LS). Eine Kombination beider Ansätze verwendet das BSG, s. Urt. v. 3.4.2014, Az.: B 2 U 21/12 R = BSGE 115, 247 (252). 340 Baldus/Grzeszick/Wienhues, Staatshaftungsrecht, 5. Aufl. 2018 Rn. 527.

341 Vgl. Korte, Jura 2017, 656 (663f.); Ebeling/Tellenbröker, JuS 2014, 217 (221f.).

342 So gilt in Bayern und Thüringen ein abweichender Zinssatz von 3\% bzw. 6\%, s. Art. 49a Abs. 3 S. 1 BayVwVfG, § 49a Abs. 3 S. 1 ThürVwVfG; in MV gilt kein Ermessen im Rahmen der Entscheidung über die Zinsfestsetzung, § 49a Abs. 3 S. 2 VwVfG M-V. 
Vorgeschlagen wird teils eine analoge Anwendung der Vorschrift auf Aufhe- 194 bungen mit ex-nunc-Wirkung. ${ }^{343} \mathrm{Zu}$ beachten ist, dass der Verwaltungsakt in diesen Fällen bis zum wirksamen Zugang des Widerrufs als Rechtsgrund für die Leistung dient. ${ }^{344}$ Eine Erstattung ist daher überhaupt nur nötig und zulässig, sofern die Behörde - versehentlich oder durch Verzögerungen im Verwaltungsablauf - auch nach dem wirksamen Widerruf weiterhin an den Begünstigten leistet. Gegen die vorgeschlagene Analogie spricht indes nicht nur der eindeutige Wortlaut der Vorschrift, sondern auch ihre Entstehungsgeschichte. ${ }^{345}$ Zudem fehlt es infolge der gewohnheitsrechtlichen Anerkennung des allgemeinen öffentlich-rechtlichen Erstattungsanspruchs an der erforderlichen planwidrigen Regelungslücke. ${ }^{346}$ Auf letzteren ist daher bei Aufhebungen mit Wirkung für die Zukunft zurückzugreifen. ${ }^{347}$

\section{bb) Anspruchsumfang und Ausschlussgründe}

Hinsichtlich des Leistungsumfangs enthält § 49a II 1 VwVfG einen Rechtsfolgenverweis auf die $\S \S 818,819$ BGB. In der Folge kann sich der Begünstigte grundsätzlich auf einen Wegfall der Bereicherung berufen. Allerdings ist der Entreicherungseinwand - strenger als im Zivilrecht - bereits bei grob fahrlässiger Unkenntnis vom Aufhebungsgrund ausgeschlossen (s. § 49a II 2 VwVfG). ${ }^{348}$

Modifikationen gelten insbesondere in Fällen unionsrechtswidrig bewil- 196 ligter Beihilfen. ${ }^{349}$ Infolge des effet utile ist der Entreicherungseinwand nach §49a II 2 VwVfG hier ausgeschlossen, soweit die Kommission die formelle und materielle Unionsrechtswidrigkeit der Beihilfe (insbesondere einen Verstoß gegen Art. 107, 108 AEUV) festgestellt hat ( $\rightarrow$ Alcan-Rechtsprechung des $\left.\mathrm{EuGH}^{350}\right) .{ }^{351}$ Dies gilt unabhängig davon, ob der Begünstigte seine Unkenntnis vom Aufhebungsgrund (grob fahrlässig) verschuldet hat. Eine andere Bewertung dieser Fälle kommt auch im Hinblick auf die Grundsätze nach Treu und Glauben nicht in Betracht. ${ }^{352}$

343 Sachs in: Stelkens/Bonk/Sachs, VwVfG, 9. Aufl. 2018, § 49a Rn. 16, 19.

344 Peine/Siegel, Allgemeines Verwaltungsrecht, 12. Aufl. 2018, § 26 Rn. 919.

345 Folnovic/Hellriegel, NVwZ 2016, 638 (642f.).

346 Peine/Siegel, Allgemeines Verwaltungsrecht, 12. Aufl. 2018, § 26 Rn. 917.

347 Kastner in: Fehling/Kastner/Störmer, VwVfG, 4. Aufl. 2016, § 49a Rn. 2.

348 Maurer/Waldhoff, Allgemeines Verwaltungsrecht, 19. Aufl. 2017, § 29 Rn. 35.

349 Übungsfall bei Hesse/Sacher, Jus 2017, 1015.

350 EuGH, Urt. v. 20.3.1997, Az.: C-24/95 = NJW 1998, 47.

351 Ausführlich Ruthig/Storr, Öffentliches Wirtschaftsrecht, 4. Aufl. 2015, § 9 Rn. 978 ff.

352 Gurlit in: Ehlers/Pünder, Allgemeines Verwaltungsrecht, 15. Aufl. 2016, § 35 Rn. 30. 
§ 814 BGB gilt hingegen im Rahmen des § 49a I VwVfG nicht. ${ }^{353}$ Denn die Vorschrift schließt die Leistung schon dem Grunde nach aus ${ }^{354}$ und wird von der Rechtsfolgenverweisung des § 49a II 1 VwVfG somit nicht erfasst. ${ }^{355}$

Der Anspruch verjährt in analoger Anwendung des § 195 BGB innerhalb von drei Jahren. ${ }^{356}$

\section{cc) Rechtsfolge: Zwingende Festsetzung durch schriftlichen Verwaltungsakt (§ 49a I S. 2 VwVfG)}

199 Bei Vorliegen der o. g. Voraussetzungen entsteht der Erstattungsanspruch ipso iure; der Behörde kommt bei der Festsetzung der Forderung per schriftlichem Verwaltungsakt kein Entschließungsermessen $\mathrm{zu}^{3{ }^{357}}$ Selbst besondere Härten (z. B. eine drohende Insolvenz des Leistungsempfängers) können dem Erlass eines Rückforderungsbescheids damit nicht entgegengehalten werden. ${ }^{358}$ Haushaltsrechtliche Mittel wie etwa eine Stundung der Leistung bleiben jedoch zulässig. ${ }^{359}$

\section{c) Der allgemeine öffentlich-rechtliche Erstattungsanspruch}

200 Greift der Anspruch aus § 49a I S. 2 VwVfG nicht durch, ist insbesondere auf den allgemeinen öffentlich-rechtlichen Erstattungsanspruch abzustellen.

\section{aa) Mögliche Anspruchsteller}

201 Dieser wird oftmals vom Staat gegen einen Bürger geltend gemacht, dem unrechtmäßig öffentliche Mittel zugewandt worden sind. ${ }^{360}$ Möglich ist jedoch auch ein Anspruch des Bürgers gegen den Staat ${ }^{361}$ oder zwischen zwei Hoheitsträgern untereinander. ${ }^{362}$

353 Kaiser/Köster/Seegmüller, Materielles Öffentliches Recht im Assessorexamen, 4. Aufl. 2018, Rn. 67.

354 BVerwG, Urt. v. 22.3.2017, Az.: 5 C 5/16 = NJW 2018, 568 (570).

355 Ramsauer in: Kopp/Ramsauer, VwVfG, 19. Aufl. 2018, § 49a Rn. 12.

356 BVerwG, Urt. v. 15.3.2017, Az.: 10 C 3/16 = NVwZ 2017, 969 (971); zustimmend Hebeler, JA 2018, 159 (169).

357 Sachs in: Stelkens/Bonk/Sachs, VwVfG, 9. Aufl. 2018, § 49a Rn. 26, 37.

358 Falkenbach in: Bader/Ronellenfitsch, VwVfG, 43. Ed., Stand: 1.4.2019, § 49a Rn. 23.

359 OVG Magedeburg, Beschl.v. 19.5.2015, Az.: 3 L 207/13, juris Rn. 17; Sachs in: Stelkens/Bonk/ Sachs, VwVfG, 9. Aufl. 2018, § 49a Rn. 37.

360 Baldus/Grzeszick/Wienhues, Staatshaftungsrecht, 5. Aufl. 2018 Rn. 524.

361 z. B. OVG Lüneburg, Urt. v. 18. 2. 2016, Az.: 1 LC 28/12 = DVBl 2016, 983 - Erstattungsanspruch wegen Nichtigkeit eines städtebaulichen (Folgekosten-)Vertrags; OVG Berlin-Brandenburg, Urt. v. 


\section{bb) Anspruchsvoraussetzungen}

Der Anspruch besteht dann, wenn im Rahmen einer öffentlich-rechtlichen 202 Rechtsbeziehung eine rechtsgrundlose Vermögensverschiebung stattgefunden hat und kein Anspruchsausschluss vorliegt.

\section{(1) Vermögensverschiebung}

Zunächst muss ein Vermögenszuwachs beim Anspruchsgegner eingetreten 203 sein, der unmittelbar und gleichsam „spiegelbildlich“ mit einer Vermögensschmälerung beim Anspruchssteller einherging. ${ }^{363}$ Zwischen Leistungs- und sonstigen Kondiktionen muss dabei anders als im Zivilrecht nicht kategorisch unterschieden werden. ${ }^{364}$

\section{(2) In einer öffentlich-rechtlichen Rechtsbeziehung}

Dies muss im Rahmen einer öffentlich-rechtlichen Rechtsbeziehung gesche- 204 hen sein; andernfalls greift unmittelbar das privatrechtliche Kondiktionsrecht der $\S \S 812$ ff. BGB (s. §1 Rn. 184). ${ }^{365}$ Maßgeblich ist hierbei die (auch nur vermeintliche) öffentlich-rechtliche Natur des Rechtsgrundes (sog. Kehrseitentheorie). ${ }^{366}$ Insbesondere bei Zahlungen auf Grundlage eines verwaltungsaktförmigen Bewilligungsbescheids besteht insoweit kein Problem.

Schwieriger kann indes die Zuordnung fehlgeleiteter Zahlungen an Dritte 205 zum öffentlichen Recht sein.

Beispiel: Einen klassischen Problemfall bildet insoweit die Rückforderung von Beihilfeleistungen, die an den Erben eines Beamten ausgezahlt wurden. ${ }^{367}$ Der zahlende Dienstherr steht hier zwar in einer öffentlich-rechtlichen Sonderverbindung zum Beamten selbst, nicht aber zu dessen Erben als tatsächlichem Leistungsempfänger. Aus diesem Grund geht eine Ansicht hier

10.7.2017, Az.: OVG 2 B 7.16 = NVwZ 2018, 271 (LS) - Erstattungsanspruch nach rechtswidriger Heranziehung zu sanierungsrechtlichem Ausgleichsbetrag nach § 154 I S. 1 BauGB.

362 z. B. OVG Lüneburg, Urt. v. 1.12.2016, Az.: 2 LC 260/15 = NdsVBl 2017, 180 - Erstattungsanspruch eines Landes gegen kommunalen Schulträger für Schulbuchkosten.

363 Kaiser/Köster/Seegmüller, Materielles Öffentliches Recht im Assessorexamen, 4. Aufl. 2018, Rn. 64.

364 Baldus/Grzeszick/Wienhues, Staatshaftungsrecht, 5. Aufl. 2018 Rn. 531.

365 Erbguth/Guckelberger, Allgemeines Verwaltungsrecht, 9. Aufl. 2018, § 42 Rn. 3.

366 Peine/Siegel, Allgemeines Verwaltungsrecht, 12. Aufl. 2018, § 26 Rn. 923.

367 Erbguth/Guckelberger, Allgemeines Verwaltungsrecht, 9. Aufl. 2018, § 42 Rn. 3; Aktuelles Beispiel auch bei BGH, Urt. vom 31.1.2018, Az.: VIII ZR 39/17 = NJW 2018, 1079 - Erstattungsanspruch des Jobcenters für an den Vermieter des Leistungsempfängers geleistete Mietzahlungen, wobei der BGH einen zivilrechtlichen Erstattungsanspruch annahm. 
von einer privatrechtlichen Rechtsbeziehung aus. Andererseits erfolgte die Zahlung auf der Grundlage öffentlich-rechtlicher Vorschriften (Beihilfenrecht) und mit einem öffentlichen Leistungszweck, was für eine Einordnung als öffentlich-rechtlich streitet. ${ }^{368}$ Für diese Lösung spricht auch, dass so eine Verhandlung von Leistungs- und Rückforderungsanspruch auf verschiedenen Rechtswegen vermieden wird. ${ }^{369}$

\section{(3) Ohne Rechtsgrund}

206 Ferner muss die Vermögensverschiebung rechtsgrundlos (sine causa) erfolgt sein. ${ }^{370}$ In Betracht kommen insoweit vor allem die anfängliche oder nachträgliche Unwirksamkeit eines Verwaltungsakts (soweit nicht schon ein Fall des § 49a I VwVfG vorliegt) oder eines öffentlich-rechtlichen Vertrags. ${ }^{371}$

\section{cc) Anspruchsumfang und Ausschlussgründe}

207 Der öffentlich-rechtliche Erstattungsanspruch richtet sich grundsätzlich auf eine Herausgabe „des Erlangten“ in natura wie auch zwischenzeitlich gezogener Nutzungen. ${ }^{372}$ Eine differenzierende Betrachtung ist jedoch bei der Frage geboten, ob der Anspruchsgegner sich nach dem Rechtsgedanken des § 818 Abs. 3 BGB auf einen Wegfall der Bereicherung berufen kann. Für den Staat als Schuldner widerspräche dies bereits der Gesetzmäßigkeit der Verwaltung und wird folglich verneint. ${ }^{373}$ Aber auch wenn sich der Erstattungsanspruch gegen einen Bürger richtet, ist der Entreicherungsweinwand nach überwiegender Ansicht ausgeschlossen. ${ }^{374}$ Zwar ließe sich zugunsten eines möglichen Entreicherungseinwands anführen, dass auch die spezialgesetzlich normierten Erstattungsansprüche regelmäßig auf $\S 818$ Abs. 3 BGB verweisen. ${ }^{375}$ Doch gewährt im öffentlichen Recht bereits die erschwerte Aufhebbarkeit begünstigender Verwaltungsakte (vgl. $\S 48$ II, § 49 II, III VwVfG) hinreichenden Vertrauensschutz, soweit die Leistung auf vorheriger Bewilligung durch Verwaltungsakt beruht. ${ }^{376}$ Auch im Übrigen übernimmt das verfassungsrechtlich verankerte Institut des Vertrauensschutzes

368 S. insgesamt Erbguth/Guckelberger, Allgemeines Verwaltungsrecht, 9. Aufl. 2018, § 42 Rn. 3.

369 Kaiser/Köster/Seegmüller, Materielles Öffentliches Recht im Assessorexamen, 4. Aufl. 2018, Rn. 65 m.w. N.

370 Peine/Siegel, Allgemeines Verwaltungsrecht, 12. Aufl. 2018, § 26 Rn. 925.

371 Baldus/Grzeszick/Wienhues, Staatshaftungsrecht, 5. Aufl. 2018 Rn. 535 f.

372 Sodan/Ziekow, Grundkurs Öffentliches Recht, 8. Aufl. 2018, § 90 Rn. 13.

373 Maurer/Waldhoff, Allgemeines Verwaltungsrecht, 19. Aufl. 2017, § 29 Rn. 35.

374 Peine/Siegel, Allgemeines Verwaltungsrecht, 12. Aufl. 2018, § 26 Rn. 926.

375 Baldus/Grzeszick/Wienhues, Staatshaftungsrecht, 5. Aufl. 2018 Rn. 543.

376 Maurer/Waldhoff, Allgemeines Verwaltungsrecht, 19. Aufl. 2017, § 29 Rn. 35.

Jana Himstedt 
im öffentlichen Recht die Funktion des Entreicherungseinwands im Privatrecht; für letzteren bleibt im Rahmen des öffentlich-rechtlichen Erstattungsanspruchs folglich kein Raum. ${ }^{377}$

Der Anspruch verjährt in analoger Anwendung der §§ 195, 199 I BGB innerhalb 208 von drei Jahren. ${ }^{378}$

\section{dd) Durchsetzung mittels Verwaltungsakts (Verwaltungsaktbefugnis)}

Eine Verwaltungsaktbefugnis bei der Durchsetzung des Erstattungsanspruchs 209 bejaht die Rechtsprechung auch ohne spezielle gesetzliche Ermächtigung (wie sie etwa § 49a I 2 VwVfG bereithält), wenn

1. ein öffentlich-rechtliches Subordinationsverhältnis zwischen den Parteien besteht ${ }^{379}$ oder

2. die rückabzuwickelnde Vermögensverschiebung ihrerseits durch Verwaltungsakt festgesetzt wurde (sog. actus-contrarius- oder Kehrseitentheorie). ${ }^{380}$

Anderer Ansicht sind Teile der Literatur, die hier stets eine besondere formellgesetzliche Ermächtigung zu der belastenden Handlungsform des Verwaltungsakts verlangen. ${ }^{381}$

\section{d) Abschließender Überblick: Der allgemeine öffentlich-rechtliche Erstattungsanspruch}

Anspruchsgrundlage: $\S \S 812 \mathrm{ff}$. BGB analog oder Grundsatz der Gesetzmäßigkeit 210 der Verwaltung (Art. 20 Abs. 3 GG), jedenfalls gewohnheitsrechtlich anerkannt

\section{Voraussetzungen:}

1. Vermögensverschiebung

2. In einer öffentlich-rechtlichen Rechtsbeziehung

3. Ohne Rechtsgrund

4. Kein Ausschluss (insbes. Wegfall der Bereicherung)

Rechtsfolge: Anspruch auf Herausgabe des Erlangten „in natura“ einschließlich gezogener Nutzungen

377 Baldus/Grzeszick/Wienhues, Staatshaftungsrecht, 5. Aufl. 2018 Rn. 543.

378 Erbguth/Guckelberger, Allgemeines Verwaltungsrecht, 9. Aufl. 2018, § 42 Rn. 10.

379 Erbguth/Guckelberger, Allgemeines Verwaltungsrecht, 9. Aufl. 2018, § 42 Rn. 11.

380 Hierzu mit praktischem Fall Pünder, JA 2004, 467 (468).

381 So Gurlit in: Ehlers/Pünder, Allgemeines Verwaltungsrecht, 15. Aufl. 2016, § 35 Rn. 32; Peine/ Siegel, Allgemeines Verwaltungsrecht, 12. Aufl. 2018, § 26 Rn. 927. 


\section{e) Literaturhinweise}

211 Ausbildungsaufsätze: Stangl, Der öffentlich-rechtliche Erstattungsanspruch; Korte, Grundlagen des Subventionsrechts, Jura 2017, 656; vertiefend Hebeler, Verjährung öffentlich-rechtlicher Erstattungsansprüche, JA 2018, 159.

Übungsklausuren und -hausarbeiten: Hesse/Sacher, Referendarexamensklausur - Öffentliches Recht: Europarecht und Verwaltungsrecht - Die Beihilfe als blinder Passagier, JuS 2017, 1015; Groh, Der praktische Fall - Die vorläufige Weinhilfe, VR 2005, 349.

\section{Ausgleich für Inhalts- und Schrankenbestimmungen (Art. 14 I S. 2 GG)}

212 Schließlich können mittels verwaltungsgerichtlicher Leistungsklage Streitigkeiten über „das Bestehen und die Höhe eines Ausgleichsanspruchs im Rahmen des Artikels 14 Abs. 1 Satz 2 des Grundgesetzes“ zur Verhandlung gebracht werden. Gemeint ist der finanzielle Ausgleich sog. Inhalts- und Schrankenbestimmungen. ${ }^{382}$

213 Inhalts- und Schrankenbestimmungen (Art. 14 I 2 GG) sind abstrakt-generell formulierte Nutzungsbeschränkungen des Eigentums ${ }^{383}$ und insoweit von Enteignungen (Art. 14 III GG), die auf den Entzug konkreter Eigentumspositionen zum Zwecke der öffentlichen Güterbeschaffung gerichtet sind, ${ }^{384}$ abzugrenzen. Bei der Ausgestaltung derartiger Bestimmungen hat der Gesetzgeber insbesondere den Grundsatz der Verhältnismäßigkeit zu beachten. ${ }^{385}$ Dies kann prinzipiell auch dadurch geschehen, dass er atypische, unzumutbare Härtefälle, die im Einzelfall durch die Regelung eintreten können, durch finanzielle Leistungen kompensiert. ${ }^{386}$

Beispiel: ${ }^{387} \mathrm{~K}$ ist Eigentümer einer forstwirtschaftlich genutzten Grundfläche, die sich innerhalb eines Naturschutzgebiets befindet und einen wesentlichen Teil seiner Lebensgnundlage bildet. Ab 2013 wird in letzterem der Elbebiber ansässig. Dessen Bauten und Dämme führen nach und nach zu Vernässungen der Landschaft, welche die Holzproduktion auf den Flächen des $K$ schließlich gänzlich unmöglich machen. Als $K$ bereits erwägt, die Biberdämme teilweise $z u$ öffnen, um die Überschwemmung zu mindern, erlässt die zuständige Naturschutzbehörde eine

382 Eingehend zur Abgrenzung zwischen Inhalts- und Schrankenbestimmung Jasper, DÖV 2014, 872 (872f.). Da die Rechtsprechung weitgehend auf eine Abgrenzung verzichtet, kann dies auch in der Klausur unterbleiben, zumal beides meist zusammentrifft, s. Kingreen, Jura 2016, 390 (396). 383 Schmidt am Busch/Nischwitz, GewArch 2018, 284 (286).

384 BVerfG, Urt. v. 6.12.2016, Az.: 1 BvR 2821/11, 1 BvR 321/12, 1 BvR 1456/12 = NJW 2017, 217 (224). 385 BVerfG, Urt. v. 6.12.2016, Az.: 1 BvR 2821/11, 1 BvR 321/12, 1 BvR 1456/12 = NJW 2017, 217 (226). 386 Ossenbühl/Cornils, Staatshaftungsrecht, 6. Aufl. 2013, S. $112 \mathrm{f}$.

387 Nach BVerwG, Urt. v. 17.5.2018, Az.: 4 C 2/17 = NVwZ-RR 2018, 722.

Jana Himstedt 
ordnungsbehördliche Verfügung an ihn, die ihn verpflichtet, jegliche Öffnungen, Beseitigungen oder anderweitige Beeinträchtigungen der Biberdämme zu unterlassen. In der Begründung des Bescheides verneint die Behörde auch - zu Recht - Ansprüche des K auf Erteilung einer naturschutzrechtlichen Befreiung von diesem Eingriffsverbot. $K$ möchte nun wenigstens Entschädigung für die Unnutzbarkeit seiner Fläche infolge des geltenden Naturschutzrechts.

\section{a) Anspruchsvoraussetzungen}

In derartigen Fällen kann der unzumutbar betroffene Bürger unter den folgenden 214 Voraussetzungen Zahlungsansprüche geltend machen:

\section{aa) Gesetzliche Ausgleichsregelung}

Zunächst bedarf es einer speziellen formell-gesetzlichen Ausgleichsregelung, 215 welche in der Klausur die Anspruchsgrundlage bildet. Beispiele solcher finden sich insbesondere in $\S 42 \mathrm{BImSchG},{ }^{388} \S 68 \mathrm{I} \mathrm{BNatSchG},{ }^{389} \S 74 \mathrm{II} 3 \mathrm{VwVfG}^{390}$ und vor allem auch den Denkmalschutzgesetzen der Länder. ${ }^{391}$

Ohne eine derartige Norm besteht grundsätzlich kein Ausgleichsanspruch; 216 insbesondere richterrechtlich begründete Entschädigungen sind unzulässig. ${ }^{392}$ Vielmehr muss sich der Betroffene, der die ausgleichslose Inhalts- und Schrankenbestimmung in seinem Fall für unverhältnismäßig hält, gegen diese selbst oder auf ihrer Grundlage ergangene Rechtsakte wenden, anstatt das Sonderopfer monetär zu liquidieren (kein „dulde und liquidiere!“). Insoweit gilt also der Vorrang des Primärrechtsschutzes. Ist auch dieser (ausnahmsweise) nicht möglich, kommt schließlich ein Anspruch des Betroffenen aus enteignungsgleichem Eingriff in Betracht (dazu $\S 11$ Rn. 90 ff.). ${ }^{393}$

Im Beispiel aus Rn. 212 könnte K seinen Anspruch auf § 68 I BNatSchG stützen.

\section{bb) Verfassungsmäßigkeit der Regelung}

Die anspruchsbegründende Norm darf zudem nicht unwirksam, also insbeson- 217 dere nicht verfassungswidrig sein. Hierbei gilt zu beachten, dass das BVerfG für die verfassungsrechtliche Zulässigkeit von Inhalts- und Schrankenbestimmungen besondere Maßstäbe entwickelt hat:

388 Jarass in: Jarass, BImSchG, 12. Aufl. 2017, § 42 Rn. 3.

389 Gellermann in: Landmann/Rohmer, 89. EL Februstar 2019, BNatSchG, § 68 Rn. 4.

390 Krohn, DVBl 2017, 278 (279).

391 Etwa § 16 Denkmalschutzgesetz Berlin.

392 Grzeszick in: Ehlers/Pünder, Allgemeines Verwaltungsrecht, 15. Aufl. 2015, § 45 Rn. 53.

393 Zum Ganzen Baldus/Grzeszick/Wienhues, Staatshaftungsrecht, 5. Aufl. 2018 Rn. $442 f$. 
So darf der finanzielle Ausgleich für eine belastende Maßnahme nur im Ausnahmefall und subsidiär zu Ausnahme-, Befreiungs- und Ausgleichsregelungen in Betracht gezogen werden (Vorrang des Bestandsschutzes vor dem Wertschutz). ${ }^{394}$ Zudem muss die formell-gesetzliche Entschädigungsregelung hinreichend bestimmt sein und verfahrensrechtlich gewährleisten, dass die Behörde gleichzeitig mit dem eigentumsverkürzenden Verwaltungsakt auch über die finanzielle Kompensation zumindest dem Grunde nach mitentscheidet. ${ }^{395}$

218 Examenswissen: Die verfassungsrechtliche Prüfung formeller Gesetze ist eigentlich der Verfassungsgerichtsbarkeit vorbehalten. Die in der verwaltungsrechtlichen Klausur angerufenen Verwaltungsgerichte müssten die Frage nach der Vereinbarkeit mit dem Grundgesetz insofern dem BVerfG vorlegen (Art. 100 I GG). Im Rahmen einer Klausur wird aber regelmäßig ein umfassendes Rechtsgutachten gefordert, sodass auch die Frage der Verfassungsmäßigkeit gesetzlicher Anspruchs- und Eingriffsgrundlagen mit erörtert werden muss. ${ }^{396}$

219 Genügt die Regelung den verfassungsrechtlichen Anforderungen nicht, ist sie rechtswidrig und nach dem rechtsstaatlichen Nichtigkeitsdogma ${ }^{397}$ unwirksam. Der Kläger hat dann keinen Entschädigungsanspruch - jedoch gelten auch die Eigentumsschranken nicht, die mit diesem ausgeglichen werden sollten.

\section{cc) Tatbestand der Ausgleichsregelung}

220 Der dann zu prüfende Tatbestand richtet sich nach der jeweiligen Ausgleichsvorschrift. Er setzt - dem Zweck der finanziellen Kompensation entsprechend oftmals die Unzumutbarkeit der Eigentumsbelastung voraus (so etwa §68 I BNatSchG), dass also die Grenze der Sozialpflichtigkeit derart überschritten wird, dass für den privatnützigen Gebrauch des Eigentums oder eine Verfügung darüber kein Raum mehr bleibt. ${ }^{398}$ Dies ist regelmäßig der Fall, wenn eine bisherige Nutzungsmöglichkeit ausgeschlossen oder wesentlich eingeschränkt wird, die sich nach Lage der Dinge objektiv anbietet oder gar aufdrängt. ${ }^{399}$

Beispiel: Nach diesen Maßstäben kann man eine Unzumutbarkeit im Beispiel aus Rn. 213 bejahen. Zwar steigert die Wertung des Art. 20a GG grundsätzlich das Ausmaß der Sozialbindung des Eigentums für solche Flächen, die für die natürlichen Lebensgrundlagen und die

394 Jarass, NJW 2000, 2841 (2842).

395 S. insgesamt Erbguth/Guckelberger, Allgemeines Verwaltungsrecht, 9. Aufl. 2018, § 39 Rn. 27. 396 So beispielsweise in Falllösungen bei: Eisele/Hyckel, VR 2016, 129 (136f.); Schmidt am Busch/Nischwitz, GewArch 2018, 284 (285).

397 Eingehend Zimmermann, JA 2018, 249.

398 BVerwG, Urt. v. 16.3.2006, Az.: 4 A 1075/04 = NVwZ-Beil. 2006, 1 (37).

399 BVerwG, Urt. v. 15.2.1990, Az.: 4 C 47/89 = NJW 1990, 2572 (2574).

Jana Himstedt 
Tiere von besonderer Bedeutung sind. ${ }^{400}$ Zudem wurde hier keineswegs staatlicherseits die Beschaffenheit des Grundstücks verändert, sondern diese wandelte sich selbständig zum Negativen, was grundsätzlich der natürlichen Situationsgebundenheit von Grundeigentum entspricht. Die Behörde verbietet $K$ lediglich, in diesen status quo einzugreifen (Beseitigung der Biberbauten). Da für K aber ohne einen entsprechenden Eingriff die bisher tatsächlich ausgeübte forstwirtschaftliche Nutzungsmöglichkeit vollständig ausgeschlossen ist, die überdies einen wesentlichen Teil seiner Lebensgrundlage bildet, und auch eine privatwirtschaftliche Veräußerung des Grundstücks wegen der Unnutzbarkeit der Flächen ausscheiden dürfte, ist hier von einer Überschreitung der Grenzen der Sozialpflichtigkeit auszugehen.

\section{b) Anspruchsumfang}

Bei der Angemessenheit der Entschädigungshöhe ist zu berücksichtigen, dass 221 grundsätzlich allein der unzumutbare Teil der Regelung durch den Gesetzgeber kompensiert werden muss, nicht aber die volle Belastung ${ }^{401}$.

\section{c) Literaturhinweise}

Muckel, Eigentumsgarantie: Ausgleichspflichtige Inhalts- und Schrankenbe- 222 stimmung, JA 2012, 314; Kingreen, Die Eigentumsgarantie (Art. 14 GG), Jura 2016, 390.

\section{Die allgemeine Leistungsklage im Polizei- und Ordnungsrecht (Nikolas Eisentraut)}

Die allgemeine Leistungsklage spielt auch im allgemeinen Polizei- und Ord- 223 nungsrecht (s. einführend zum Polizei- und Ordnungsrecht § 2 Rn. 1008 ff.) eine zentrale Rolle. Dies liegt darin begründet, dass die Polizei- und Ordnungsbehörden nicht nur auf die Handlungsform des Verwaltungsakts zurückgreifen, sondern auch im Realbereich handeln (Realakte).

Nicht als Verwaltungsakt qualifiziert, sondern dem Realbereich des Handelns 224 der Verwaltung zugeordnet werden insbesondere Warnungen (etwa die Gefährderansprache $\mathrm{e}^{402}$ bzw. das Gefährderanschreiben ${ }^{403}$ ), Datenerhebung und -ver-

400 BVerfG, Beschl v. 10.10.1997, Az.: 1 BvR 310/84 = NJW 1998, 367.

401 Baldus/Grzeszick/Wienhues, Staatshaftungsrecht, 5. Aufl. 2018 Rn. 430, 438.

402 Dazu Hebeler, NVwZ 2011, 1364 (1365); eine Falllösung zur Problematik findet sich bei Hebeler/Spitzlei, JA 2019, 282.

403 Götz/Geis, Allgemeines Polizei- und Ordnungsrecht, 16. Aufl. 2017, §12 Rn. 5; Schoch, in: Schoch, Besonderes Verwaltungsrecht, 2018, Kapitel 1 Rn. 229.

Jana Himstedt/Nikolas Eisentraut 


\title{
arbeitung, heimliche informationelle Eingriffe und die unmittelbare Aus- führung von Maßnahmen. ${ }^{404}$
}

Zwei Fallkonstellationen können unterschieden werden:

225 Zum einen kann es um die Geltendmachung eines Anspruchs auf polizeiliches Einschreiten in Form eines Realakts gehen. In diesem Fall wäre die allgemeine Leistungsklage statthaft.

\begin{abstract}
Beispiel: Schiedsrichter S wendet sich eine Woche vor einem brisanten Derby an die Polizei. Er möchte, dass die Polizei einen Brief an den in der Ultra-Szene bekannten U aufsetzt, in dem sie $U$ „nahelegt“, sich beim Derby an keinerlei gewalttätigen Aktivitäten zu beteiligen. Einen solchen Anspruch könnte S mit der allgemeinen Leistungsklage verfolgen, wobei näher geklärt werden müsste, ob S überhaupt klagebefugt ist und ob ihm ein solcher Anspruch auf ein Gefährderanschreiben materiell-rechtlich überhaupt zustehen kann.
\end{abstract}

226 Zum anderen kann der Kläger begehren, dass die Polizei oder Ordnungsbehörde einen Realakt unterlässt. In diesem Fall wäre die allgemeine Leistungsklage in Form der (ggf. vorbeugenden) Unterlassungsklage einschlägig.

Beispiel: Auf der Hamburger Reeperbahn werden Überwachungskameras aufgestellt. Dies führt dazu, dass der an der Reeperbahn ansässige A stets dabei gefilmt wird, wenn er seine Wohnung betritt und wieder verlässt. Da die Videoüberwachung als Realakt zu qualifizieren ist (keine Regelungswirkung), kann A einen Unterlassungsanspruch mittels der allgemeinen Leistungsklage verfolgen.

227 Hat sich der Realakt hingegen bereits erledigt, insbesondere durch Zeitablauf, kommt nur noch die allgemeine Feststellungsklage in Betracht (s. dazu näher $\S 6$ Rn. 46).

Beispiel: Im Beispiel aus Rn. 226 haben die Ordnungsbehörden die Überwachungskameras nach Anwohnerbeschwerden wieder abgebaut. A will dennoch wissen, ob die Überwachung rechtmäßig war. Ein Unterlassungsanspruch führte ins Leere, weil die Überwachung nicht mehr gegenwärtig ist. Mittels der allgemeinen Feststellungsklage kann A jedoch sein Rechtsschutzziel verfolgen.

\section{Anspruch auf polizeiliches Realhandeln}

228 Macht der Kläger einen Anspruch auf polizeiliches Realhandeln geltend, gilt in der Prüfungsstruktur das zur Verpflichtungsklage Ausgeführte (s. näher dazu $\S 3$ Rn. 122ff.): Zunächst muss die Anspruchsgrundlage ermittelt werden, bevor

404 Götz/Geis, Allgemeines Polizei- und Ordnungsrecht, 16. Aufl. 2017, § 12 Rn. 1.

\section{Nikolas Eisentraut}


sodann zu prüfen ist, ob auch die formellen und materiellen Voraussetzungen für den Anspruch vorliegen.

\section{Anspruch auf Unterlassung polizeilichen Realhandelns}

Macht der Kläger einen Anspruch auf Unterlassung polizeilichen Realhandelns geltend, muss der öffentlich-rechtliche Unterlassungsanspruch geprüft werden (s. zu den Voraussetzungen näher Rn. $134 \mathrm{ff}$.). Inzident muss dabei die Rechtmäßigkeit des polizei- bzw. ordnungsbehördlichen Handels überprüft werden.

In der Prüfungsstruktur eines Realakts ergibt sich im Grundsatz nichts Ab- 230 weichendes gegenüber der Rechtmäßigkeitsprüfung eines Verwaltungsakts. ${ }^{405}$ Es ist mithin zu untersuchen, ob die Behörde ermächtigt ist, einen Realakt vorzunehmen und ob der Realakt den formellen und materiellen Rechtmäßigkeitsvoraussetzungen genügt (s. dazu näher $§ 6 \mathrm{Rn}$. 108ff.).

Im Detail ergeben sich indes Abweichungen zur Rechtmäßigkeitsprüfung 231 eines Verwaltungsakts. So muss bei der Frage der Ermächtigungsgrundlage diskutiert werden, ob eine solche für Realakte überhaupt erforderlich ist. Bei im Polizei- und Ordnungsrecht typischerweise auftretenden eingreifenden Maßnahmen wird diese Frage meistens zu bejahen sein.

Examenswissen: Auch für die offene, also für den Betroffenen erkennbare Videoüberwachung, 232 bei der auch keine Aufzeichnung stattfindet, bejaht die überwiegende Ansicht einen Eingriff in das Grundrecht auf informationelle Selbstbestimmung (Art. 2 I i.V.m. 1 I GG). ${ }^{406}$

Weiterhin ergeben sich in formeller Hinsicht Abweichungen, weil das VwVfG auf 233 Realakte nicht anwendbar ist.

In materieller Hinsicht ist sodann in Entsprechung zum Verwaltungsakt zu 234 prüfen, ob der Realakt den Tatbestand der Ermächtigungsgrundlage erfüllt und von dessen Rechtsfolge gedeckt ist.

Beispiel: Eine auf die polizeiliche Generalklausel gestützte Gefährderansprache muss deren bereits in $\S 2$ Rn. 1081 ff. ausführlich dargelegten Voraussetzungen entsprechen. Es bedarf also einer Gefahr für die öffentliche Sicherheit und Ordnung und der Inanspruchnahme des richtigen Adressaten. Schließlich darf die Behörde nicht ermessensfehlerhaft gehandelt haben.

405 Kingreen/Poscher, Polizei- und Ordnungsrecht mit Versammlungsrecht, 10. Aufl. 2018, § 27 Rn. 1.

406 Waldhoff, JuS 2013, 94 (95). 


\section{Die allgemeine Leistungsklage im Kommunalrecht (Sebastian Piecha)}

235 Im Kommunalrecht kommt die allgemeine Leistungsklage dann in Betracht, wenn das begehrte Handeln oder Unterlassen der Kommune keinen Verwaltungsakt darstellt.

\section{Kommunalverfassungsstreit in Leistungssituationen}

236 Ein Klassiker in der kommunalrechtlichen Klausur ist der sog. Kommunalverfassungsstreit, den es sowohl in Leistungs- als auch Feststellungssituationen gibt (s. daher auch $\S 6$ Rn. $186 \mathrm{ff}$.). Im Folgenden werden erst einige einleitenden Worte zu dem Begriff verloren, bevor auf die Prüfung von Zulässigkeit und Begründetheit eingegangen wird.

237 Beim sog. Kommunalverfassungsstreit handelt es sich nicht um eine weitere Klageart, sondern um spezielle Konstellationen in Leistungs- oder Feststellungsklagen, ${ }^{407}$ die Auseinandersetzungen zwischen Organen oder Organteilen einer kommunalen Gebietskörperschaft (Gemeinde, Kreis) wegen der Wahrnehmung oder einer möglichen Verletzung der ihnen als solchen zustehenden Kompetenzen zum Gegenstand haben. ${ }^{408}$ Der Begriff „Verfassung“ meint hier die kommunale Binnenorganisation im Sinne des Kommunalverfassungsrechts (dazu näher $\S 2$ Rn. 1268). ${ }^{409}$

238 Hausarbeits-/Examenswissen: Früher wurde teilweise in der Rechtsprechung vertreten, dass sich der Kommunalverfassungsstreit als „Klage sui generis“ nicht in die in der VwGO vorgesehenen Klagearten einordnen lasse, da es um die Rechtsbeziehungen innerhalb einer Kommune handele. ${ }^{410}$ Diese Ansicht ist zwar mittlerweile veraltet, sollte aber gerade in Hausarbeiten oder Examensklausuren angesprochen und im Ergebnis abgelehnt werden.

239 Beim Kommunalverfassungsstreit unterscheidet man terminologisch zwischen einem Inter- und Intraorganstreit: Dabei können verschiedene kommunale Organe (Interorganstreit) (z. B. Bürgermeister und Rat) oder Teile desselben Organs (z. B. Ratsfraktion und Ratsmitglied) miteinander streiten (Intraorganstreit).

407 BVerwG, Urt. v. 26.1.1996, Az. 8 C 19/94 = BVerwGE 100, 262.

408 Otto, ZJS 2015, 382 m.w.N.

409 Burgi, Kommunalrecht, 6. Aufl. 2019, § 14 Rn. 7.

410 Maßgeblich: OVG Münster, Urt. v. 4.4.1962, Az. III A 1122/61 = OVGE 17, 261 (263); Urt. v. 2. 2. 1972, Az. III A 887/69 = OVGE 27, 258 (260). 


\section{a) Zulässigkeit}

In der Zulässigkeit ist dann insbesondere bei der Eröffnung des Verwal- 240 tungsrechtsweges nach $\S 40$ I VwGO zu erörtern: Es handelt sich mangels doppelter Verfassungsunmittelbarkeit jedenfalls um eine „Streitigkeit nichtverfassungsrechtlicher Art“, da nicht zwei Staatsorgane um Verfassungsrecht streiten, sondern Verwaltungsorgane um Kompetenzen nach dem Verwaltungsrecht (hier: Kommunalrecht).

Hausarbeits-/Examenswissen: Nach der früher vertretenen Impermeabilitätstheorie waren solche Streitigkeiten nicht justiziabel, da es sich um bloßes Innenrecht der Kommune handele. ${ }^{411}$ Diese Ansicht ist zwar erwähnen, jedoch im Ergebnis abzulehnen, da die Prüfung sonst schon an dieser Stelle vorbei wäre und hilfsgutachterliche Ausführungen der restlichen Klausuroder Hausarbeitsprobleme regelmäßig nicht gewollt sein können.

Die statthafte Klageart richtet sich nach den allgemeinen Vorschriften (s. aus- 242 führlich $\S 1$ Rn. 222ff.). Der Kommunalverfassungsstreit ist nach ganz h.M. keine eigene Klageart (s. Rn. 237). Die Leistungsklage ist dann statthaft, wenn ein Handeln oder Unterlassen verlangt wird. Wird hingegen die Feststellung der Rechtmäßigkeit oder Rechtswidrigkeit einer Handlung eines Organs oder Organteils begehrt, so ist die Feststellungsklage statthaft (s. dazu näher $\S 6$ Rn. $186 \mathrm{ff}$.).

Bei der Klagebefugnis muss nach § 42 II VwGO analog erörtert werden, ob die 243 Möglichkeit der Verletzung organschaftlicher Rechte (Innen- bzw. Binnenrecht) des Klägers besteht. Es muss also die Möglichkeit der Verletzung etwa von (subjektiven) Mitwirkungs- oder Beteiligungsrechten des betreffenden Organs gegeben sein, der Kläger benötigt also eine sog. wehrfähige Innenrechtsposition. Diese kann sich dabei aus dem jeweiligen Kommunalverfassungsrecht, einer Satzung oder einer Geschäftsordnung der jeweiligen Kommune ergeben. ${ }^{412}$ Die Möglichkeit und das verletzte Recht sollten dabei hier kurz zumindest benannt werden. Die Berufung auf Grundrechte ist jedoch unzulässig. ${ }^{413}$ Die objektive Rechtmäßigkeitsprüfung einzelner Maßnahmen, etwa ob die Satzung oder Geschäftsordnung ihrerseits rechtmäßig ist, kann nur im Rahmen einer Normenkontrolle nach $\S 47$ VwGO überprüft werden (dazu näher $\S 7$ Rn. 119ff.).

Auch ist die Beteiligtenfähigkeit der streitenden Organe oder Organteile 244 nach $\S 61$ VwGO ausdrücklich zu erörtern: Diese folgt aus § 61 Nr. 2 VwGO, da

411 Ausführlich Rupp, Grundfragen der heutigen Verwaltungsrechtslehre, 1965, S. $19 \mathrm{ff}$.

412 Burgi, Kommunalrecht, 6. Aufl. 2019, § 14 Rn. 13.

413 BVerfG, Beschl.v. 10.7.1991, Az. 2 BvE 3/91 = BVerfGE 84, 290 (299); BVerfG, Urt. v. 20.7.1998, Az. 2 BvE 2/98 = BVerfGE 99, 19 (29). 
danach die Beteiligtenfähigkeit bei Kollegialorganen (Rat) von der Fähigkeit zur Inhaberschaft des geltend gemachten Rechtes abhängt bzw. bei Einzelorganen (wenn es das Organ des Bürgermeisters oder klagende Organteile und Ratsmitglieder betrifft) aus § 61 Nr. 2 VwGO analog. ${ }^{414} \S 61 \mathrm{Nr} .1$ VwGO ist nicht anwendbar, da es hierbei um die persönliche Rechtsstellung der natürlichen und juristischen Personen, sondern die Geltendmachung von Organrechten geht. Gleiches gilt für $§ 61$ Nr.3 VwGO, da hierbei nicht Behörden nach außen für die Kommune handeln.

245 Die Herleitung der Prozessfähigkeit beim Kommunalverfassungsstreit ist umstritten: Teilweise soll sie aus §62 III VwGO direkt folgen, weshalb sich das betreffende Organ stets durch seinen Organwalter (Organ Bürgermeister durch den Bürgermeister) oder ein für den Organteil allgemein vertretungsberechtigten vertreten lassen muss (Rat durch den Ratsvorsitzenden), ansonsten durch eine Prozessvollmacht für den Einzelfall (bei Ratsfraktionen oder einzelnen Ratsmitgliedern). ${ }^{415}$ Andere leiten sie aus $\S 62$ I Nr. 1 VwGO analog ab, so dass der Organwalter des Organs oder Organteils sein soll. ${ }^{416}$

246 Der richtige Klagegegner wird nicht nach $\S 78$ VwGO bestimmt, da dieser weder direkt (gilt nur für Anfechtungs- und Verpflichtungsklagen) noch analog bzw. dem Rechtsgedanken des allgemeinen Rechtsträgerprinzips nach (es geht nicht um ein Recht der ganzen Kommune, sondern eines Teils) anwendbar ist, womit das angegriffene Organ oder der Organteil direkt der Klagegegner ist. ${ }^{417}$

\section{b) Begründetheit}

247 Im Rahmen der Begründetheit kommt es dann darauf an, ob ein Anspruch auf das begehrte Handeln oder Unterlassen besteht (s. zur Begründetheit der allgemeinen Leistungsklage Rn. $49 \mathrm{ff}$.).

248

In Abhängigkeit des jeweiligen Landesrechts sind insbesondere Ansprüche zu diskutieren in Bezug auf: 418

- Einberufung einer Sitzung

- Ergänzung oder Streichung von Punkten auf der Tagesordnung des Rates

- Herstellung oder Ausschluss der Sitzungsöffentlichkeit

414 Burgi, Kommunalrecht, 6. Aufl. 2019, § 14 Rn. 12; Otto, ZJS 2015, 381 (384).

415 So etwa Burgi, Kommunalrecht, 6. Aufl. 2019, § 14 Rn. 12; Detterbeck, Allgemeines Verwaltungsrecht, 17. Aufl. 2019, Rn. 1473.

416 Otto, ZJS 2015, 381 (384).

417 Burgi, Kommunalrecht, 6. Aufl. 2019, § 14 Rn. 12.

418 Zum Ganzen Burgi, Kommunalrecht, 6. Aufl. 2019, § 14 Rn. 14; Gern/Brüning, Deutsches Kommunalrecht, 4. Aufl. 2019, Rn. 716 m.w. N. 
- Gewährung von Akteneinsicht durch den Bürgermeister

- Ordnungsmaßnahmen (sog. innerorganisatorischer Störungsbeseitigungsanspruch (hier insbesondere abzugrenzen: Mandats- und Grundverhältnis) ${ }^{419}$

\section{Zulassung zu kommunalen Einrichtungen in privater Trägerschaft}

Im Gegensatz zum Zulassungsanspruch direkt aus dem Kommunalrecht bei öf- 249 fentlichen Einrichtungen in öffentlich-rechtlicher Organisationsform (s. näher $\S 3$ Rn. 159 ff.) ergibt sich bei privater Trägerschaft folgender Unterschied: Da kein Verwaltungsakt begehrt wird, ist die allgemeine Leistungsklage statthaft, mit dem Begehren auf Einwirkung auf den privaten Träger der kommunalen Einrichtung, die Zulassung zu erwirken. Der Zulassungsanspruch (Begründetheit) ergibt sich sodann aus einer analogen Anwendung der kommunalrechtlichen Norm.

\section{Wirtschaftliche Betätigung von Kommunen}

Die wirtschaftliche Betätigung von Kommunen ist eine häufige Fallgestaltung 250 in Leistungsklagesituationen. Kommunen beteiligen sich insbesondere im Bereich der Daseinsvorsorge (beispielsweise Stadtwerke, öffentlicher Nahverkehr, Stadthallen) (privat)wirtschaftlich. ${ }^{420}$ Dabei betätigt sich eine Kommune entweder im Wege eines Eigenbetriebes oder einer eigenbetriebsähnlichen Einrichtung oder sie gründet hierzu eigene Gesellschaften (z. B. Stadthallen-GmbH, Stadtwerke AG). Die Ausgestaltung der wirtschaftlichen Betätigung gehört zur kommunalen Selbstverwaltungsgarantie aus Art. 28 II GG (s. dazu § 2 Rn. 1259 ff.). ${ }^{421}$

Was überhaupt wirtschaftliche Betätigung oder der Betrieb eines wirtschaft- 251 lichen Unternehmens ist, wird in den meisten Kommunalordnungen nicht definiert. Als wirtschaftliches Unternehmen wird jedoch eine rechtlich selbstständige oder unselbstständige Zusammenfassung (Organisationseinheit) von Personalund Sachmitteln in der Hand eines Rechtsträgers mit dem Ziel der Teilnahme am Wirtschaftsverkehr durch Produktion und Umsatz von Gütern und Dienstleistungen mit regelmäßiger Gewinnerzielungsabsicht verstanden. ${ }^{422}$ Einige Länder haben in ihrem Kommunalrecht jedoch Negativdefinitionen, die ausdrücklich bestimmen, was hierunter nicht zu verstehen ist (z. B. die Erfüllung von Pflichtaufgaben, Betrieb von Einrichtungen im Bildungs-, Gesundheits- oder Kulturbereich, etwa in

419 Burgi, Kommunalrecht, 6. Aufl. 2019, § 12 Rn. $37 \mathrm{ff}$.

420 Burgi, Kommunalrecht, 6. Aufl. 2019, § 17 Rn. 8.

421 Burgi, Kommunalrecht, 6. Aufl. 2019, § 17 Rn. 8.

422 Gern/Brüning, Deutsches Kommunalrecht, 4. Aufl. 2019, Rn. 994. 
$\S 107$ II GO NRW). ${ }^{423}$ Die einzelnen Kommunalgesetze der Flächenländer stellen den gesetzlichen Rahmen hierfür auf, wobei einzelne Länder Vollregelungen für Gemeinden und Landkreise haben, während andere auf die für Gemeinden geltenden Vorschriften verweisen:

\begin{tabular}{|c|c|}
\hline Land & Wirtschaftliche Betätigung von Kommunen \\
\hline Baden-Württemberg & $\begin{array}{l}\S 102 \text { I Gem0 BW } \\
\text { (Verweis auf Gem0 über) § } 48 \text { LKrO BW }\end{array}$ \\
\hline Bayern & $\begin{array}{l}\text { Art. } 87 \text { I } 1 \text { BayGO } \\
\text { Art. } 75 \text { BayLKrO }\end{array}$ \\
\hline Brandenburg & § 91 II, 3 BbgKVerf \\
\hline Hessen & $\begin{array}{l}\S 121 \text { I } 1 \text { HGO } \\
\text { (Verweis auf HGO über) } \S 52 \text { I HKO }\end{array}$ \\
\hline Mecklenburg-Vorpommern & $\S 68$ II $1 \mathrm{KV} \mathrm{M-V}$ \\
\hline Niedersachsen & $\S 136$ I 2 NKomVG \\
\hline Nordrhein-Westfalen & $\begin{array}{l}\text { § } 107 \text { I } 1 \text { GO NRW } \\
\text { (Verweis auf GO über) § } 53 \text { I KrO NRW }\end{array}$ \\
\hline Rheinland-Pfalz & $\begin{array}{l}\S 85 \text { I } 1 \text { Gem0 RP } \\
\text { (Verweis auf Gem0 über) § } 57 \text { LKO RP }\end{array}$ \\
\hline Saarland & $\S 108$ I KSVG \\
\hline Sachsen & $\begin{array}{l}\text { § } 94 a \text { I } 1 \text { SächsGem0 } \\
\text { (Verweis auf Gem0 über) § } 63 \text { SächsLKrO }\end{array}$ \\
\hline Sachsen-Anhalt & $\S 128$ I 1 KVG LSA \\
\hline Schleswig-Holstein & $\begin{array}{l}\S 101 \text { I } 1 \text { GO S-H } \\
\text { (Verweis auf GO über) } \S 57 \text { KrO S-H }\end{array}$ \\
\hline Thüringen & § 71 II ThürKO \\
\hline
\end{tabular}

252 Auch wenn sich die Regelungen je nach Bundesland unterscheiden, so sind den Rahmenbedingungen für kommunale Wirtschaftstätigkeiten im Wesentlichen gemein (sog. Schrankentrias):

1. Öffentlicher Zweck: Die Kommune muss einen öffentlichen Zweck mit der Wirtschaftstätigkeit verfolgen. Sie muss sich an den durch Art. 28 II GG geregelten Aufgaben der Kommunen orientieren und durch besondere Interessen der All-

423 Burgi, Kommunalrecht, 6. Aufl. 2019, § 17 Rn. 39 f. 
gemeinheit oder der Einwohner gerechtfertigt sein, wobei dies stark einzelfallabhängig ist. ${ }^{424}$

2. Angemessenes Verhältnis zu Leistungsfähigkeit der Kommune und zum örtlichen Bedarf: Es muss ein angemessenes Verhältnis zur Leistungsfähigkeit zur Leistungsfähigkeit und zum örtlichen gegeben sein. Dies würde etwa dann fehlen, wenn die Kommune sich mit dem Unternehmen wirtschaftlich übernehmen würde oder Dienstleistungen anbieten würde, die über den örtlichen Bedarf hinausgehen, was eine hierauf bezogene Prognose voraussetzt. ${ }^{425}$

3. Subsidiaritätsklausel: Die Kommune darf nur dann tätig werden, wenn ein örtlicher Bedarf vorliegt: Dabei ordnet man die unterschiedlichen Regelungen in den Ländern meist als einfache oder qualifizierte Subsidiaritätsklausel ein: Eine einfache (unechte) Subsidiaritätsklausel ${ }^{426}$ fordert, dass der mit der wirtschaftlichen Betätigung verfolgte Zweck nicht besser und wirtschaftlicher durch einen privaten Dritten erfüllt werden kann, während die qualifizierte (verschärfte) Subsidiaritätsklausel ${ }^{427}$ dass der Zweck nicht ebenso gut und wirtschaftlich durch einen anderen (Privaten) erfüllt werden kann. ${ }^{428}$ Die Subsidiaritätsklauseln bieten wegen ihrer ausdrücklichen Bezugnahme auf Dritte einen Ansatzpunkt für die Diskussion, ob es sich bei der Vorschrift um eine drittschützende Norm handelt (dazu Rn. 255).

Dass sich für die kommunalwirtschaftliche Betätigung möglicherweise 253 Grenzen aus dem sonstigen Recht, auch Unionsrecht (etwa Beihilfen- oder Kartellrecht) ergeben, muss zudem beachtet werden. ${ }^{429}$ Wegen der kommunalen Selbstverwaltungsgarantie aus Art. 28 II GG ist insbesondere problematisch, wenn eine Kommune im Hoheitsgebiet einer anderen Kommune tätig wird und so ihre Verbandskompetenz überschreitet, was durch die o.g. Vorschriften landesrechtlich unter bestimmten Voraussetzungen zulässig sein kann oder jedenfalls im Wege der kommunalen Zusammenarbeit einvernehmlich möglich ist. ${ }^{430}$

Statthaft ist die allgemeine Leistungsklage in Form einer sog. Konkurren- 254 tenklage, da von einem Dritten begehrt wird, dass die Kommune sich wirtschaftlich

424 Gern/Brüning, Deutsches Kommunalrecht, 4. Aufl. 2019, Rn. $999 \mathrm{ff}$.

425 Gern/Brüning, Deutsches Kommunalrecht, 4. Aufl. 2019, Rn. $1002 \mathrm{ff}$.

$426 \S 107$ I GO NRW, § 91 III BbgKVerf, § 136 I NKomVG, § 94a I SächsGemO, § 128 I KVG LSA, $\S 101 \mathrm{I}$ GO S-H.

$427 \S 102$ I GemO BW, Art. 87 I BayGO, § 121 I HGO, § 68 KV M-V, § 85 I GemO RP, § 108 I KSVG, $\S 71$ II ThürKO.

428 Gern/Brüning, Deutsches Kommunalrecht, 4. Aufl. 2019, Rn. 985.

429 Dazu etwa Petzold, KommJur 2017, S. 401 ff.; Weck, DÖV 2015, 500 (506f.).

430 Vgl. Scharpf, NVwZ 2005, 148ff.; grundlegend Gern/Brüning, Deutsches Kommunalrecht, 4. Aufl. 2019, Rn. 1009 m.w. N.; Burgi, Kommunalrecht, 6. Aufl. 2019, § 17 Rn. 47 ff. 
nicht (mehr) betätigt oder auf das von ihr gehaltene Kommunalunternehmen dergestalt Einfluss nimmt, dass die wirtschaftliche Tätigkeit unterlassen werde. Im ersteren Falle wird dies auf einen öffentlich-rechtlichen Unterlassungsanspruch, im letzteren auf die Landesrechtsnorm direkt als Anspruchsgrundlage gestützt.

Zudem ist dann regelmäßig die Frage zu diskutieren, ob der private Dritte oder einer anderen Kommune nach $\S 42$ II VwGO analog klagebefugt sind. Das erfordert ein subjektives Recht des Klägers. Dies ist nach der Schutznormtheorie regelmäßig der Fall, wenn eine drittschützende Norm vorliegt (dazu Rn. 257).

256 Hausarbeitswissen: Aus den Grundrechten lässt sich kein subjektives Recht für einen Unternehmer ableiten, denn die Berufsfreiheit aus Art. 12 GG schützt nicht vor Wettbewerb und das Recht am eingerichteten und ausgeübten Gewerbebetrieb aus Art. 14 GG schützt nur das Erworbene, nicht jedoch Erwerbschancen.

257 Bei der Leistungsklage auf Unterlassen der kommunalwirtschaftlichen Betätigung kann sich ein Dritter nur dann auf eine Norm berufen, wenn sie drittschützenden Charakter hat. Dies ist jeweils durch genaue Auslegung zu ermitteln. Die Subsidiaritätsklauseln (s. Rn. 252) bieten den Ansatzpunkt hierfür, da dort Bezüge zur Wahrnehmung wirtschaftlicher Tätigkeit von Dritten bestehen. Mit wohl eindeutiger Ausnahme von Brandenburg ${ }^{431}$ und der zumindest zweifelhaften drittschützenden Wirkung der kommunalrechtlichen Vorgaben in Bayern, Sachsen-Anhalt und Schleswig-Holstein kann man im Ergebnis davon ausgehen, dass die entsprechenden Vorschriften in den Kommunalverfassungsgesetze drittschützenden Charakter aufweisen. ${ }^{432}$

258 Hausarbeits-/Examenswissen: Dies ist je nach Bundesland stark umstritten und sollte an dieser Stelle jedenfalls diskutiert werden..$^{433}$

259 Bei der Leistungsklage auf Unterlassen der kommunalwirtschaftlichen Betätigung durch eine andere Kommune könnte diese sich auch in ihrer Selbstverwaltungsgarantie aus Art. 28 II GG möglicherweise verletzt sein.

260 Die Leistungsklage ist bei kommunalen Unternehmen dann begründet, wenn der Dritte einen öffentlich-rechtlichen Unterlassungsanspruch gegen die wirtschaftliche Betätigung der Kommune hat. ${ }^{434}$

431 Vgl. zur Vorgängerregelung VG Potsdam, Beschl.v 29.7.2004, Az. 12 L 631/04, Rn. 21.

432 Dazu ausführlich m.w. N. Gern/Brüning, Deutsches Kommunalrecht, 4. Aufl. 2019, Rn. 1016 und Burgi, Kommunalrecht, 6. Aufl. 2019, § 17 Rn. $63 \mathrm{ff}$.

433 Zum Streitstand Jungkamp, NVwZ 2010, 546 (547 ff.); Gern/Brüning, Deutsches Kommunalrecht, 4. Aufl. 2019, Rn. $1015 \mathrm{ff}$.

434 Beispielfall: Jürgensen/Laude, JuS 2018, $635 \mathrm{ff}$. 
Die Herleitung der Ermächtigungsgrundlage ist bereits strittig. Jeden- 261 falls sollte festgestellt werden, dass der öffentlich-rechtliche Unterlassungsanspruch gewohnheitsrechtlich bzw. richterrechtlich anerkannt ist. ${ }^{435}$

Hausarbeitswissen: Teilweise wird der öffentlich-rechtlich Unterlassungsanspruch aus dem 262 Rechtsstaatsprinzip (Art. 20 III GG), teilweise aus Freiheitsrechten oder aus den Rechtsgedanken der $\S \S 906,1004$ BGB hergeleitet. ${ }^{436}$

Sodann sind die Voraussetzungen des öffentlich-rechtlichen Unterlas- 263 sungsanspruchs zu prüfen (s. dazu ausführlich Rn. 134ff.). Sind diese gegeben, so ist die Leistungsklage als Konkurrentenklage begründet. Zunächst muss (1) ein subjektiv-öffentliches Recht betroffen sein, wobei die Auslegung der Landesrechtsnorm und ihr drittschützender Charakter eine Rolle spielt. Wendet sich eine Nachbarkommune gegen eine wirtschaftliche Betätigung, so ist hier noch auf die Selbstverwaltungsgarantie aus Art. 28 II GG einzugehen. Zudem muss (2) ein hoheitlicher, unmittelbar bevorstehender oder andauernder Eingriff vorliegen und festgestellt werden. Dieser müsste (3) rechtswidrig sein. An dieser Stelle sind dann die jeweiligen Gegebenheiten der Landesrechtsnorm zu prüfen (formelle Erwägungen, Marktanalysen, öffentlicher Zweck usw.). Schließlich müsste (4) ein Kausalzusammenhang zwischen dem kommunalen Handeln und der Beeinträchtigung des subjektiven Rechts gegeben sein.

Bei von der Kommune beherrschten Unternehmen (insbesondere in Pri- 264 vatrechtsform) ist die Leistungsklage als Konkurrentenklage begründet, wenn ein Anspruch auf aktives Einwirken und kein Unterlassungsanspruch besteht. Dabei kommt die o.g. jeweilige Landesrechtsnorm als Anspruchsgrundlage in Frage. ${ }^{437}$

\section{Beratung und Entscheidung eines Einwohnerantrages}

Während nach ganz h.M. die Entscheidung über die Zulässigkeit eines Bürger- 265 bzw. Einwohnerantrages als Verwaltungsakt im Rahmen einer Verpflichtungsklage angefochten werden kann (s. § 3 Rn. 179), so ist die anschließend durchzuführende Beratung und Entscheidung im Rat kein Verwaltungsakt, sondern ein bloßer Realakt, der im Rahmen der allgemeinen Leistungsklage beklagt werden kann. Ist die Zulässigkeit des Bürgerantrages vom Rat oder gerichtlich festgestellt, so hat dieser ihn zu beraten und entscheiden. Tut er dies nicht oder

435 Etwa OVG Münster, Urt. v. 23.4.1999, Az. 21 A 490/97 = NVwZ-RR 2000, 599 (600).

436 Herleitung grundlegend bei Laubinger, VerwArch 80 (1989), 261 (289ff.).

437 Geis/Madeja, JuS 2013, 248 (253). 
nicht in der gesetzlich vorgesehenen Frist, so kann der Bürger dagegen vor dem Verwaltungsgericht vorgehen.

266 Im Rahmen der Begründetheit der Leistungsklage dürfte dann inzident die Zulässigkeit des Einwohnerantrages (s. § 3 Rn. 179) in der Regel mitgeprüft werden, da die Verpflichtung zur Beratung und Entscheidung nur bei Zulässigkeitsentscheidung durch Rat oder Gericht möglich ist.

\section{Fachaufsichtsmaßnahmen}

267 Maßnahmen der Fachaufsicht sind mangels Außenwirkung keine Verwaltungsakte und daher nur mit der Leistungsklage angreifbar. Gleichwohl fehlt hier die Klagebefugnis i.S.v. § 42 II VwGO grundsätzlich, da nicht in Selbstverwaltungsrechte eingegriffen wird. Ausnahmsweise ist dies jedoch möglich, wenn geltend gemacht wird, dass die Maßnahme außerhalb des fachlichen Weisungsbereichs im kommunalen Selbstverwaltungsbereich erfolgt. Hier ist jedoch umstritten, ob es sich dann nicht doch um einen Verwaltungsakt handelt, wogegen die Anfechtungsklage statthaft wäre. ${ }^{438}$

438 Zum Streit Gern/Brüning, Deutsches Kommunalrecht, 4. Aufl. 2019, Rn. 364. 